\title{
Numerical Simulation Analysis of the Interaction of Lakes and Ground Water
}

GEOLOGICALSURVEY PROFESSIONAL PAPER IOOI

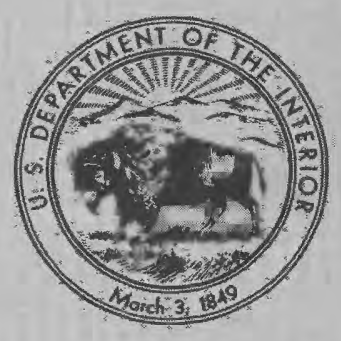




\section{Numerical Simulation Analysis of the Interaction of Lakes and Ground Water}

By THOMAS C. WINTER

GEOLOGICAL SURVEY PROFESSIONAL PAPER 1001

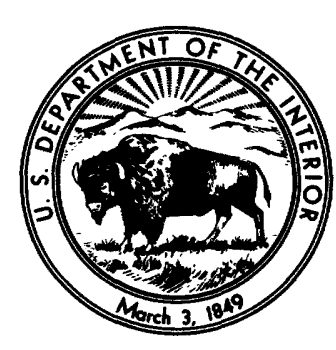

UNITED STATES GOVERNMENT PRINTING OFFICE, WASHINGTON : 1976 


\title{
UNITED STATES DEPARTMENT OF THE INTERIOR
}

THOMAS S. KLEPPE, Secretary

\section{GEOLOGICAL SURVEY}

\author{
V. E. McKelvey, Director
}

\footnotetext{
First printing 1976

Second printing 1977
}

Library of Congress Cataloging in Publication Data

Winter, Thomas $\mathbf{C}$.

Numerical simulation analysis of the interaction of lakes and ground water.

(Geological Survey Professional Paper 1001)

Bibliography: p.

1. Groundwater flow-Mathematical models. 2. Groundwater flow-Data processing. 3. Lakes-Mathematical models. 4. LakesData processing. 5. Numerical analysis.

I. Title. II. Series: United States Geological Survey Professional Paper 1001.

GB1001.72M 35W56 551.4'82 76-608309

For sale by the Branch of Distribution, U.S. Geological Survey

1200 South Eads Street, Arlington, VA 22202 


\section{CONTENTS}

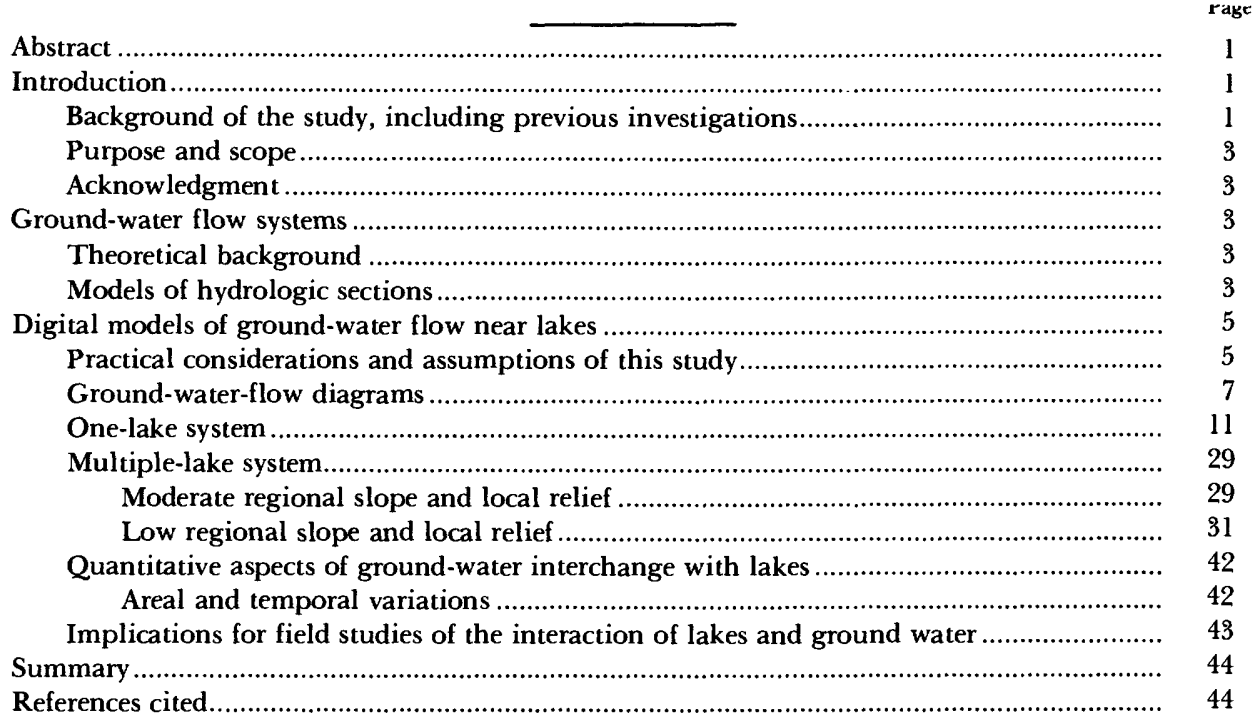

\section{ILLUSTRATIONS}

FIGURE 1. Sketch showing physical meaning of mathematical expressions for boundaries of hydrologic-section models

2. Hydrologic section showing local, intermediate, and regional ground-water-flow systems determined from an analytical solution to the ground-water-flow equation

3. Hydrologic section showing ground-water-flow systems determined from a numerical solution to the ground-water-flow equation.

4. Hydrologic section showing a quasi-quantitative flow net of ground-water flow near lakes in a multiple-lake system that does not contain aquifers

5. Hydrologic section showing a quasi-quantitative flow net of ground-water flow near lakes in a multiple-lake system that contains aquifers.

6. Hydrologic section showing distribution of hydraulic head in the ground-water reservoir of a multiple-lake system that does not contain aquifers.

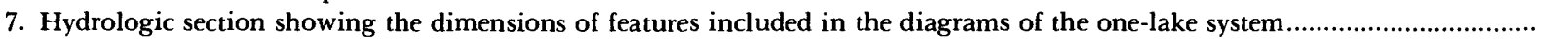

8. Hydrologic section showing distribution of hydraulic head in the ground-water reservoir of a one-lake system that does not contain aquifers or lake sediments.

9. Hydrologic section showing distribution of hydraulic head in the ground-water reservoir of a one-lake system that contains lake sediments but does not contain aquifers.....

10. Hydrologic section showing distribution of hydraulic head in the ground-water reservoir of a one-lake system that has a low water-table mound on the downslope side of the lake and does not contain aquifers

11. Hydrologic section showing distribution of hydraulic head in the ground-water reservoir of a one-lake system that has low water-table mounds on both sides of the lake and does not contain aquifers

12. Hydrologic section showing distribution of hydraulic head in the ground-water reservoir of a one-lake system that has an extensive aquifer of relatively low hydraulic conductivity at the base of the system.

13. Hydrologic section showing distribution of hydraulic head in the ground-water reservoir of a one-lake system that has an extensive aquifer of relatively high hydraulic conductivity at the base of the system......

14. Hydrologic section showing distribution of hydraulic head in the ground-water reservoir of a one-lake system that has an extensive aquifer of relatively low hydraulic conductivity in the middle of the system.

15. Hydrologic section showing distribution of hydraulic head in the ground-water reservoir of a one-lake system that has an aquifer of limited extent upslope from the lake at the base of the system.

16. Hydrologic section showing distribution of hydraulic head in the ground-water reservoir of a one-lake system that has an aquifer of limited extent beneath the lake at the base of the system. 
FIGURE 17. Hydrologic section showing distribution of hydraulic head in the ground-water reservoir of a one-lake system that has an aquifer of limited extent downslope from the lake at the base of the system...

18. Hydrologic section showing distribution of hydraulic head in the ground-water reservoir of a one-lake system that has a deep lake and an extensive aquifer of relatively low hydraulic conductivity at the base of the system.

19. Sketch showing key to table 1

20. Hydrologic section showing distribution of hydraulic head in the ground-water reservoir of a multiple-lake system that has an extensive aquifer of relatively high hydraulic conductivity at the base of the system

21. Hydrologic section showing distribution of hydraulic head in the ground-water reservoir of a multiple-lake system that has water-table mounds of various height and aquifers of limited extent in the middle of the system

Hydrologic section showing distribution of hydraulic head in the ground-water reservoir of a multiple-lake system that

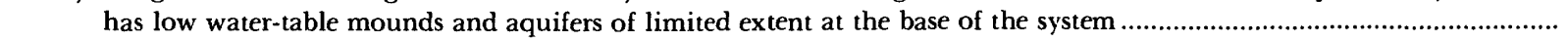

23. Hydrologic section showing distribution of hydraulic head in the ground-water reservoir of a multiple-lake system that has low water-table mounds and aquifers of limited extent in the middle of the system .....

24. Hydrologic section showing distribution of hydraulic head in the ground-water reservoir of a multiple-lake system that has high water-table mounds and aquifers of limited extent at the base of the system..........

25. Hydrologic section showing distribution of hydraulic head in the ground-water reservoir of a multiple-lake system that

has deep lakes, high water-table mounds, aquifers of limited extent at the base of the system, and $K_{h} / K_{v}=1,000 \ldots \ldots . . . \ldots . .$.
26. Hydrologic section showing distribution of hydraulic head in the ground-water reservoir of a multiple-lake system that has deep lakes, high water-table mounds, aquifers of limited extent at the base of the system, and $K_{h} / K_{v}=100 \ldots$

27. Hydrologic section showing distribution of hydraulic head in the ground-water reservoir of a multiple-lake system that has low regional slope and does not contain aquifers.

28. Hydrologic section showing distribution of hydraulic head in the ground-water reservoir of a multiple-lake system that low regional slope and aquifers of limited extent in the middle of the system.......

\section{TABLES}

TABLE 1. Results of digital simulations of the one-lake system-comparison of the effects of all combinations of the parameters that control ground-water flow on lake-ground water interaction

mmary of simulations of one-lake system.....

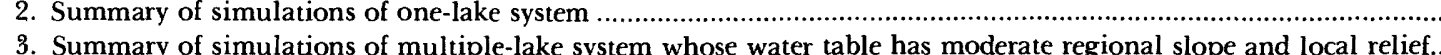

4. Summary of simulations of multiple-lake system whose water table has low regional slope and local relief..... 


\title{
NUMERICAL SIMULATION ANALYSIS OF THE INTERACTION OF LAKES AND GROUND WATER
}

\author{
By Thomas C. Winter
}

\begin{abstract}
Because the interrelationship of lakes and ground water is perhaps the least understood aspect of lake hydrology, vertical-section, steadystate, numerical-model simulations were run to evaluate the factors that control the interaction of lakes and ground water. The study is concerned only with lakes encircled by water-table mounds that are at a higher altitude than lake level. Simulations of one-lake and multiple-lake systems in vertical sections show that for many hydrogeologic settings, the line (divide) separating local from regional ground-water flow systems is continuous beneath individual lakes. If the divide is continuous, there exists a point along it at which the head is a minimum compared to all other points along the divide. This point of minimum head is always greater than the head represented by lake level, therefore in such a setting there can be no movement of lake water through the lake bed to the ground-water system. In a setting where the divide is not continuous, the lake loses water through part of its bed, but rarely in the littoral zone of the lake.

Factors that strongly influence the position, shape, and continuity of the flow-system divide beneath lakes are height of the water table on the downslope side of the lake relative to lake level, position and hydraulic conductivity of aquifers within the ground-water reservoir, ratio of horizontal to vertical hydraulic conductivity of the groundwater system, and lake depth.
\end{abstract}

\section{INTRODUCTION}

\section{BACKGROUND OF THE STUDY, INCLUDING PREVIOUS INVESTIGATIONS}

Lakes are a valuable natural resource in many areas of the United States. In addition to being sources of water supply for many communities, they are the focus of recreational activity and their aesthetic qualities are highly valued. That they are a desirable feature is evidenced by the large number of small reservoirs being constructed throughout much of the United States for a wide variety of purposes. Increasingly, lakes are being used as the focal point in planning urban developments.

Unfortunately, the popularity of lakes often leads to their deterioration. The increased input of nutrients through the activities of man causes the organisms in lakes to flourish at rates far in excess of natural conditions. This increased productivity in turn causes chemical changes in lakes that result in obnoxious odors, fish kills, and unsightly conditions in the lakes and along their shorelines.

The number of problem lakes is sharply increasing. In order to evaluate lake problems and the effect of management projects, nutrient budgets and water budgets of lakes are needed. Only by thorough understanding of the interrelationships of lake hydrology, chemistry, and biology can progress be made in alleviating present lake problems and preventing more problems from arising.

In recent years, much money and research effort have been expended to understand the principles of lake chemistry, biology, and the nutrient balance of lakes. At the same time, comparatively little money and effort have been devoted to understanding the principles of lake hydrology or the water balance of lakes. With few exceptions, the relationship of ground water to lakes has been a minor part of the hydrologic studies, and it remains the least studied and least understood aspect of lake hydrology.

In most studies of lake hydrology, atmospheric water (precipitation and evaporation) and surface-water interchange with lakes is measured. Ground water is generally calculated as the residual. This practice can lead to serious misunderstandings about the interaction of lakes and ground water, especially when the error of measurement inherent in precipitation and particularly evaporation is considered. Further, only through careful field techniques can streamflow measurement error be kept to relatively low values.

Some misconception of the interaction of lakes and ground water has resulted from lack of understanding of ground-water flow, which leads to inadequate instrumentation and data collection. Poorly executed studies have led to various erroneous ideas concerning the interaction of lakes and ground water, to the detriment of sound lake management. Some scientists and managers believe all lakes are discharge points of the ground-water system and therefore do not lose water through their beds. Others believe that lakes are points of recharge to the ground-water system. Some believe ground water flows in 
one side of lakes and out the other, a flow-through condition. Others believe all three situations exist.

Most studies of the interaction of lakes and ground water have been in response to a need for water budget information for a particular lake or groups of lakes. Some studies have not used observation-well instrumentation to define the ground-water flow systems, but instead assumed certain hydrogeologic conditions. Generally those that used wells either used too few wells, that is they assumed a simple relationship between lakes and ground water that could be determined by one or two wells near the shoreline, or they installed too many wells within the immediate drainage basin of the lake. Some studies assumed that definition of the water table near a lake was sufficient to understand the interactions.

The relation of ground water to prairie potholes in North Dakota was studied by Eisenlohr and others (1972). Although in the early stages of this study the ground-water component was calculated as a residual, a seepage measuring device was subsequently developed. In latter stages of the study, wells were placed near some potholes to determine the relationship of ground-water levels to pothole water levels (Sloan, 1972).

The ground-water relation to small lakes in Minnesota was studied by Manson and others (1968) and Allred and others (1971) by placing one or several wells near the lake shores. The study approach was similar to that of Eisenlohr and others (1972). The general conclusion of these studies was that most of the lakes studied had a net loss to ground water.

In a study of Lake Sallie, Minnesota (McBride, 1969), the ground-water component of the lake-water budget was a primary interest. Wells were placed within the entire drainage basin of Lake Sallie to define lateral groundwater movement. At some sites several closely spaced wells were completed at different depths to define the vertical component of ground-water flow. Flow nets were then constructed to calculate the quantities of ground water moving into and, in one small area during part of the year, out of Lake Sallie. McBride used a digital modeling technique to define the vertical distribution of hydraulic head in the ground-water system near a lake. His models are of the flow within the immediate drainage basin of the lake itself-from the local ground-water divide to the midpoint of the lake (McBride and Pfannkuch, 1975).

Studies of the interaction between lakes and ground water similar to those conducted by McBride (1969), although not using simulation modeling, were done in Wisconsin by Hackbarth (1968), Hennings (1974), and Possin (1973). The lakes in these studies are the flowthrough type-ground water enters one side of the lakes, and the lakes leak to the ground-water system on the other side.

Meyboom (1966, 1967) studied ground-water flow systems in the vicinities of lakes and potholes in the prairie provinces of Canada. Meyboom's work is some of the first to examine the problem of determining ground-water flow systems and the strength and position of groundwater divides or absence of such divides beneath lakes. Studies by Freeze (1969a, 1969b) consider the relationship of ground-water flow systems within large drainage basins to lakes in the prairie provinces of Canada. The scale of the hydrologic sections, however, is such that the detailed flow patterns by the lakes can not be defined.

Williams (1968) examined ground-water flow systems in vertical sections near small depressions, and the relationship of those flow systems to wetlands in northern Illinois. The techniques of investigation and results of the study were similar to the work of Meyboom. Studies similar to and using the techniques of Meyboom were also done in East Germany by Schumann (1973).

A general overview of studies of the interaction of lakes and ground water, including a literature review, is given by Born and others (1974). They also discuss and present conceptual diagrams of many variations of ground-water flow systems near lakes.

The relationship of ground water to large lakes and reservoirs has been studied by several Russian hydrogeologists. Zektzer (1973) discussed the role of groundwater flow in water and salt balances of Lake Baikal and the Caspian Sea. Zektzer and Kudelin (1966) discussed the methods of determining ground-water flow to lakes with special reference to Lake Ladoga, USSR. Payne (1970) used radioactive tracer techniques to study the groundwater aspect of the water balance of Lake Challa, Africa. Haefeli (1972) has calculated the ground water inflow into Lake Ontario from the Canadian side. The study made use of the cross-sectional digital ground-water flow model of Freeze (1969b). Van Everdingen (1972), as part of an intensive study of the Lake Diefenbaker, Saskatchewan, site, constructed a series of piezometer nests (closely-spaced group of wells, each well completed at a different depth) before the dam was constructed. The changes in the potentiometric level of different aquifers in the ground-water system were observed as the lake filled. The study showed reversals of flow within some of the aquifer zones as a result of the creation of Lake Diefenbaker. A similar study is under way at the Kendrid Lake site, North Dakota, by Downey and Paulson (1974).

Careful review of the above literature leads one to the conclusion that much work needs to be done to identify and evaluate the factors that control lake hydrology, especially the factors that control the relationship of ground water to lakes. The general principles underlying the interaction of lakes and ground water need to be defined on theoretical grounds to solve even such basic problems as determining the optimum number and placement of observation wells needed to define ground-water flow systems near lakes.

A logical first step in defining the general principles 
controlling the interaction of lakes and ground water is to use simulation modeling to examine the detailed patterns of ground-water flow around and beneath lakes for a wide variety of hydrogeologic settings.

\section{PURPOSE AND SCOPE}

The purpose of this report is to examine ground-water flow systems near lakes through digital models simulating ground-water flow in vertical sections. Use of such models makes it possible to examine the general principles of the interaction of lakes and ground water. By varying shape and altitude of the water table in relation to lake levels, lake depth, sediment distribution, size and position of aquifers within the ground-water system, ratio of horizontal to vertical hydraulic conductivity, ratio of hydraulic conductivity of aquifers to that of the surrounding finer-grained materials, and thickness of the ground-water reservo: $;$, it is possible to locate the position and strength (explained later) of the divide that exists under a lake or the percentage of the lake bottom through which water moves to the ground-water system if there is no continuous divide. Although the cross sections are hypothetical, the values of the parameters listed above are realistic and representative of physiographic and hydrogeologic conditions in glacial terrane, the geologic environment in which most natural lakes occur. Lakes in this type of terrane are of primary interest in this study, but the models used to define the interaction of lakes and ground water and the general principles evolved from this study should have general application to all types of geologic terrane.

\section{ACKNOWLEDGMENT}

This study constituted part of a dissertation (Winter, 1976a), which was submitted to the Faculty of the Graduate School at the University of Minnesota in partial fulfillment of the requirements for the degree of Doctor of Philosophy. Dr. H. O. Pfannkuch provided overall guidance during the course of the study. With minor modifications the dissertation was released to the open-file (Winter, 1976b).

\section{GROUND-WATER FLOW SYSTEMS}

\section{THEORETICAL BACKGROUND}

This study is concerned only with two-dimensional, steady-state, non-homogeneous and (or) anisotropic, cross-sectional systems. Thus the basic equation of ground-water flow that is used in this report for defining the head distribution within the ground-water system is

$$
\frac{\delta}{\delta x}\left[K(x, z) \frac{\delta h}{\delta x}\right]+\frac{\delta}{\delta z}\left[K(x, z) \frac{\delta h}{\delta z}\right]=0,
$$

where $\mathrm{K}(x, z)=$ hydraulic conductivity in the two coordinate directions and $\frac{\delta h}{\delta x}, \frac{\delta h}{\delta z}=$ gradient of hydraulic head.

Equation 1 results from coupling Darcy's equation with the equation of continuity. It assumes that fluid density is constant and the coordinate axes are aligned collinear with the principal directions of anisotropy. Development of the equation is discussed in most textbooks of groundwater hydrology (e.g., Domenico, 1972; DeWiest, 1965).

In order to solve equation 1 , it is necessary to define mathematically the boundary conditions for the region of interest. A general model for the type of flow section of interest in this report is shown in figure 1 . This figure represents an $x-z$ coordinate system that has the origin in the lower left corner. For any point $(P)$ in the system there corresponds a value of hydraulic head. Because there is no flow across the vertical boundaries projected down from the major divide and the major sink, the head gradient is zero $\left(\frac{\delta h}{\delta x}=0\right)$ along the two sides of the diagram. It is also assumed that the base of the system is impermeable, thus $\frac{\delta h}{\delta z}=0$. The pressure along the water table is atmospheric and the head $(h)$ there is a function of $x$ only. The hydraulic conductivity $(K)$ values are different for each geologic unit within the system. For this study, the size and position of zones of high hydraulic conductivity (termed aquifers for convenience) are varied, and the degree of anisotropy is varied.

Recent development of numerical methods as approximate solutions to the equation of ground-water flow (Remson and others, 1971; Trescott and Pinder, 1975; Cooley, 1974; Prickett and Lonnquist, 1971; Freeze, 1969b) has made it possible to simulate complex ground-water flow systems. Although a variety of numerical techniques are being developed, the finite-difference method has been well documented and has been used successfully in a number of studies. The finite-difference models used herein have been developed by the U.S. Geological Survey over a number of years (Pinder and Bredehoeft, 1968; Pinder, 1970; Trescott, 1973; Trescott and Pinder, 1975).

The alternating-direction-implicit method (ADI) was used to calculate the distribution of hydraulic potential within some of the cross-sectional simulations but, as more complex models were considered, it was necessary to turn to the strongly implicit procedure (SIP) (Stone, 1968). As an example of SIP's greater efficiency, some checkruns were made on the same section, using both numerical techniques; ADI did not converge after 99 iterations, whereas SIP needed as few as 16 . It was found that SIP adequately handled all conceivable simulations except one, where extremely high hydraulic conductivity contrasts existed in close proximity, both in the vertical and horizontal directions.

\section{MODELS OF HYDROLOGIC SECTIONS}

Only two comprehensive theoretical studies appear to have been published on modeling ground-water flow in 


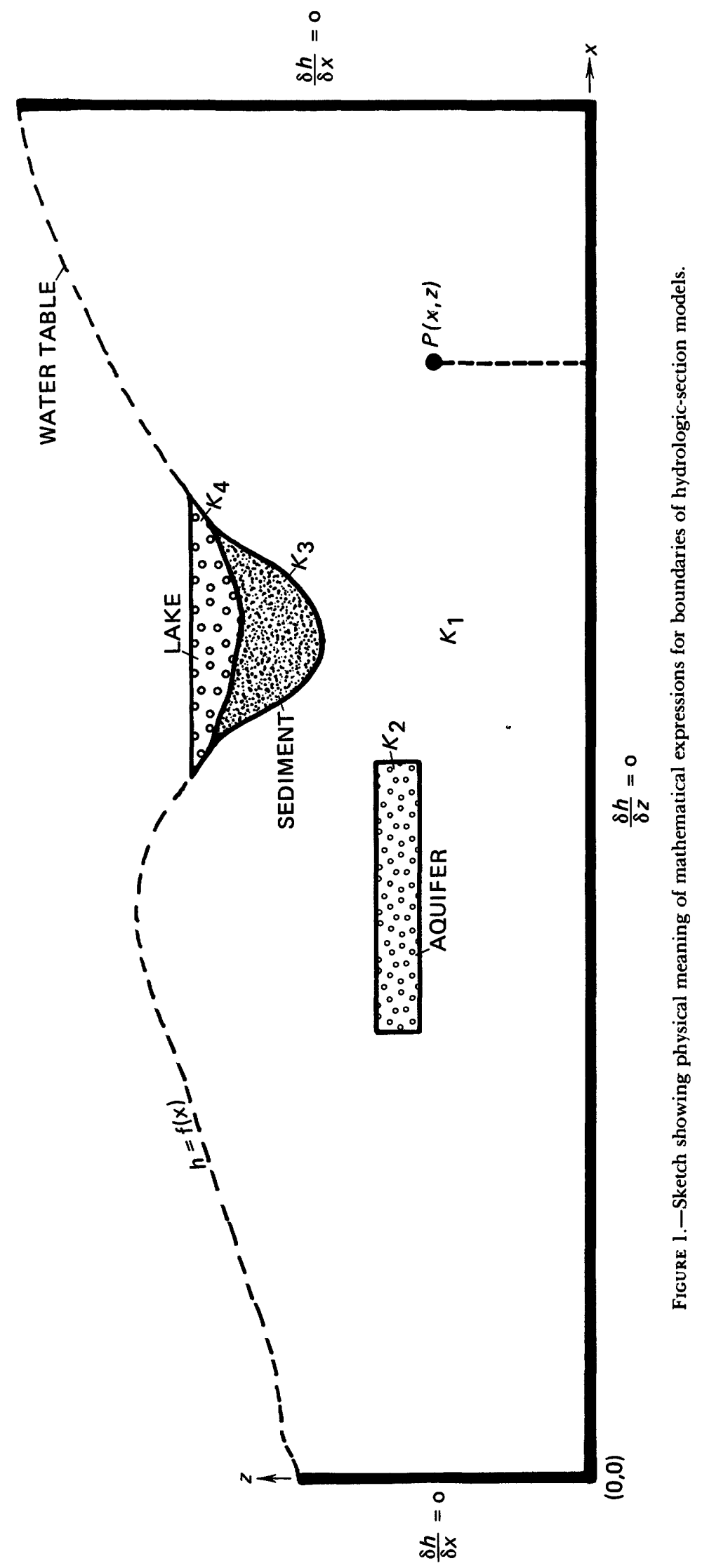


vertical section (Tóth, 1963; Freeze, 1969b). Subsequent work based on the report by Freeze has been done by Haefeli (1972) and by Freeze (1969a). These studies have concentrated on ground-water-flow patterns in vertical section in large basins and, although lakes occur along some of the sections modeled, the scale of the sections were such that detailed flow patterns in the immediate vicinity of lakes could not be shown.

Tóth's work is based on an analytical solution to the ground-water-flow equation, whereas the work of Freeze is based on a numerical solution. Freeze $(1969 \mathrm{~b})$ discusses the advantages and disadvantages of each approach. In the analytical-solution approach Tóth had to make some rigid simplifying assumptions: The field has to be approximated by a rectangle; the ratio of horizontal to vertical hydraulic conductivity must be 1 , that is, the porous media must be isotropic; the water table is simulated by superimposing a sine curve on a low regional slope. The analytical approach requires that equations be set up for each individual case considered according to the boundary configurations. There is no general analytical solution to the ground-water-flow equation that is valid for all boundary conditions at the same time.

The advantages of the numerical solution as outlined by Freeze (1969b), on the other hand, are as follows: Many of the restrictions of the analytical solution are removed; the true shape of the water table can be approximated, that is, it is not restricted to the equation for a sine curve; equation 1 can be handled in the numerical solution, that is, anisotropic and heterogeneous conditions can be simulated. The numerical solution available in the USGS program is general; it was designed to handle a wide variety of hydrogeologic problems, including the vertical section simulations used in this study.

Both basic studies by Tóth and Freeze assume no-flow boundaries at the base of the system and no-flow boundaries beneath the regional topographic highs and lows. In addition, the water table is at steady state.

An example of one of Tóth's cross-sectional groundwater flow simulations is shown in figure 2 . The simulation is of a thick ground-water system that has low regional slope and low local relief. Although Tóth presents many such diagrams showing the effects on ground-water flow of many combinations of slope, relief and system thickness, this diagram best depicts his delineation and definition of local, intermediate, and regional flow systems.

An example of the flexibility of numerical models in closely simulating field conditions is shown in figure 3 (Freeze, 1969b). The diagram is of a hydrogeologic setting that has a variable water table in different parts of the section, anisotropic media, and zones of different hydraulic conductivities.

\section{DIGITAL MODELS OF GROUND-WATER FLOW NEAR LAKES}

\section{PRACTICAL CONSIDERATIONS AND ASSUMPTIONS OF THIS STUDY}

The boundary conditions assumed for this study relate closely to those of Freeze (1969b), that is: (1) The base of the system is considered to be impermeable; (2) the vertical noflow boundaries at each end of the section are considered to be controlled by the major topographic high and the major drain on the ground-water system; and (3) the upper boundary of the flow system is the water table and it is at steady state. In the model used for this study, the steadystate water table is specified by assigning effectively infinite storage to the water-table nodes. Freeze discusses thoroughly the justification for these boundary conditions and particularly the assumption that vertical noflow boundaries exist at the two end positions. As he points out, many workers have found that vertical no-flow boundaries do not occur beneath every topographic high. This is undoubtedly true, but the assumption that they do exist beneath the major high and low is considered to be valid.

Although the sections discussed in this report are hypothetical, they closely approximate field conditions for lakes in glacial terrane. The variations in height of the water table relative to lake level are reasonable for this type of terrane. Although the hydraulic conductivities that have been assigned to the geologic matrix in general are representative of silty till, in the simulations of this study, the relative values of hydraulic conductivity are the controlling factor, not the actual values. The simulated sections apply equally to geologic settings that have the given relative hydraulic conductivities, whether the setting is sand within till, or gravel within sand. The hydraulic conductivities assigned to the zones of higher relative hydraulic conductivity vary from 100 to 1,000 times greater than the surrounding geologic materials. There are, of course, some zones within glacial drift that have hydraulic conductivity values greater than 1,000 times that of the surrounding materials, but the values chosen are representative of a great many geologic settings. For convenience in this report, the geologic matrix is referred to as "till," and the zones of relatively higher hydraulic conductivity are referred to as "aquifers."

The hydraulic conductivities assigned to lake sediments are as low as can be assigned with the computer program used. In most lakes, the littoral zone is free of fine grained sediment; therefore, in the models that considered lake sediments, the sediments purposely were not extended to the shore line.

Lake water was simulated by assigning very high 

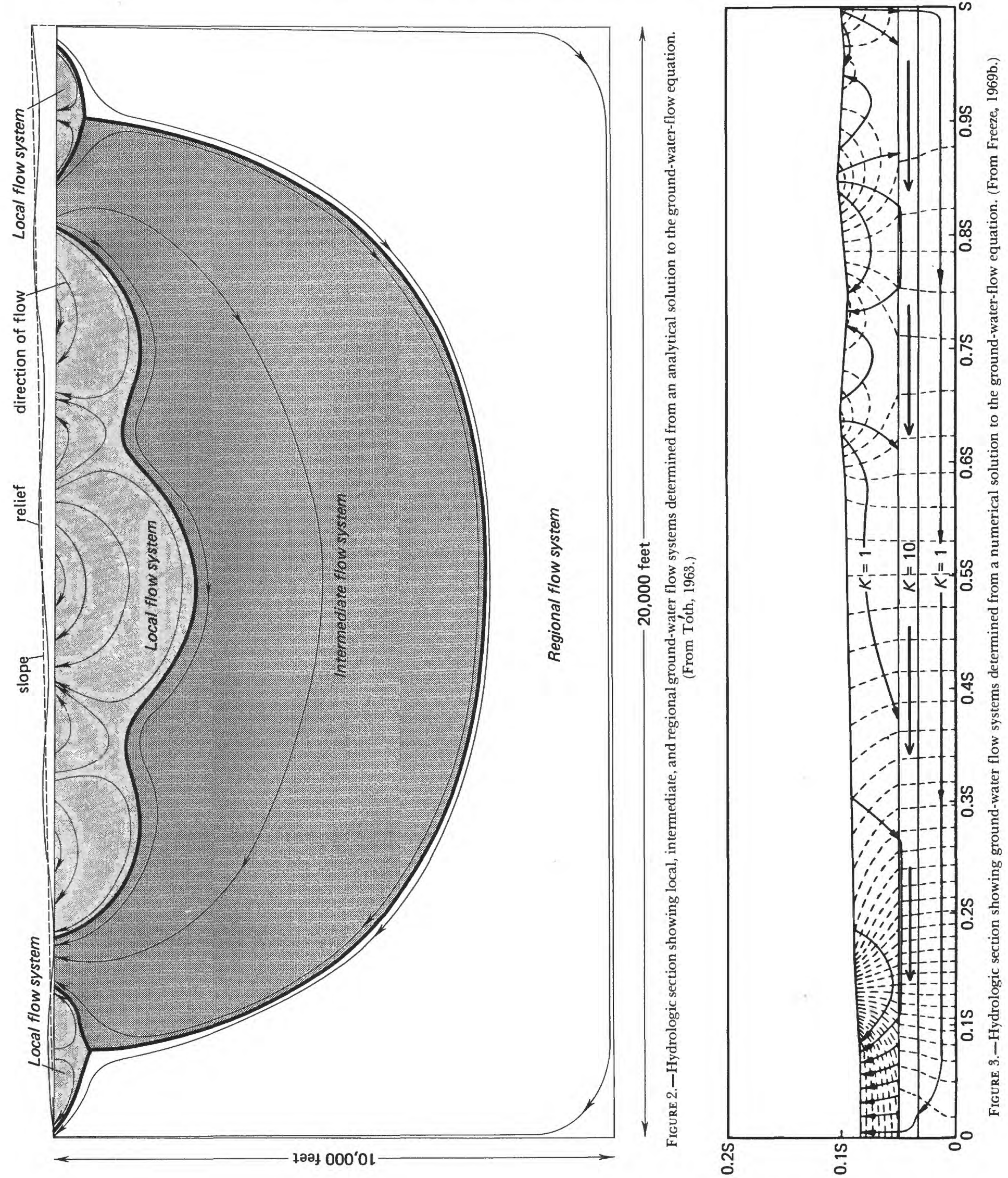
hydraulic conductivity values to the nodes within lakes. This proved to adequately simulate lakes because the calculated head values were identical to the initial head values within each lake simulated in this study.

The least well known parameter needed in the groundwater-flow model is the ratio of horizontal to vertical hydraulic conductivity $\left(K_{h} / K_{v}\right)$. This ratio has generally not been determined in glacial terrane and it is a point around which much of the discussion of the following section of this report centers. It will be shown that it is critical to the interaction of lakes and ground water. If the ratio is less than 100 , lakes rarely lose water to the ground-water system under the conditions simulated in the models and if the ratio is greater than 1,000 , lakes lose water under many conditions. If the ratio is between 100 and 1,000 , other factors that control ground-water flow become more important in the relationship of ground water to lakes.

Weeks (1969) measured $K_{h} / K_{v}$ within a single outwash sand and gravel aquifer in Wisconsin and found the ratio to be not more than 20. Vecchioli and others (1974) calculated $K_{h} / K_{v}$ for part of the drift section of Long Island, New York as approximately 500. Bennett and Giusti (1971), in using electric-analog techniques to study ground-water flow in the coastal plain of Puerto Rico, show that the ratio had to be 1,000 for the simulations to match field data. The importance of this parameter in ground-water-flow modeling has been recognized because it is the topic of recent papers by Freeze (1972) and Gillham and Farvolden (1974). Freeze concludes that $K_{h} / K_{v}$ values of 100 or larger are not uncommon, and in fact were necessary to correlate simulations with field measurements in his study of the Old Wives Lake basin in Saskatchewan (Freeze, 1969a). Gillham and Farvolden (1974) tested the sensitivity of the ratio and found it to be particularly important in areas of recharge and discharge.

Considering the above studies, the models discussed in the following section of this report use both 100 and 1,000 as lower and upper examples.

\section{GROUND-WATER-FLOW DIAGRAMS}

Much of the remainder of this report is a discussion of ground-water flow systems near lakes, which are best illustrated by diagrams showing ground-water flow in cross section. Understanding of the important features of this type of diagram is basic to the discussion of the simulation results. A ground-water-flow diagram shows the distribution of hydraulic head within the groundwater system. After the head is calculated for each node, lines of equal head, equipotential lines, are drawn. Ground-water flow lines are drawn perpendicular to the equipotential lines, if the medium is isotropic. Equipotential lines are the projections of water-table contours into the subsurface (figure 4).

The finite difference grid used in this study is a network of uniform rectangles. About 900 nodes were used for the one-lake simulations and about 1,800 nodes for the threelake simulations.

To give the most accurate picture of ground-water flow systems, and to estimate relative quantities of ground water moving through various parts of the ground-water reservoir, a flow net should be drawn. Construction of a quantitative flow net in a medium that is isotropic $\left(K_{h} /\right.$ $K_{v}=1$ ), requires that flow lines and equipotential lines be orthogonal such that curvilinear squares are formed (Harr, 1962).

If the medium is anisotropic $\left(K_{h} / K_{v} \neq 1\right)$ the squares are deformed according to the degree of anisotropy. In this study, $K_{h} / K_{v}$ is either 100 or 1,000 . To compensate for the anisotropy, in homogeneous media equation 1 can be transformed to the LaPlace equation by a transformation of coordinates. The scale factor used to do this, which was not applied to the diagrams in this report (discussed later), is the square root of the ratio $K_{h} / K_{v}$ (Harr, 1962, p. 29).

A requirement for constructing precise flow nets is that the section have no vertical exaggeration (Van Everdingen, 1963). Vertical exaggeration is usually used for convenience in illustrating important details of geology and ground-water movement that would be lost if the true scales were used. The sections discussed in this study have a vertical exaggeration of 80:1. Because the graphical correction of Van Everdingen (1963) was not applied to the sections in this study, they cannot be used as exact quantitative diagrams. The diagrams of Van Everdingen (1963) provide good examples of the effect of the correction on the ground-water-flow fields. The effect basically is that the corrected flow nets are much more rectangular and the local systems extend deeper into the ground-water reservoir than in flow sections not corrected for vertical exaggeration. The flow nets (figures 4 and 5 ) were drawn as if the porous medium were isotropic and homogeneous merely to show the general concept of flow nets and the different-magnitude flow systems that can occur near lakes and within the ground-water reservoir. Although the two flow nets drawn for this study are not quantitatively precise, they do show relative proportions of flow in different parts of the ground-water system.

The ground-water system illustrated in figure 4 consists of several flow systems of different magnitude. The upper part of the ground-water system consists largely of local flow systems where water moves from high points on the water table (water-table mounds) to adjacent lowlands occupied by lakes. Regional ground-water flow occurs deep in the system. Recharge to the regional flow system occurs at the major drainage divide and discharge from this system is to the major drain (stream). A zone of intermediate flow (darkly stippled area) is recharged at the water-table mound between lakes 2 and 3 and is discharged into lake 1 . It should be noted, but will be discussed in more detail later, that much more ground water moves through local flow systems than through the deep 

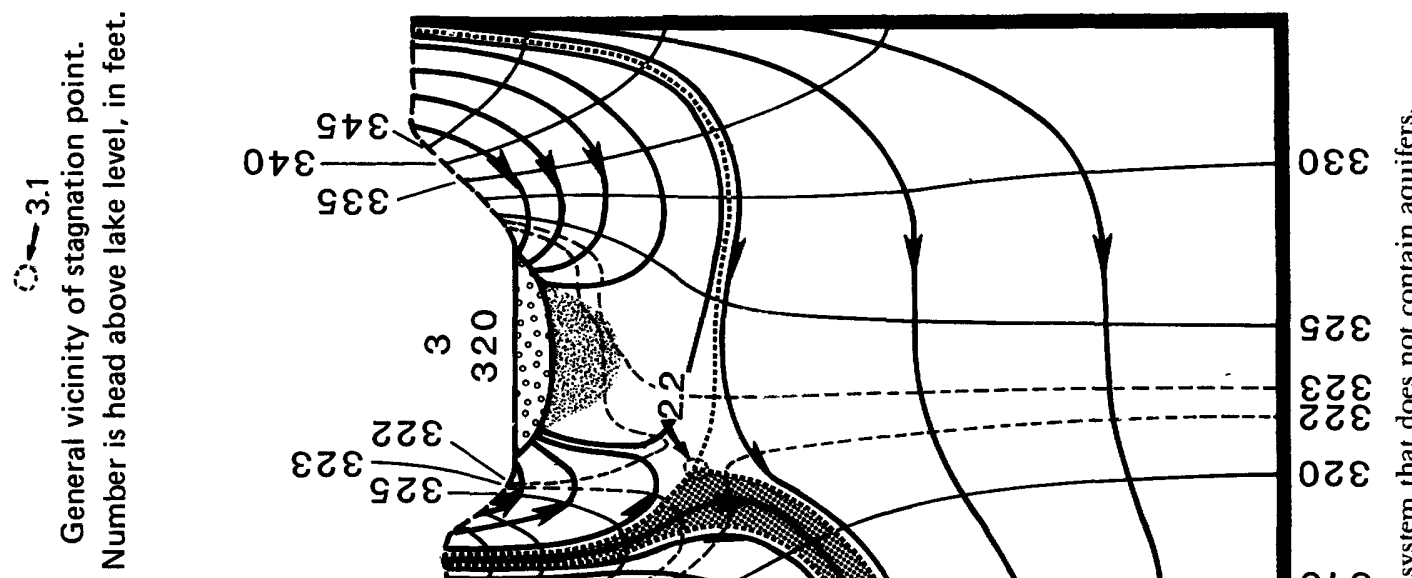

દ己દ

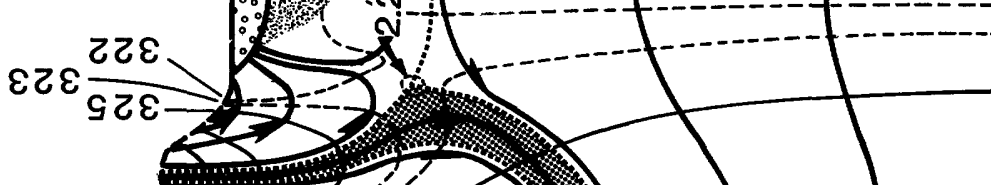

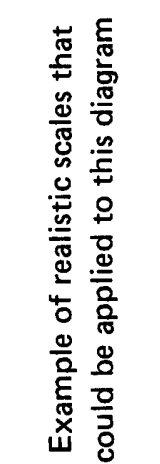
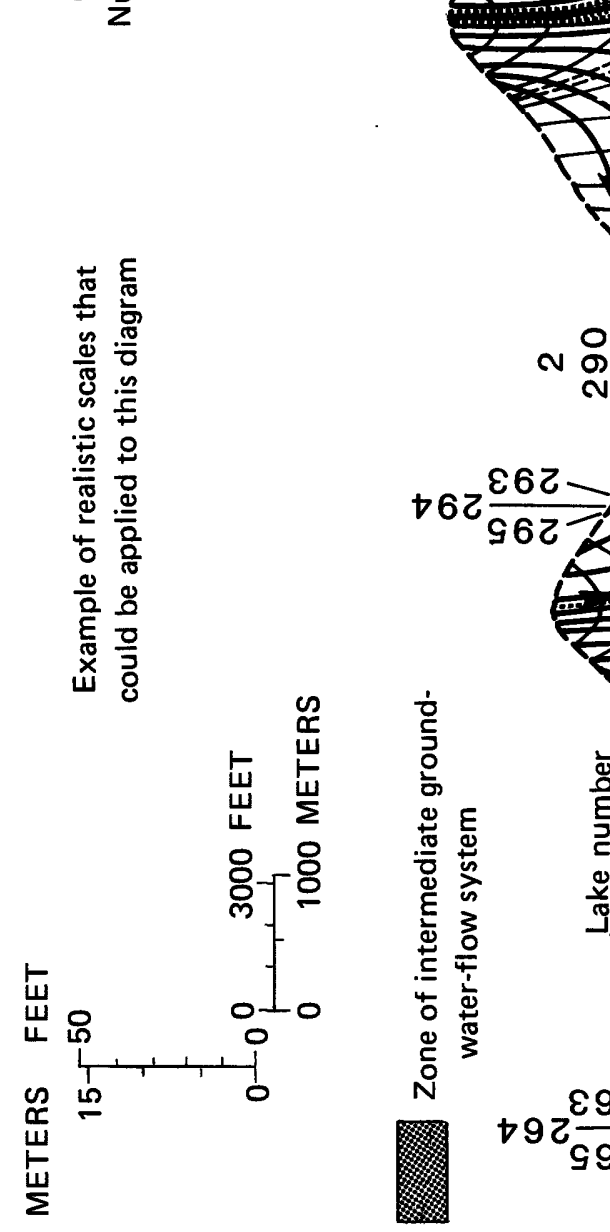
regional system as shown by the closer spacing of the flow lines in the local systems. A thorough discussion of similar type ground-water-flow diagrams is given by Tóth (1963), Meyboom (1966, 1967), and Freeze (1969b).

Of special interest to this study are the lines, hereafter referred to as divides, separating the several types of flow systems. In following the line dividing the zone of local flow from zones of larger magnitude flow (by lake 3, fig. 4, for example), it should be noticed that there is a point on the divide at which the head is a minimum compared to every other point along the divide. This point of minimum head occurs beneath the shoreline on the downslope side of the lake. In the case illustrated, the hydraulic head at this point is 2.2 feet $(0.7 \mathrm{~m})$ higher than the waterlevel altitude of lake 3 . The hydraulic head everywhere else along the divide is greater than 2.2 feet $(0.7 \mathrm{~m})$ above the lake-level altitude. Thus, under the given conditions, it is impossible for water to move from the lake to the groundwater system because the hydraulic gradient is upward toward the lake bottom.

This point of minimum head is the stagnation point commonly referred to in the ground-water-flow literature (for example, Harr, 1962). It is a point in the flow field at which vectors of flow are equal in opposite directions and therefore cancel. A value of head exists at the stagnation point and, as will be shown below, it is this value of head relative to the head represented by lake level that is of prime interest in understanding the interaction of lakes and ground water. If a stagnation point exists that has a head greater than that of lake level, a continuous groundwater divide exists beneath the lake making it impossible for water to move against the hydraulic gradient from the lake to the ground-water system. The position of the stagnation point is determined by the distribution of head within the ground-water system.

The stagnation point is a point of diversion of groundwater-flow paths (fig. 4). Water moving downward from the water-table mound on the downslope side of the lake is diverted upward toward the lake. A small amount of water that moves beneath the lake from the upslope side is diverted upward toward the lake on the downslope side. Water moving in the local or intermediate flow systems of the lakes at lower altitudes is diverted downslope and water moving in the regional flow system is diverted deeper into the ground-water reservoir.

Much of the remainder of the report is concerned with the effect of varying the height of the water table in relation to lake level, $K_{h} / K_{v}, K_{a q} / K_{t}$ (ratio of the hydraulic conductivity of aquifers to that of the surrounding till), position and size of aquifers, and lake depth, on the position and head value of the stagnation point relative to lake level.

To illustrate the effect of varying several parameters on the ground-water flow systems in general and the stagnation point in particular, figures 4 and 5 can be compared.
The presence of aquifers of limited extent, which have hydraulic conductivity 1,000 times greater than the till and are at an intermediate depth within the ground-water system, change the configuration of the flow systems. The aquifers also decrease the head at the stagnation points relative to the level of each lake and move the points closer to the bottom of lakes 1 and 2. In addition to having a limited aquifer beneath the water-table mound between lakes 2 and 3 , the height of the water table was decreased on both sides of lake 3 . These two changes near lake 3 result in reduced local ground-water flow into one-half of lake 3 on the upslope side, a small amount of ground-water flow into the littoral zone of the lake on the downslope side, and loss of lake water to the ground-water system through most of the downslope half of the lake bottom.

To appreciate fully the discussion in the following part of the report, the diversion of ground-water-flow lines caused by the presence of aquifers of limited extent within the till should be noted (fig. 5). It should be noted also that an intermediate flow system was sketched in figure 4, but not in figure 5. Although an intermediate flow system could have been included in figure 5 and deleted from figure 4 , the intermediate system was included in figure 4 to illustrate where such systems can occur, where they are recharged, and where they discharge. The intermediate system could be recharged at any of the upper three water table mounds or discharged into any of the lower lakes or the major drain. Such systems have importance especially in explaining differences in water chemistry in lakes occurring at different altitudes in a region.

Ground-water chemistry is controlled partly by the length of time a particle of water is in contact with minerals in the geologic framework through which the water flows. Thus, the longer the flow path, or the lower the hydraulic conductivity, the longer the residence time, and the greater will be the opportunity for chemical interchange. For lakes situated on geologic materials of similar hydraulic conductivity, those that receive ground water from intermediate or large local ground-water flow systems are more likely to contain more, and a wider variety of, dissolved minerals than lakes that receive ground water from small local flow systems. It will be seen in the remainder of the report that the size of local flow systems alone can vary widely. Therefore, the large variation in lake-water chemistry that is so frequently noted in lakes in close proximity in many lake regions is not at all surprising. On the contrary, after becoming aware of the factors that control the interaction of lakes and ground water discussed in this report, and realizing that virtually every lake has its unique ground water contribution, a wide variety in the chemistry of lakes should be expected.

Because the stagnation point is the key to understanding the relation of ground-water to lakes and it is determined by the distribution of head, the remainder of the illustrations in the report are contoured computer 

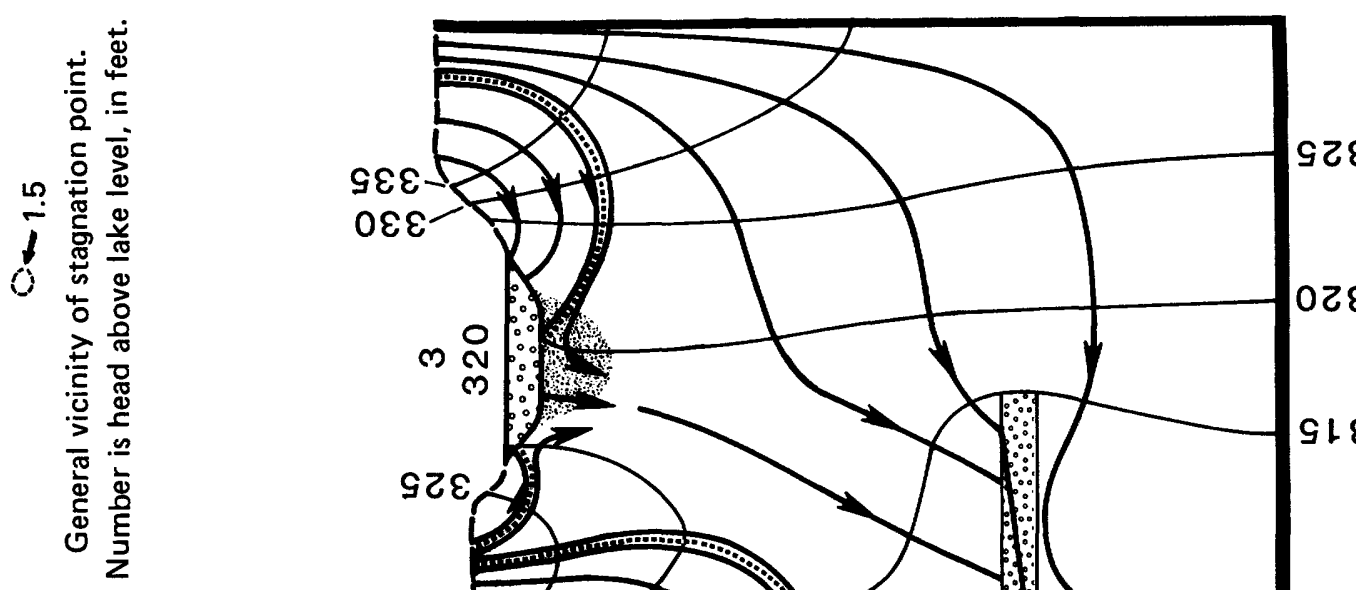

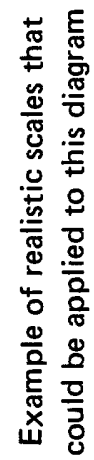

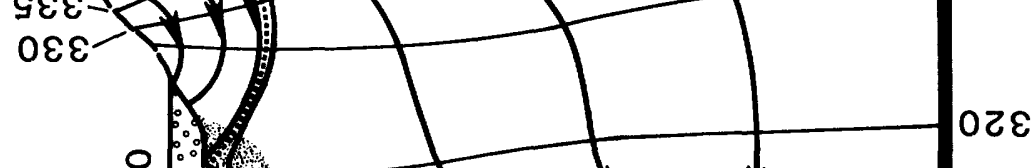

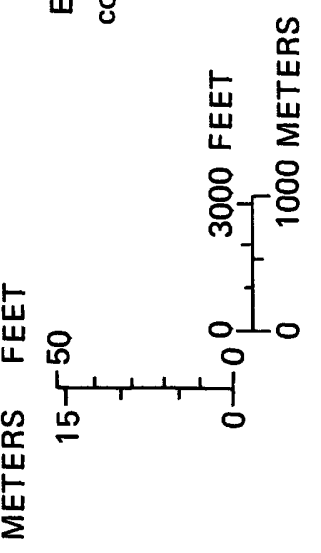
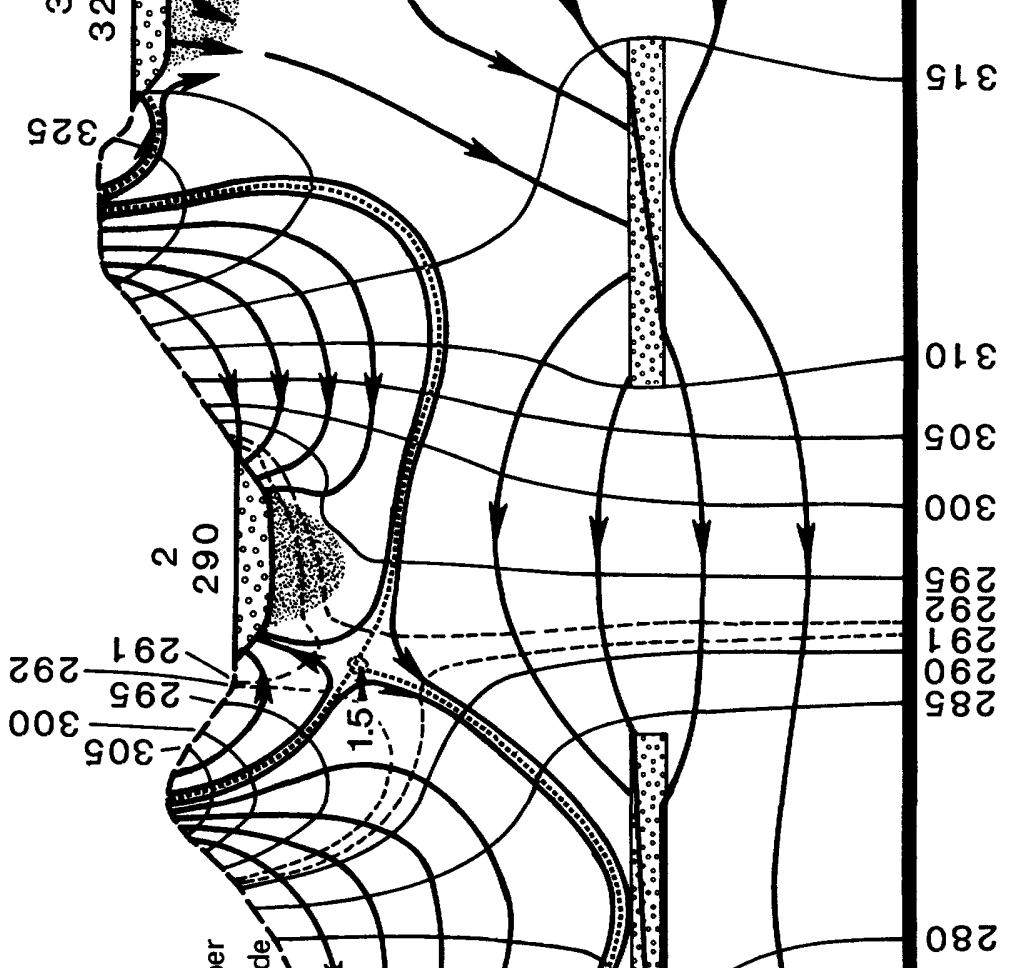

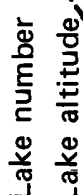

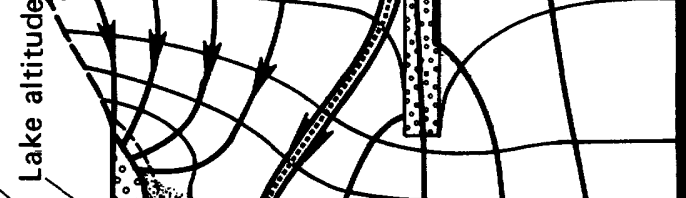

$9<2$ $0<2$

992

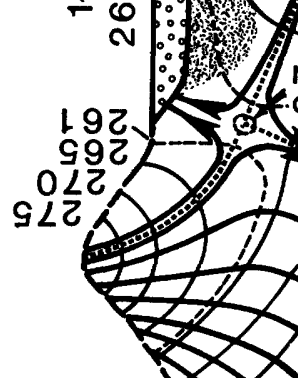

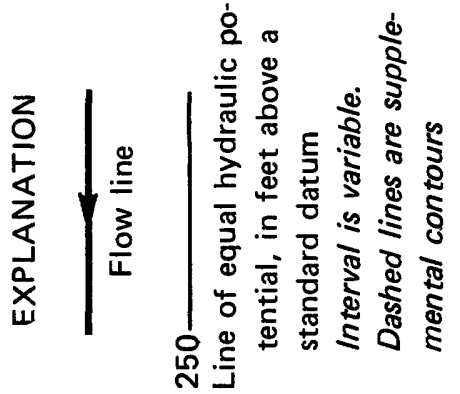

$E$
0
0
0
0
3
0
$\frac{0}{4}$
4
0
$\frac{2}{0}$
$\frac{0}{0}$
5
0
0
0

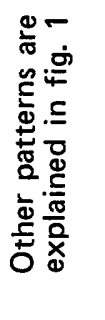

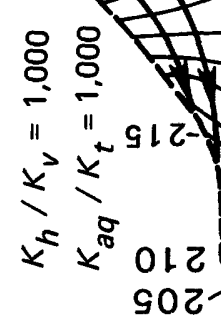


printouts that show only isopotential lines. The isopleth interval is variable; only enough lines were drawn to depict the general distribution of hydraulic head, the specific location and head of the stagnation point, or the percent of lake bottom through which the lake loses water to the ground-water system. Figure 4, a specially constructed flow net, can be compared with figure 6 , a contoured computer printout, to aid in understanding the remainder of the illustrations in this report. Both diagrams are of identical settings.

The following sections of the report discuss two general settings. In the first, one lake is situated within the side of a drainage basin. The interaction of lakes and ground water is thoroughly studied for this type of setting by examining all possible combinations of the parameters mentioned previously. In the second general setting, three lakes are situated within the side of a drainage basin to examine the relationship of the lakes to each other and to compare the results to the one-lake setting.

The diagrams of vertical ground-water flow are discussed in dimensionless terms. But because lakes in glacial terrane are of primary interest in this study, the dimensions expected to be of most general interest are also given.

It must be kept in mind, however, that the specific results of this study apply to ground-water systems that approximate the given conditions. If the boundaries were greatly changed relative to each other, the problem would then be changed. However, if the new problem were analyzed as in this study, the general conclusions would be similar to this study.

\section{ONE-LAKE SYSTEM}

The approximate dimensions, relative to total length and thickness of the ground-water system, of features in the one-lake system are given in the following paragraphs and in figure 7. Realistic examples of the dimensions are shown in parentheses.

The thickness of the system ranges from $0.35 T(70 \mathrm{ft} ; 21$ $\mathrm{m}$ ) at the lower end of the basin to $T$ (as much as $200 \mathrm{ft} ; 61$ $\mathrm{m})$ at the upper end. The length of the system $(L)$ is approximately 6 miles $(9 \mathrm{~km})$. The height of the water table above lake level is varied between $0.20 T$ and $0.35 T$ ( 40 and $70 \mathrm{ft} ; 12$ and $21 \mathrm{~m}$ ) on the upslope side of the lake and between $0.05 T$ and $0.10 T$ ( 10 and $20 \mathrm{ft} ; 3$ and $6 \mathrm{~m}$ ) on the downslope side. Lake depths simulated are $0.05 T$ and $0.25 T$ (10 and $50 \mathrm{ft} ; 3$ and $15 \mathrm{~m}$ ). Values of $K_{h} / K_{v}$ (horizontal to vertical hydraulic-conductivity ratio) used in the simulations are 100 and 1,000 . Simulated aquifers vary from full aquifers $(0.05 T \times L)$ that extend the entire length of the basin to aquifers of limited extent $(0.05 T \times 0.25 L)$ that occur upslope from the lake (center point at $0.85 \mathrm{~L}$ ), beneath the lake (center point at $0.60 \mathrm{~L}$ ), and downslope from the lake (center point at $0.35 \mathrm{~L}$ ). The aquifers are placed both at the base and at an intermediate level (center point at $0.25 T$ above the base of the system) of the ground-water reservoir. The lake surface is at $0.65 T$ above the base and the midpoint is about $0.60 \mathrm{~L}$ from the downslope end of the section for all simulations of the one-lake system. The system simulated can be thought of as a ground-water reservoir that has a datum of 100 feet $(30$ m) (bottom of the ground-water reservoir). The values of head are in feet relative to that datum, thus the lake surface has an altitude of 230 feet $(70 \mathrm{~m})$, the higher water table at the upslope end of the section 300 feet $(100 \mathrm{~m})$, and the water table at the downslope end 170 feet $(52 \mathrm{~m})$.

A large number of simulations could be run varying each of these parameters. Generally, the parameters are varied between two values so the general direction of change of the stagnation point could be determined. If a change in a parameter lowers the head at the stagnation point relative to lake level, an even greater change of that parameter in the same direction would lower the head at the point even more.

The pattern of ground-water flow near a lake that has a water table $0.35 T$ higher than lake level on the upslope side and 0.1T higher on the downslope side, has no sediments, and $K_{h} / K_{v}=1,000$, is shown in figure 8 . A groundwater divide occurs deep beneath the lake that has a head at the stagnation point $0.009 T(1.8 \mathrm{ft} ; 0.5 \mathrm{~m})$ higher than lake level. The position of the stagnation point is approximately $0.2 T$ above the base of the system. In contrast, if lake sediments are simulated, and all other parameters are held constant, the ground-water divide shifts slightly upward, and the head at the stagnation point increases to $0.02 T(4.2 \mathrm{ft} ; 1.3 \mathrm{~m})$ higher than lake level (fig. 9). Thus, it is evident that the presence of lake sediments has a significant effect on the position and head of the stagnation point. Because lakes without sediments are virtually unknown, much of the remainder of this report is concerned with lakes that have a sediment layer.

The effect on the interaction of lakes and ground water of lowering the water table $0.05 T(10 \mathrm{ft} ; 3 \mathrm{~m})$ on the downslope side and holding all other parameters as in figure 9 , is shown in figure 10. The head at the stagnation point drops to $0.007 T(1.4 \mathrm{ft} ; 0.4 \mathrm{~m})$ above lake level and the point moves closer to the bottom of the lake. Again, holding all parameters as in figure 10 , but lowering the water table on the upslope side of the lake to $0.20 T$ ( $40 \mathrm{ft}$; $12 \mathrm{~m}$ ) above lake level, decreases the head at the stagnation point to $0.004 T(0.9 \mathrm{ft} ; 0.3 \mathrm{~m}$ ) above lake level (fig. 11). The stagnation point remains at about the same position as in figure 10. This suggests that the height of the water table relative to lake level on the upslope side of a lake has less influence on the stagnation point of the ground-water divide beneath a lake than that on the downslope side. 


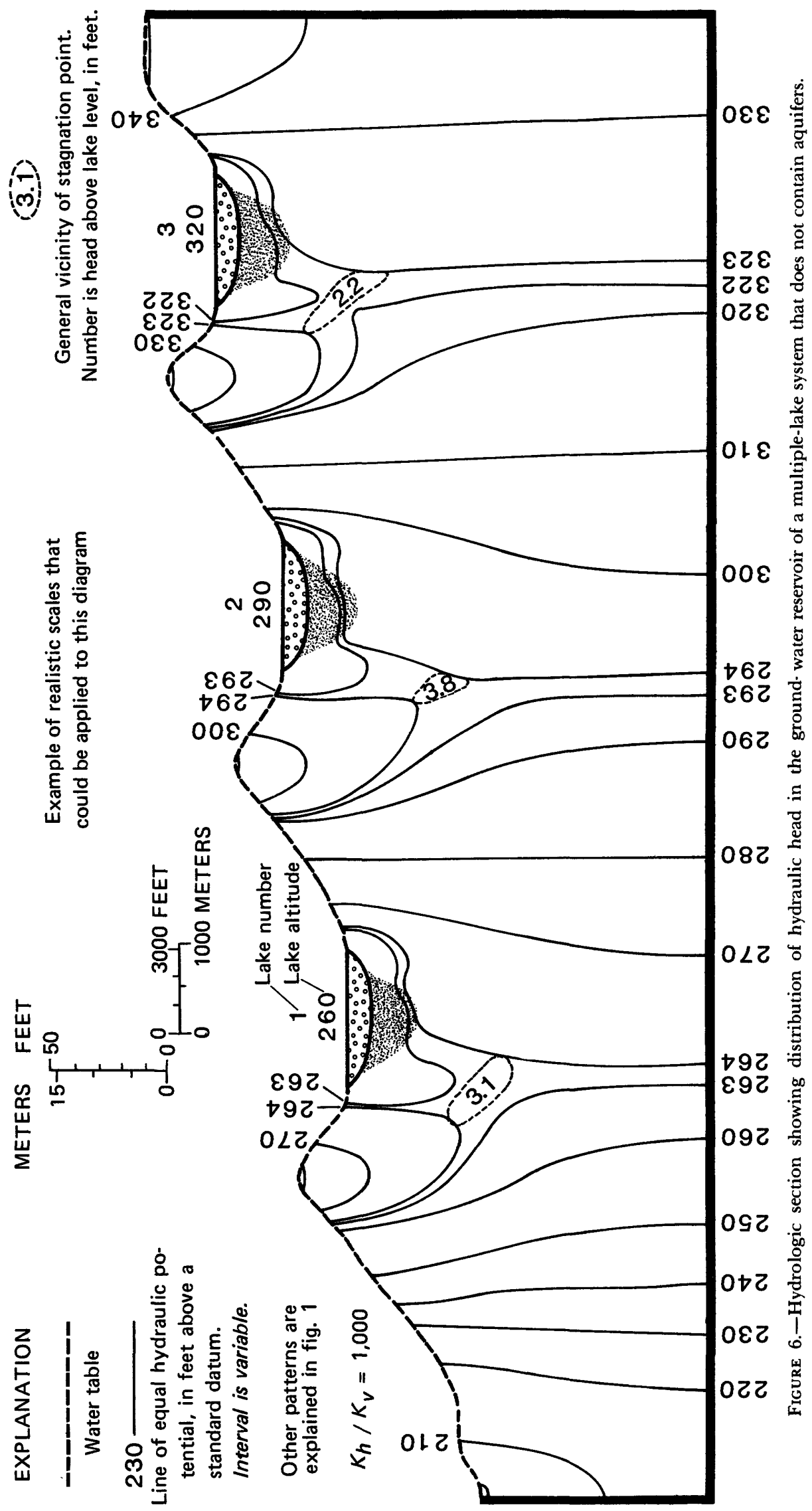




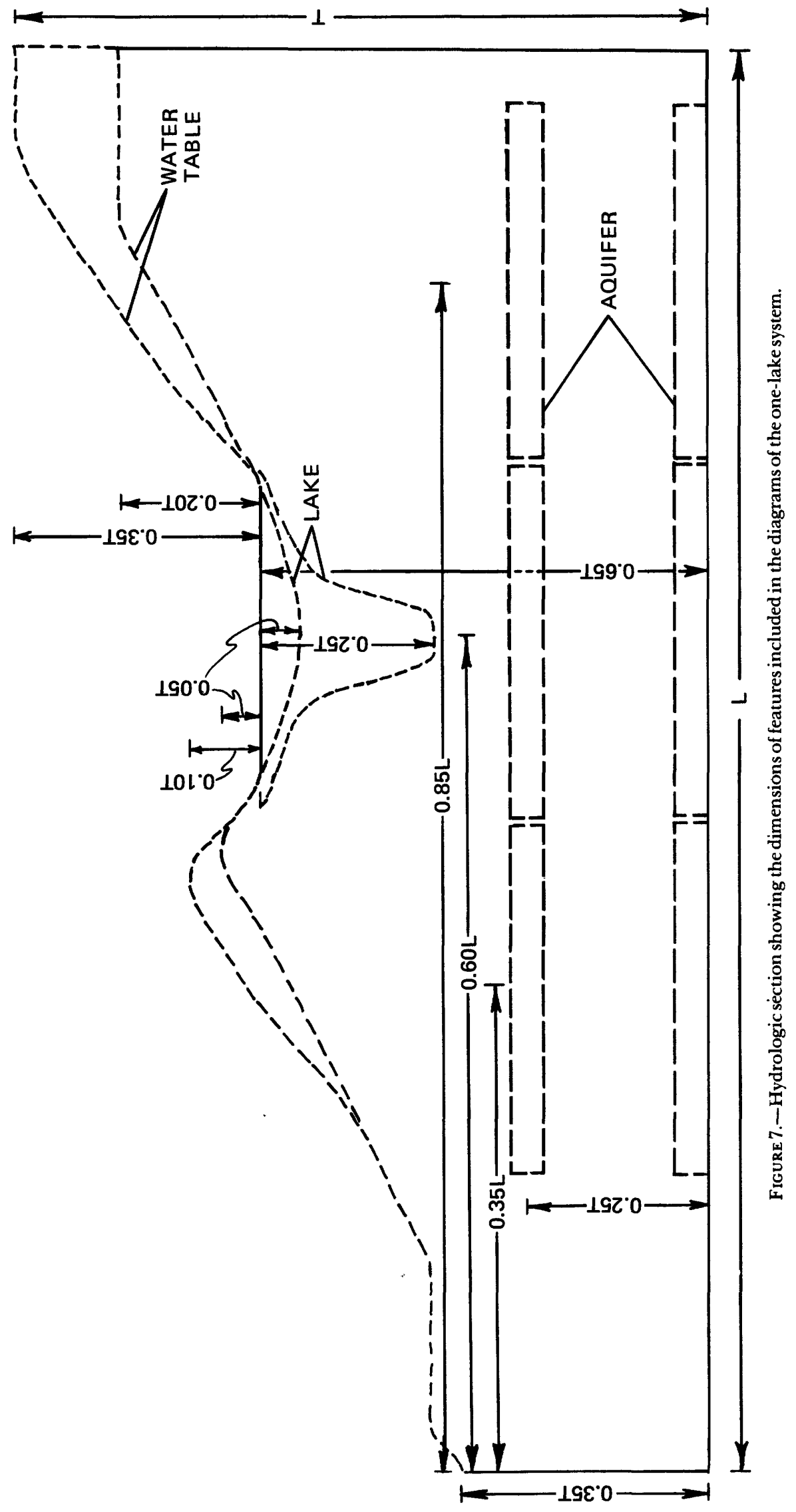



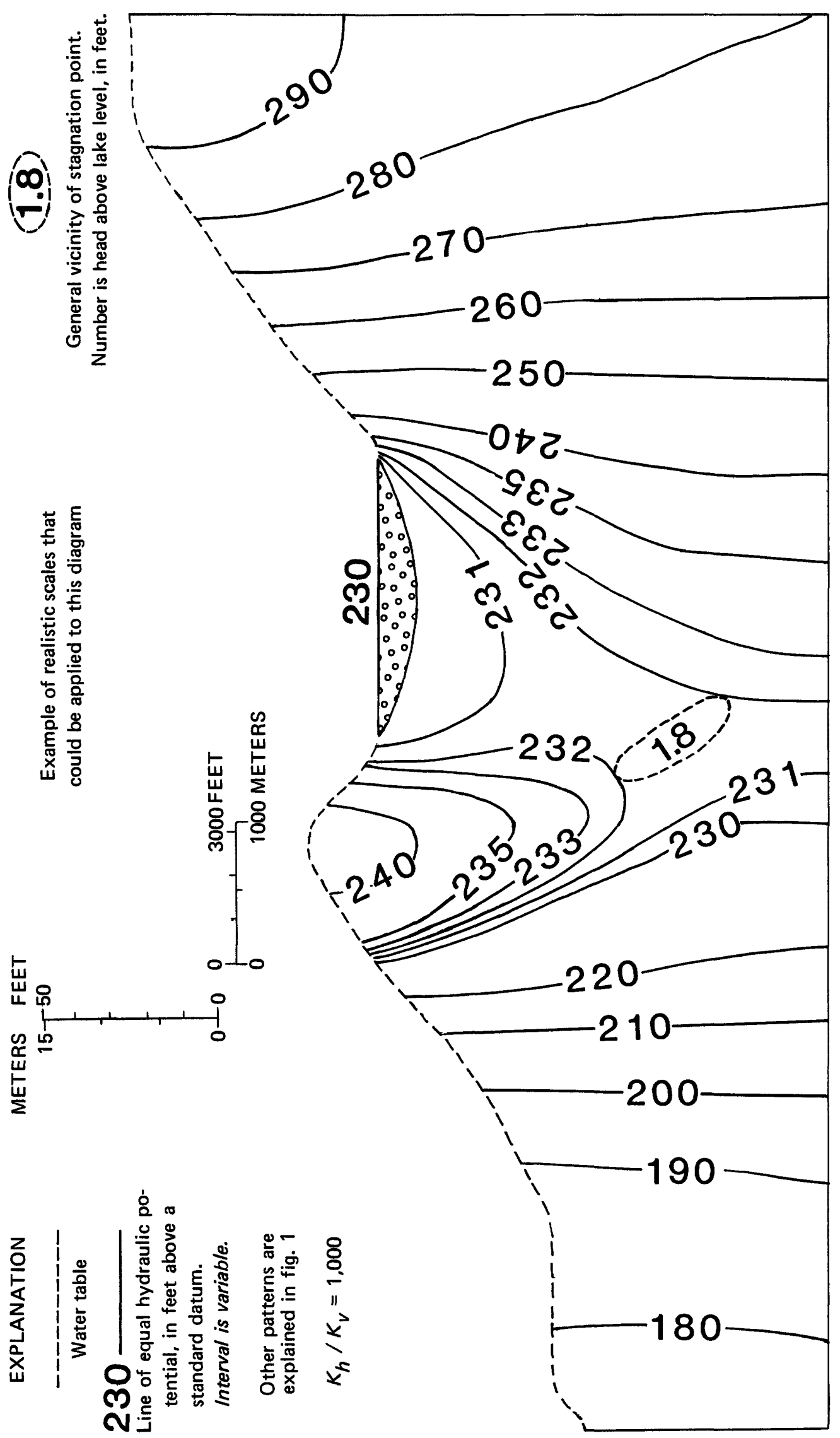

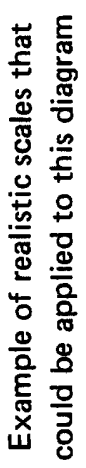
$2^{8}$
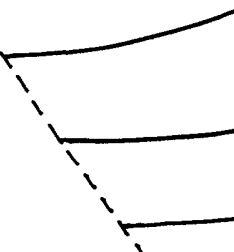

1

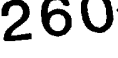

270 
The presence of extensive aquifers within the groundwater reservoir has a significant effect on the interaction of lakes and ground water as seen in figure 12. Given the same setting as in figure 9 , but simulating an aquifer at the base of the ground-water system that extends the full length of the basin and has $K_{a q} / K_{t}=100$, decreases the head at the stagnation point from $0.02 T(4.2 \mathrm{ft} ; 1.3 \mathrm{~m})$ (figure 9) to $0.001 T(0.2 \mathrm{ft} ; 0.1 \mathrm{~m})$ higher than lake level. Again, holding all parameters constant, but increasing $K_{a q} / K_{t}$ to 1,000 causes the lake to lose water to the groundwater system through its entire bed (fig. 13).

The effect on the interaction of lakes and ground water of raising the extensive aquifer vertically to the $0.25 T$ (intermediate) level in the ground-water system, where the setting is otherwise similar to figure 12, is shown in figure 14. The weak ground-water divide (head at the stagnation point is $0.001 T(0.2 \mathrm{ft} ; 0.1 \mathrm{~m})$ higher than lake level) in the former is obliterated and the lake loses water through three-eighths of its bed.

The position of smaller aquifers of limited extent within the ground-water reservoir also has varying influences on the interaction of lakes and ground water. All parameters other than the location of the limited aquifer at the base of the ground-water system are held constant in figures 15,16 , and 17 . In the simulation that has a limited basal aquifer upslope from the lake $(0.85 \mathrm{~L})$ (figure 15), the head at the stagnation point is $0.006 \mathrm{~T}(1.3$ $\mathrm{ft} ; 0.4 \mathrm{~m}$ ) above lake level. With the limited basal aquifer beneath the lake $(0.60 L)$ (figure 16 ), the head at the stagnation point is $0.009 T(1.8 \mathrm{ft} ; 0.5 \mathrm{~m})$ above lake level. The limited basal aquifer underlying the water-table mound on the downslope side of the lake $(0.35 L)$ causes the lake to lose water through three-eighths of its bed (figure 17).

Similar patterns of ground-water flow near lakes hold for settings that have aquifers at the same position laterally but moved vertically to $0.25 T$ above the base of the ground-water system. One difference is that, if a limited aquifer directly beneath a lake is raised vertically, it tends to increase the head at the stagnation point. In a section simulating this situation, the head at the stagnation point increases from $0.009 T(1.8 \mathrm{ft} ; 0.5 \mathrm{~m})$ (figure 16) to $0.012 T(2.5 \mathrm{ft} ; 0.8 \mathrm{~m})$ higher than lake level with the aquifer at the higher position. If the limited aquifer is raised to directly under, and in contact with, the lake sediments, the head at the stagnation point increases to $0.016 T$ $(3.3 \mathrm{ft} ; 1.0 \mathrm{~m})$ higher than the lake level. If the aquifer is at an intermediate level but downslope from the lake $(0.25 T$, $0.35 \mathrm{~L}$ ), a situation parallel to that shown in figure 17 , the percentage of lake bottom through which water moves to the ground-water system increases from three-eighths to four-eighths.

These simulations suggest that the position of limited aquifers beneath or upslope from a lake has little influence on the interaction of lakes and ground water. But if the limited aquifer underlies the water-table mound on the downslope side of the lake, there is a strong tendency for the head at the stagnation point to be only slightly above lake level, if at all; in the latter case the lake loses water through part of its bed.

The effect of lake depth on the interaction of lakes and ground water can be seen by comparing figure 18 with figure 12. All parameters in these two simulations, except depth, are identical. The small difference between lake level and head at the stagnation point associated with the shallow lake (fig. 12) is eradicated in the deep-lake setting, and the lake loses water through about six tenths of its bed. This example is one of the more dramatic in comparing ground-water flow near shallow and deep lakes. In some simulations the difference is not as great, but in all cases the difference between lake level and the head at the stagnation point for deep lakes is less, or they have more tendency to lose water, than shallow lakes in equivalent settings.

It is evident that a large number of simulations would be needed to examine all possible combinations of the variables considered in this study. To keep the analysis as simple as possible, yet show the underlying relationships of the interaction of lakes and ground water, a parallel series of lake-ground water settings are compared and summarized in table 1 . At first glance the table might seem complex, but with a little study it is not so formidable. It should be realized that many variables are summarized in this one table.

The table consists of four quadrants, each of which is subdivided into four subquadrants. Each subquadrant has an upper and a lower part. For ease of discussion, the different parts of the table are referred to as shown in figure 19. The major quadrants are the combinations of hydraulic conductivity $\left(K_{h} / K_{v}\right.$ and $\left.K_{a q} / K_{t}\right)$ used in the study. In quadrant $I$, both ratios are 100 and in quadrant IV, both are 1,000. Within the subquadrants are combinations of the height of the water table above lake level for both sides of the lake. In subquadrant I- 1 the water table is $0.35 T(70 \mathrm{ft} ; 21 \mathrm{~m})$ higher on the upslope side and $0.10 T(20$ $\mathrm{ft} ; 6 \mathrm{~m}$ ) higher on the downslope side. In subquadrant I-4, the water table on the upslope side is $0.20 T(40 \mathrm{ft} ; 12 \mathrm{~m})$ higher than lake level and $0.05 T(10 \mathrm{ft} ; 3 \mathrm{~m})$ higher on the downslope side. Within each of the subquadrants, the upper part (a) refers to shallow lakes and the lower part (b), refers to deep lakes. Within each part ( $a$ and $b$ ), the position and size of the aquifers are listed in a parallel fashion as follows:

FB-Full (extensive) aquifer at the base of the groundwater system.

FM-Full (extensive) aquifer at an intermediate level $(0.25 T)$ of the ground-water system.

PBU-Partial (limited extent) aquifer at the base of the ground-water system upslope from the lake $(0.85 L)$.

PBB-Partial (limited extent) aquifer at the base of the ground-water system beneath the lake $(0.60 L)$. 


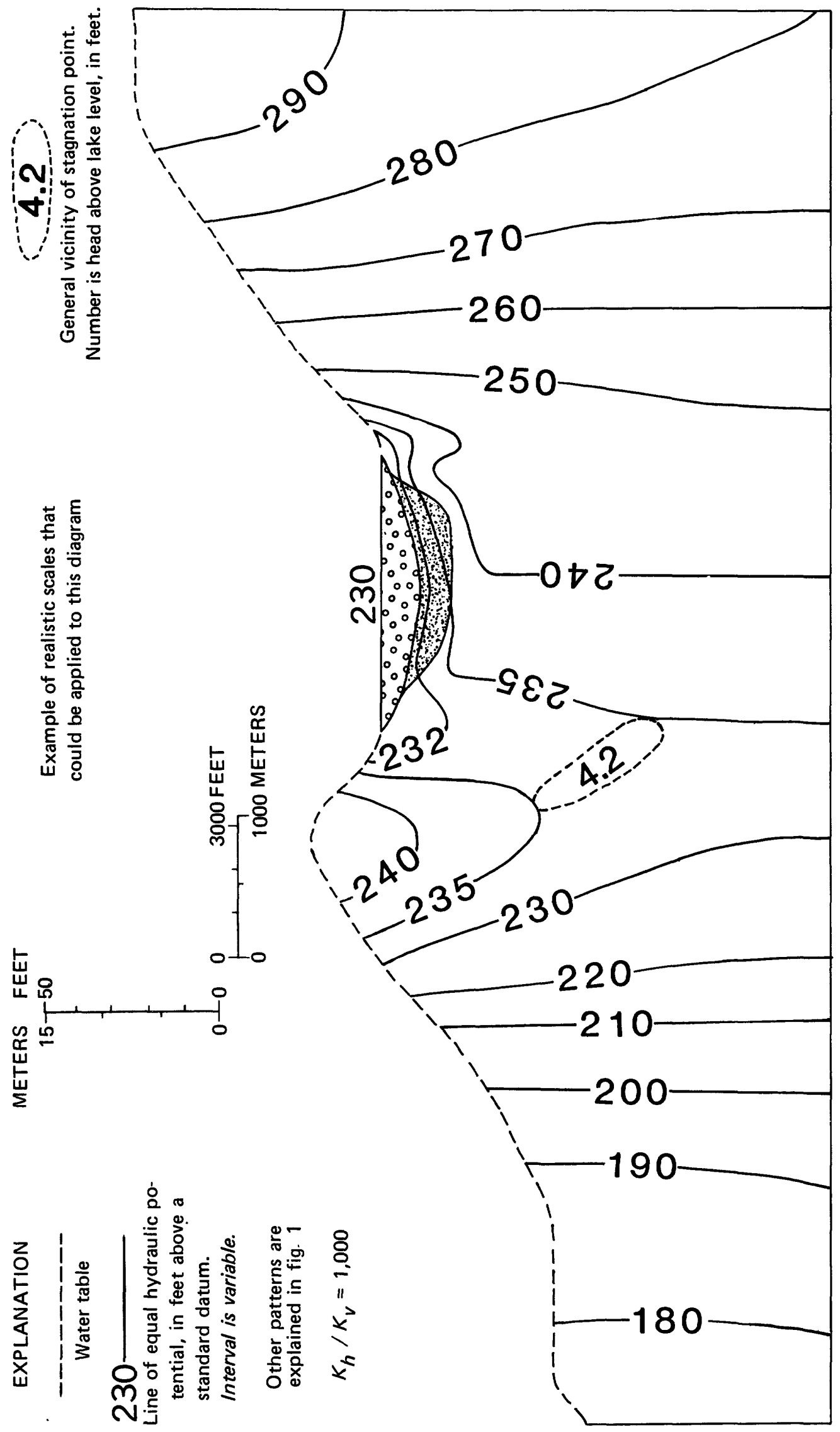




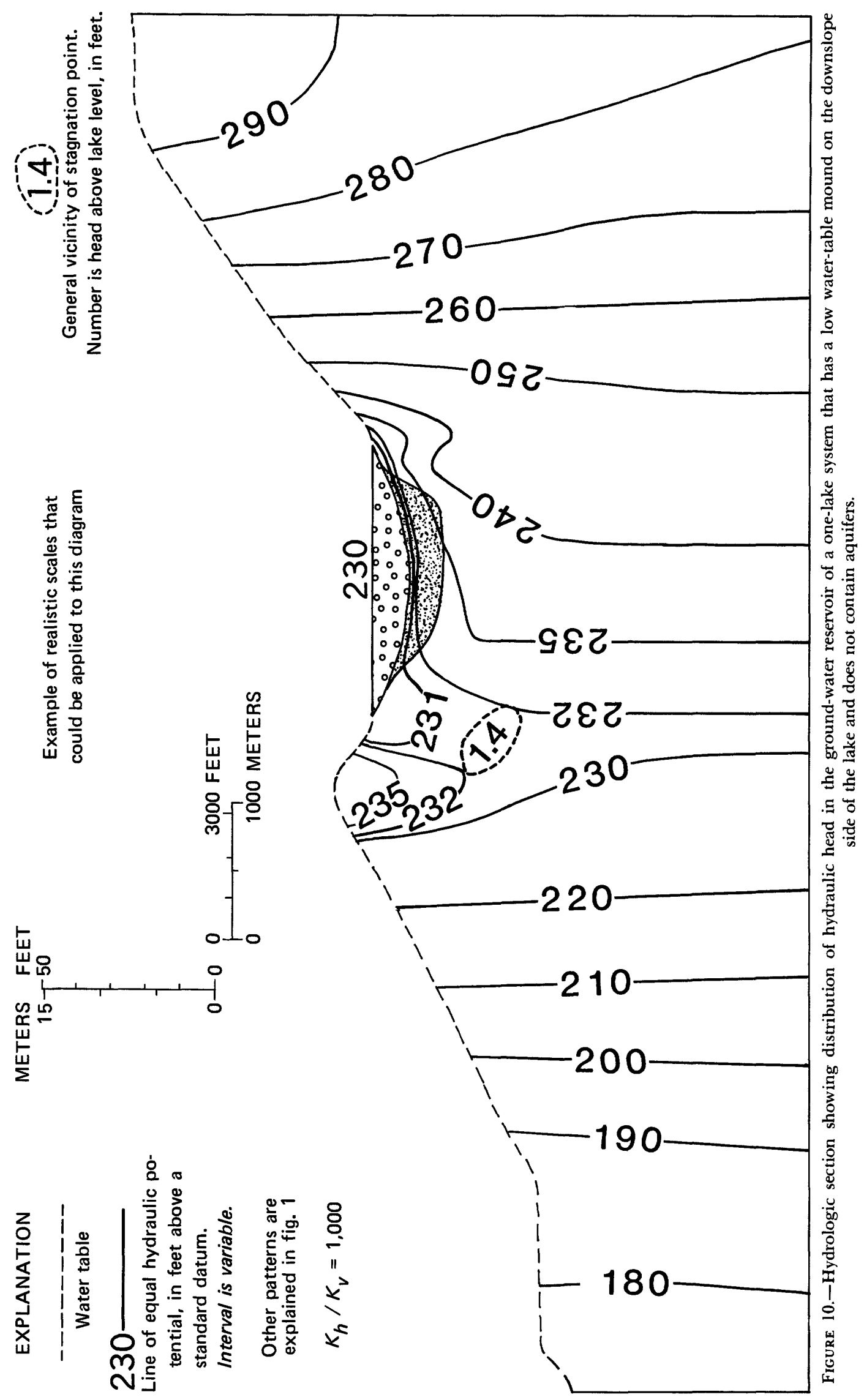


INTERACTION OF LAKES AND GROUND WATER

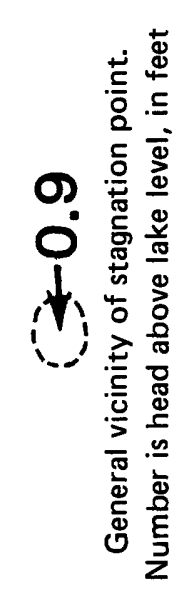

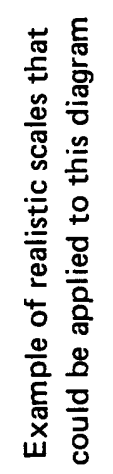

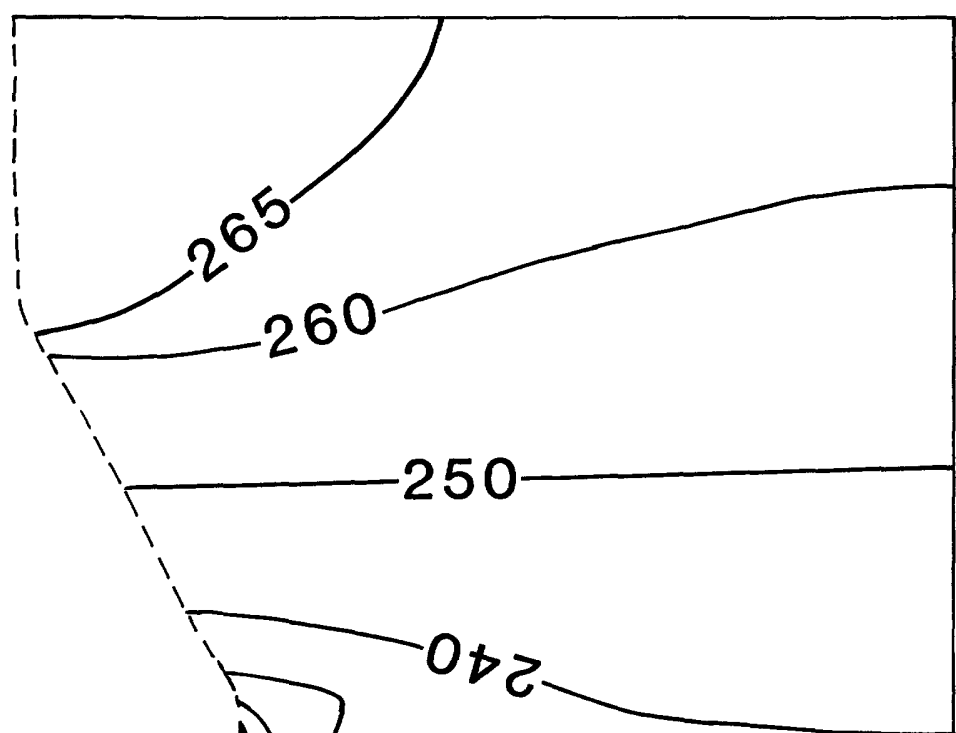

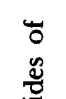

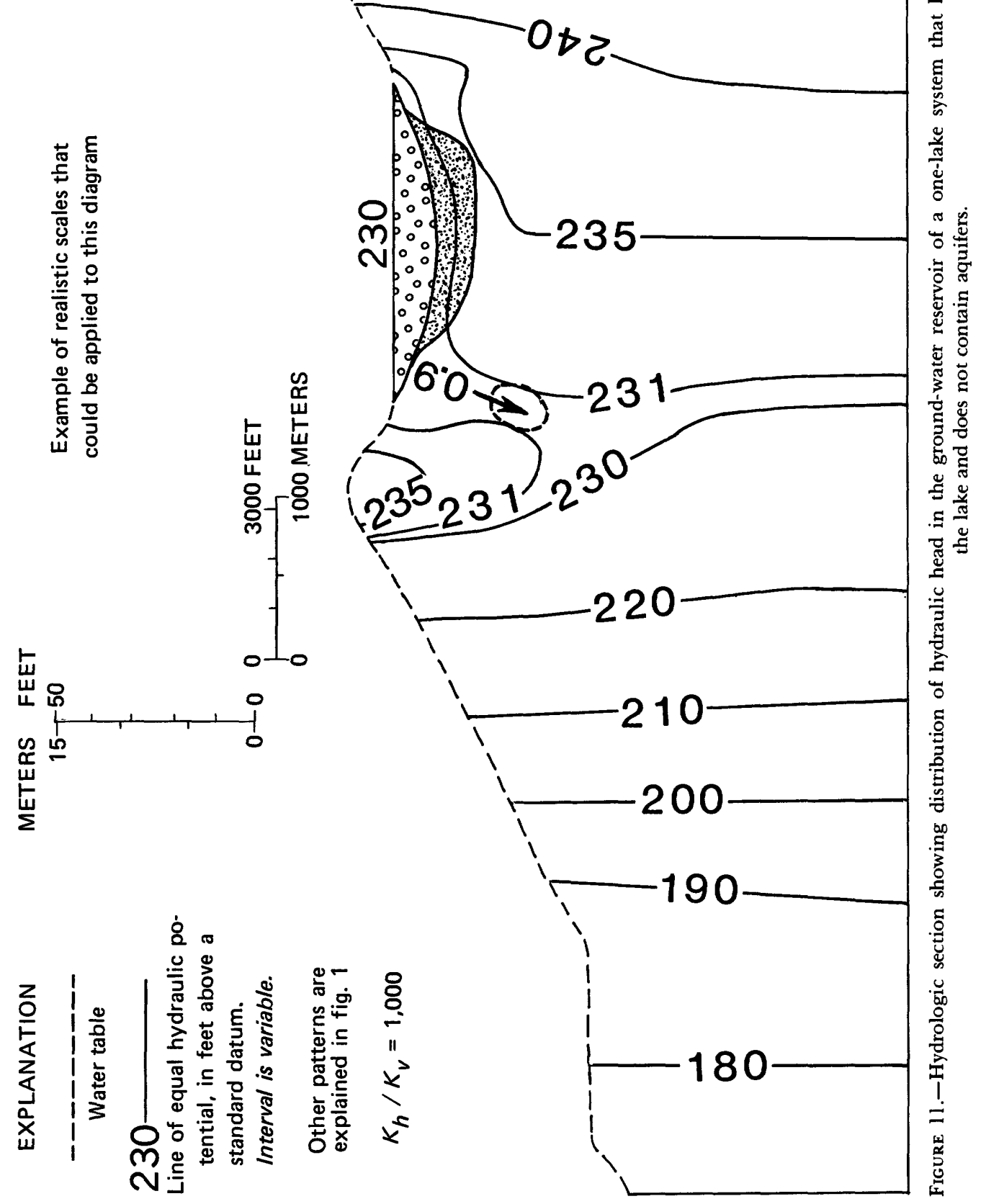




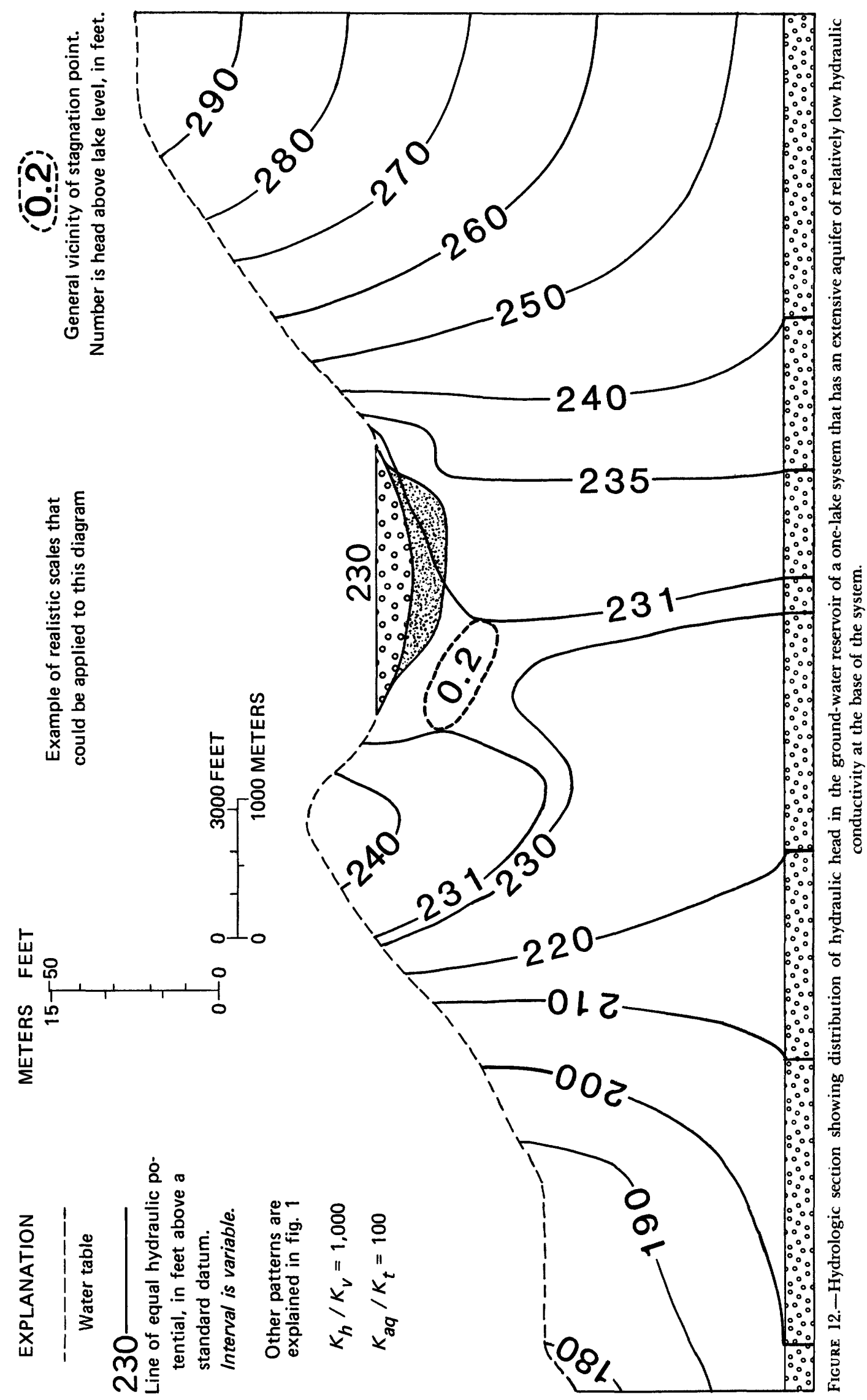




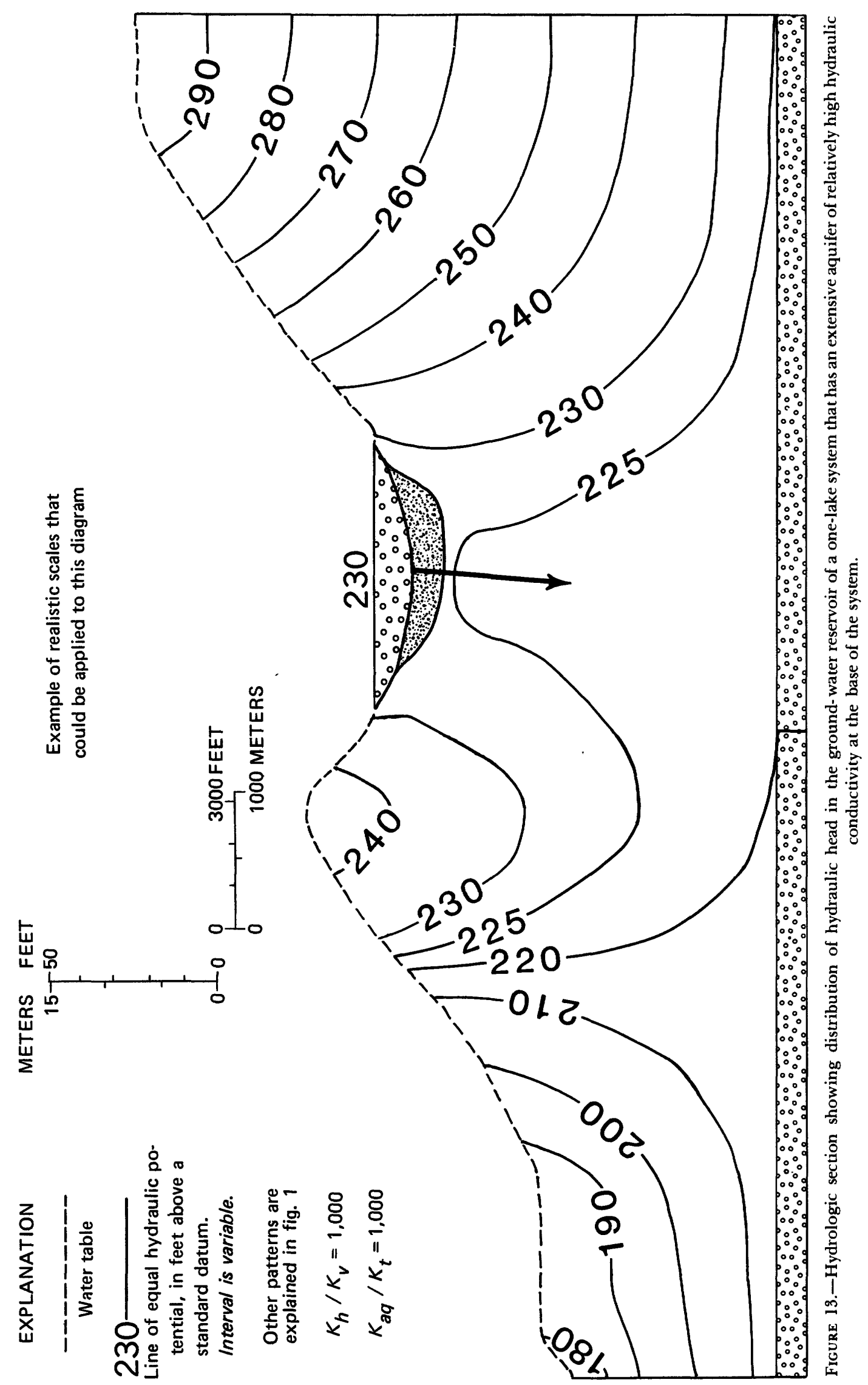




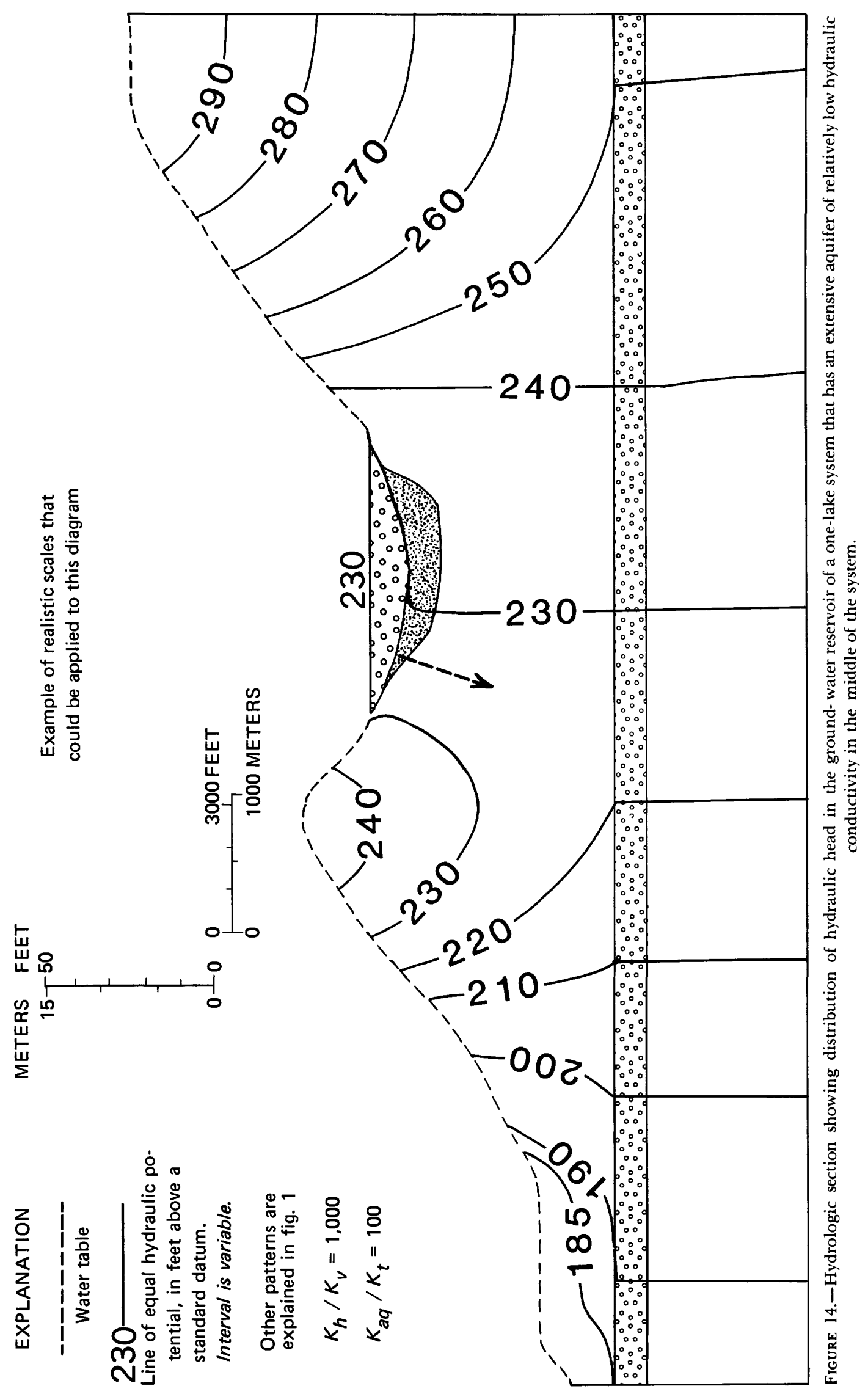



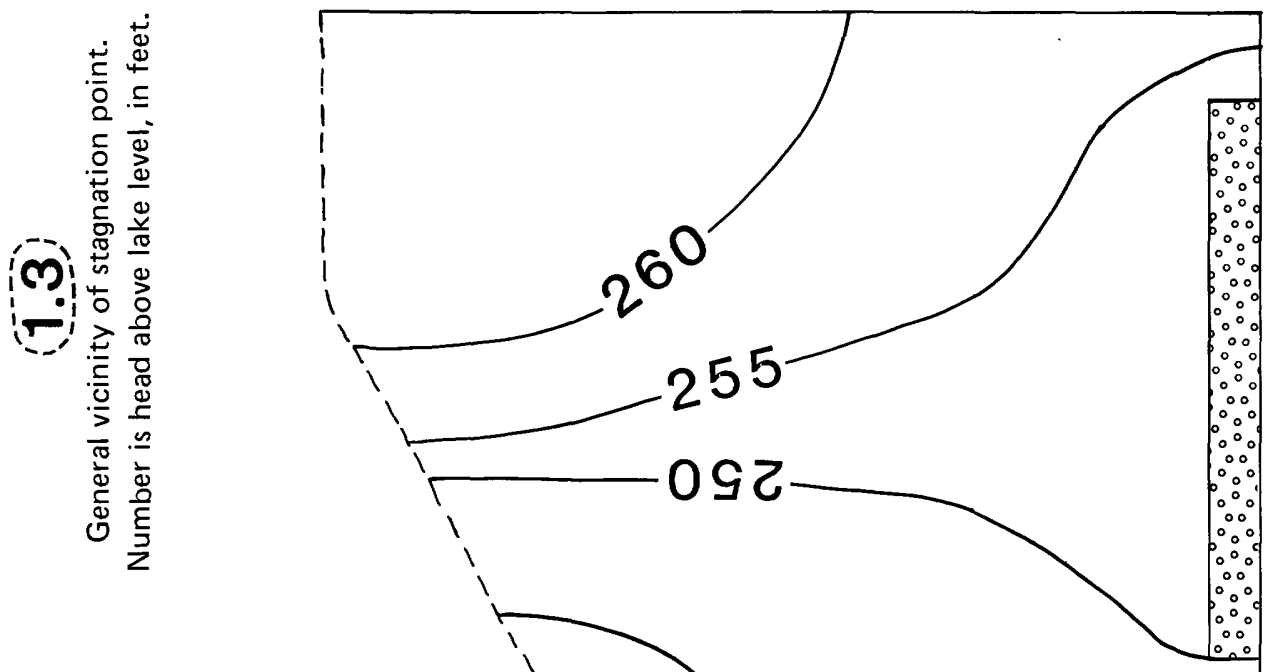

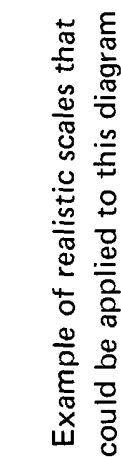
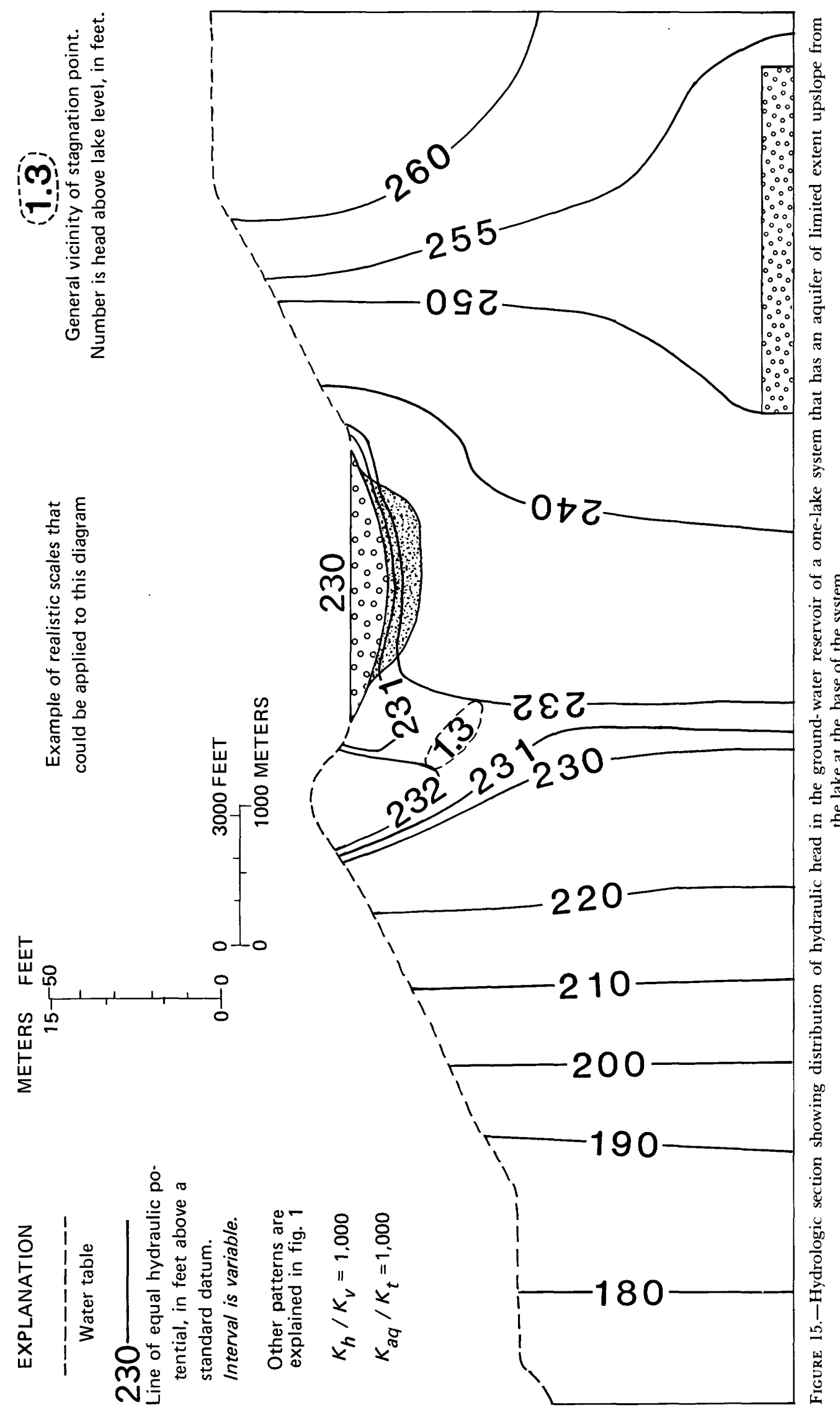
ONE-LAKE SYSTEM
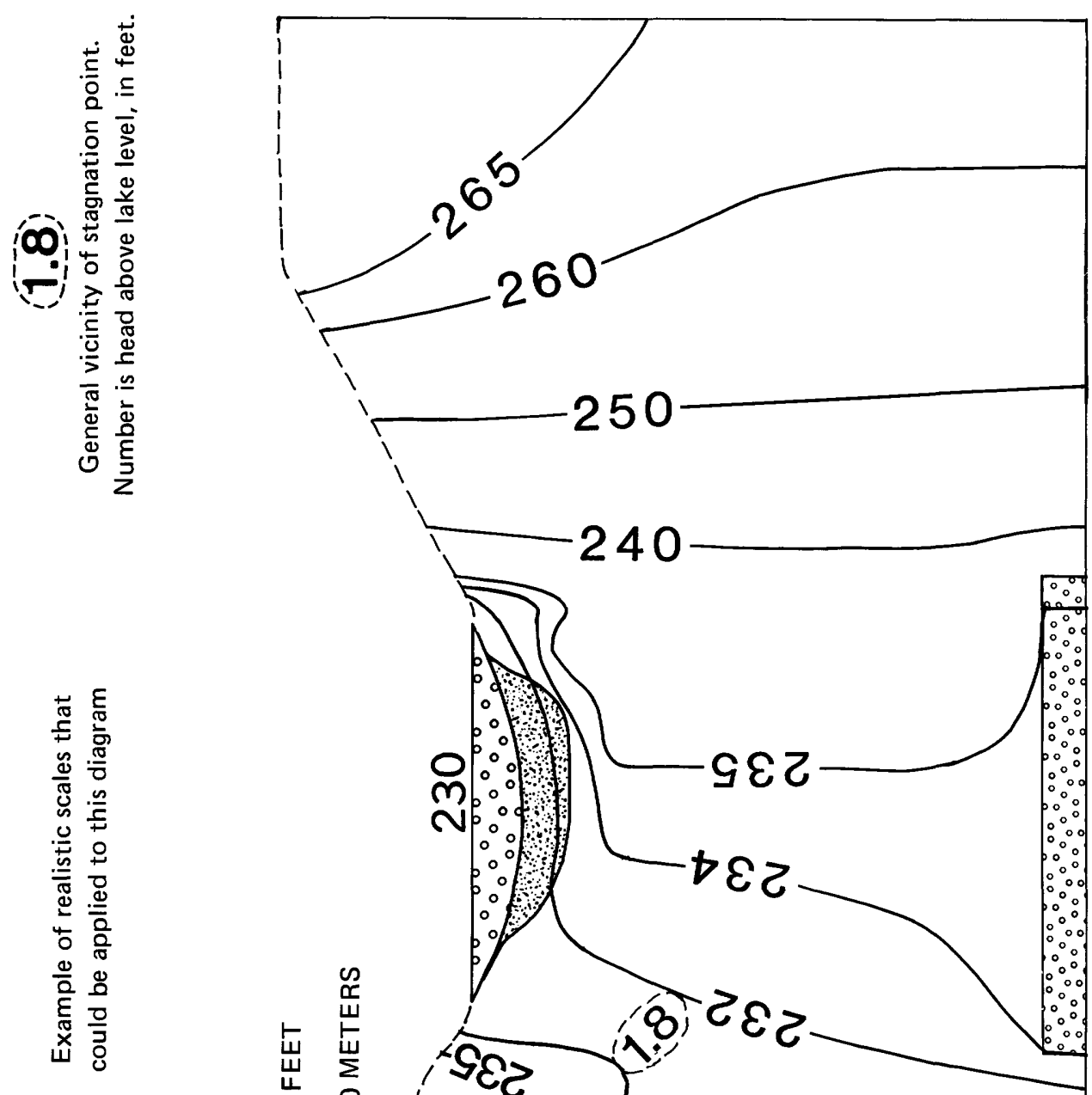

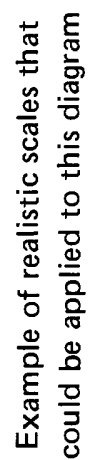

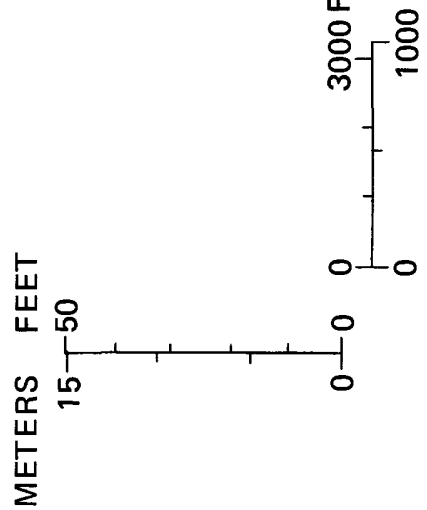

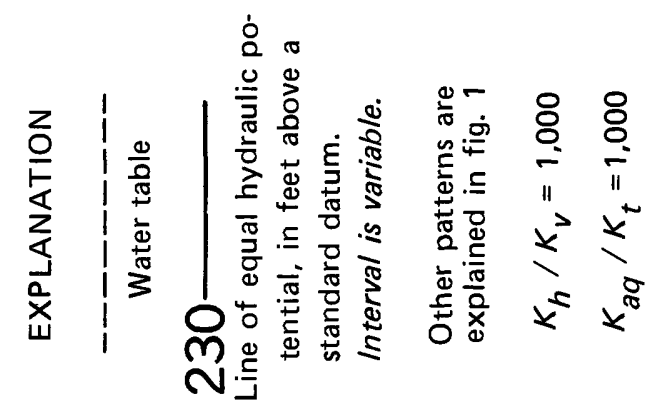

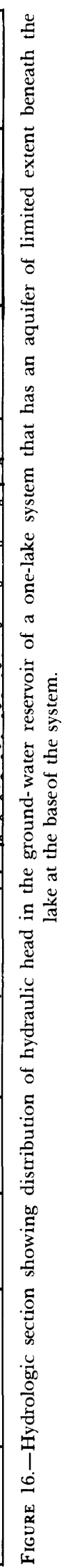




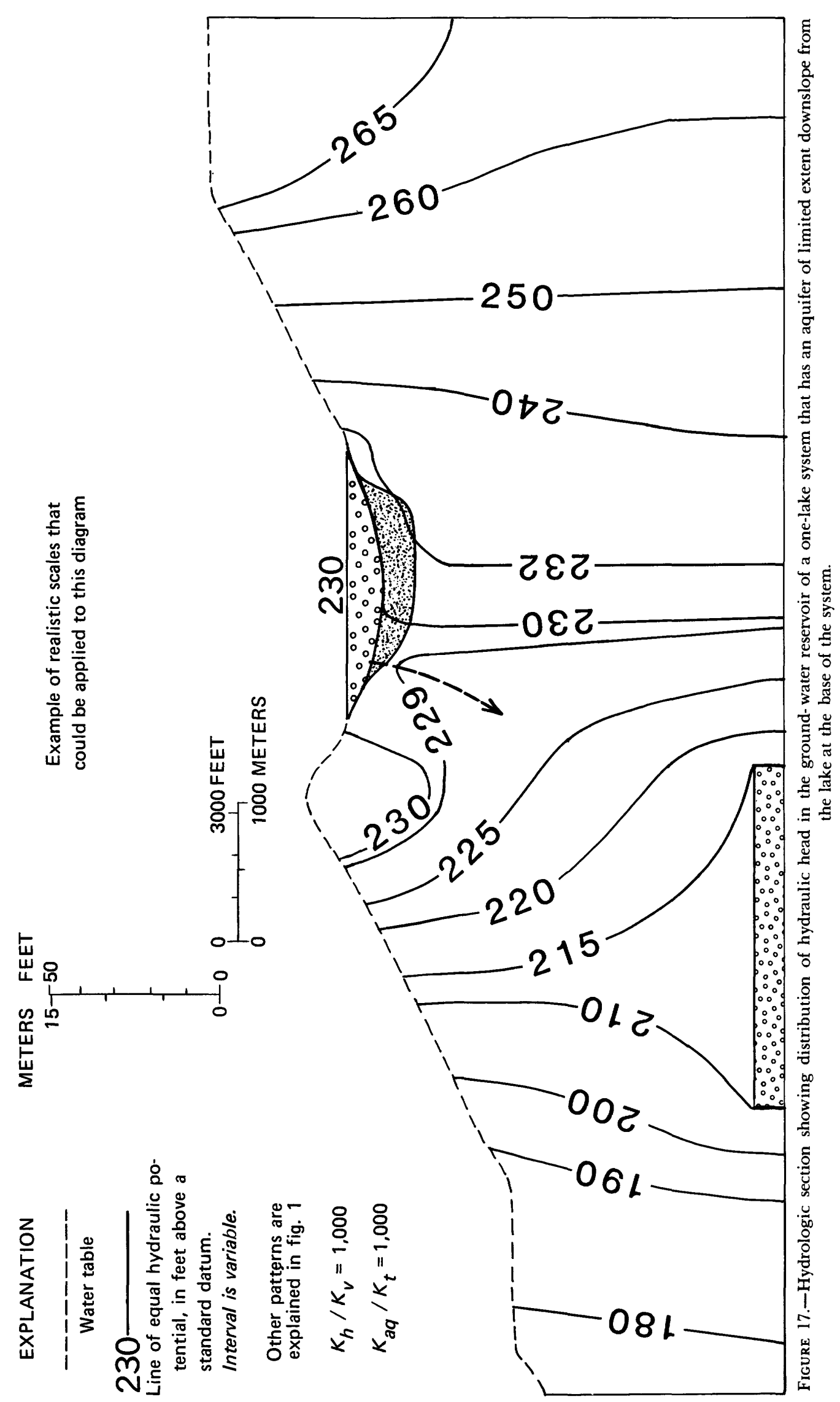




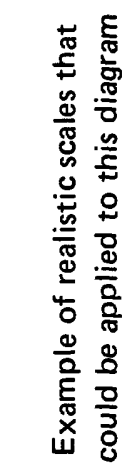
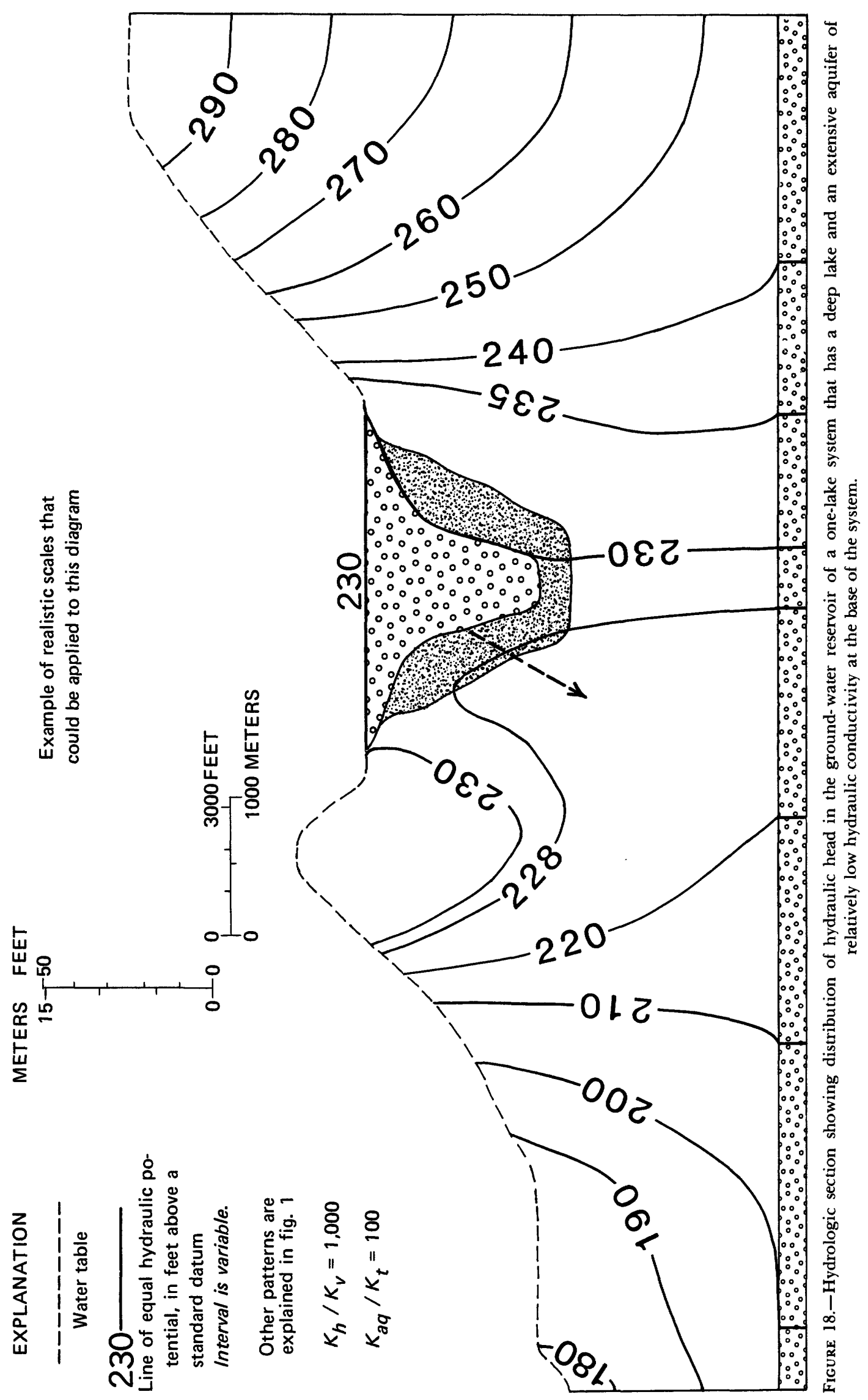
TABLE 1.-Results of digital simulations of the one-lake system-comparison of the effects of all combinations of the parameters tested that control ground-water flow on lakeground water interaction.

[0.35T, 0.10T: height of water table above lake level on upslope and downslope sides, respectively]

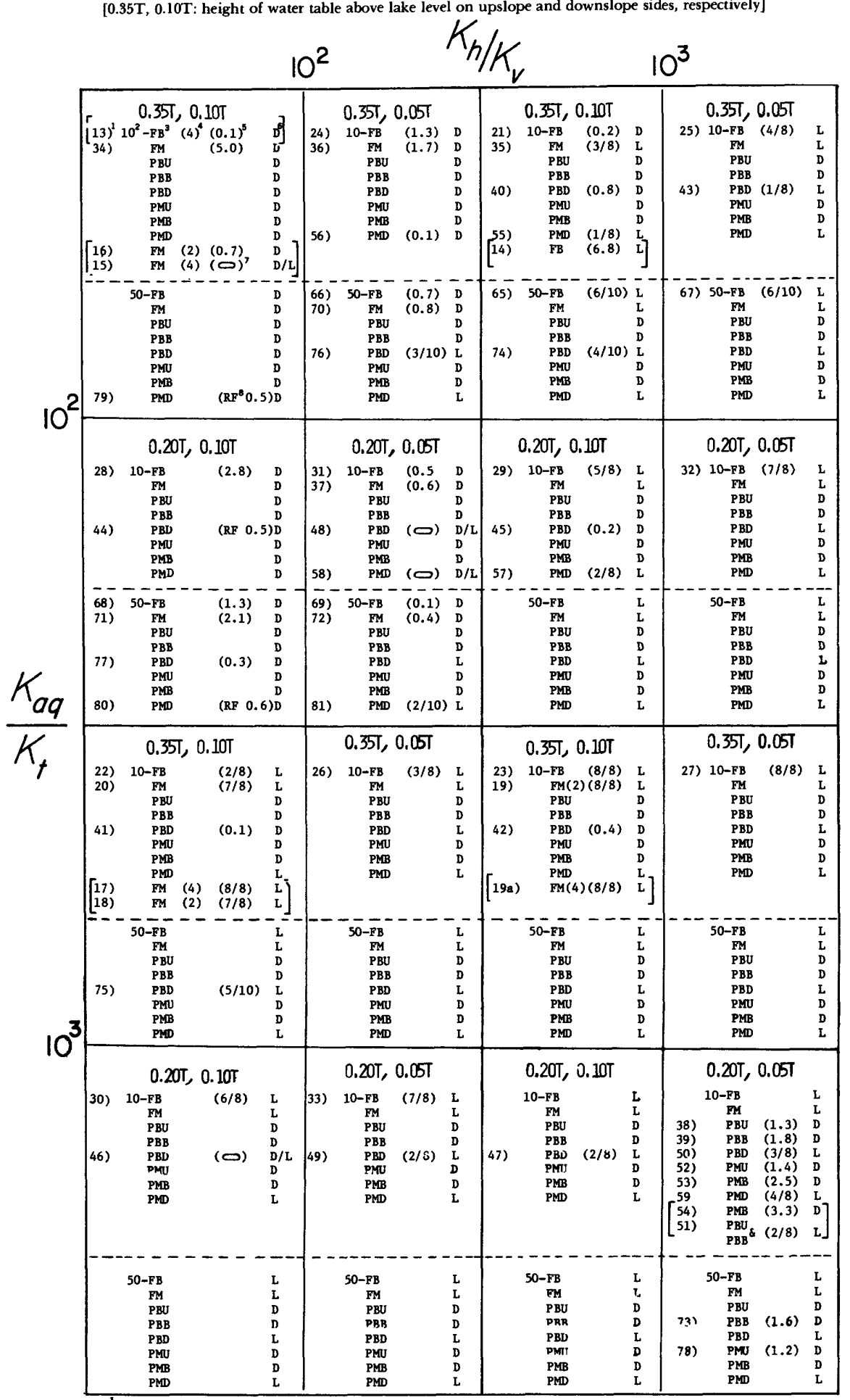

I Simulation number, keyed to table 2 .

${ }^{2}$ Lake depth. In each cell, entries abuve dashed 1ine are sha1low 1akes $(0.05 \mathrm{~T})$ and those below it are deep lakes $(0.35 \mathrm{~T})$.

${ }^{3}$ Aquifer position. (See text for explanation.)

${ }^{4}$ Thickness of aquifer 1 f greater than $0.05 T ; 2=0.10 \mathrm{~T}, 4=0.20 \mathrm{~T}$.

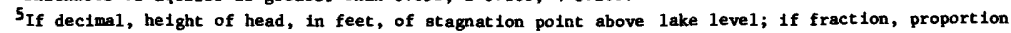
of lake bed that leaks.

6D, divide exists beneath 1ake; L, lake loses water through Its bed.

$7 \bigcirc$ indicates the stagnation point is at the threshold of being obliterated-the head value 18 the same as lake level.

$8 \mathrm{RF}$, Influence of the water-table mound on the downslope side of a lake extends to the base of the ground-water aystem, such that at the base the gradient of head is to the right (upslope direction) and there is no regional movement beyond that point. 


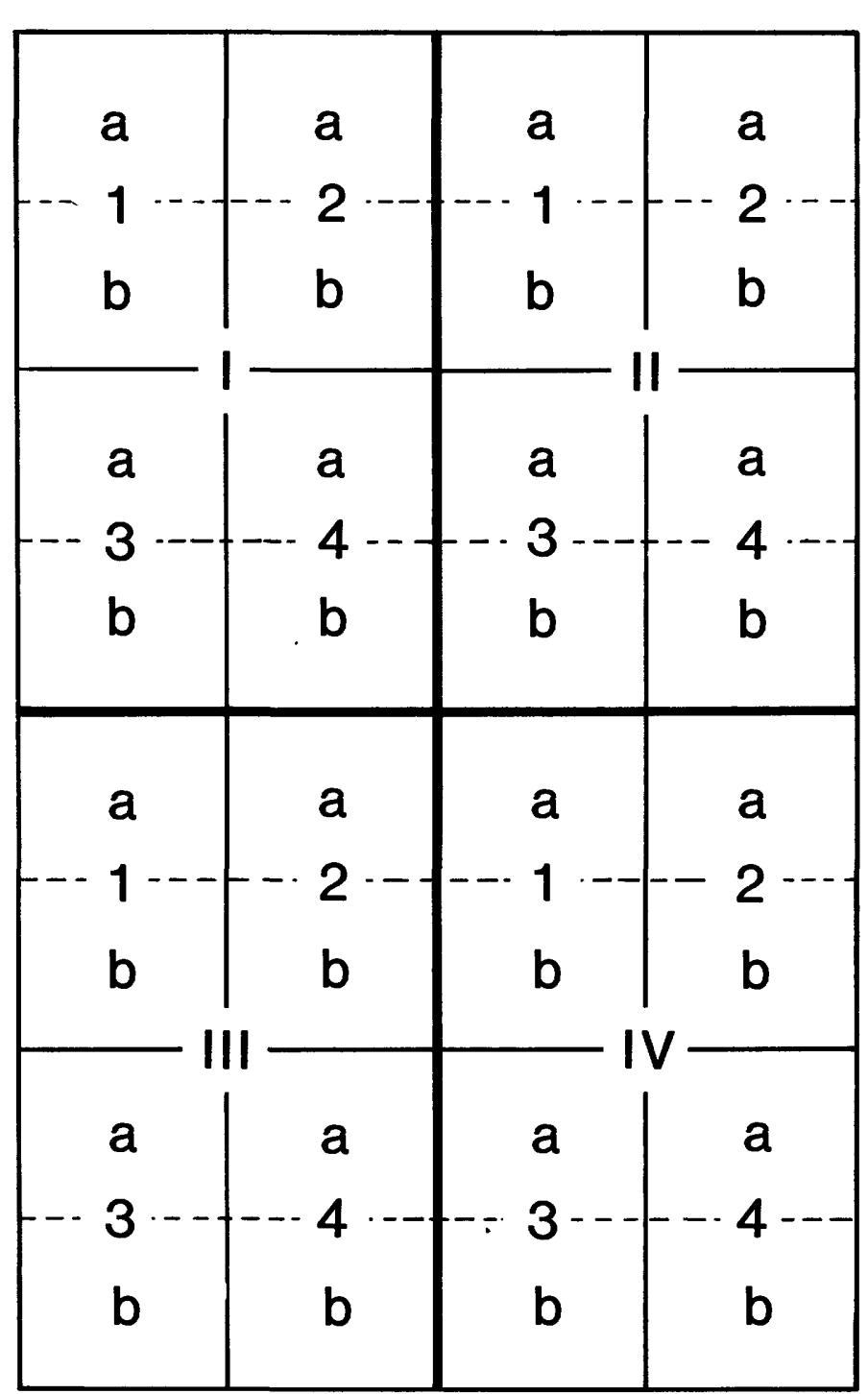

FigURE 19.-Sketch showing key to table 1 .

PBD-Partial (limited extent) aquifer at the base of the ground-water system downslope from the lake (0.35L).

PMU-Partial (limited extent) aquifer at an intermediate level of the ground-water system upslope from the lake $(0.25 T, 0.85 L)$.

PMB-Partial (limited extent) aquifer at an intermediate level of the ground-water system beneath the lake $(0.25 T, 0.60 L)$.

PMD-Partial (limited extent) aquifer at an intermediate level of the ground-water system downslope from the lake $(0.25 T, 0.35 L)$.

The simulations shown in brackets in table 1 are included for comparison purposes. They are generally of settings similar to one in the subquadrant but, for example, the aquifer might be more than one node thick.
Table 2 is a general summary of the one-lake simulations run for this study, and it includes those simulations in which aquifers were not included.

The parallel construction of table 1 makes it relatively easy to compare the effect of changes in the various parameters on the interaction of lakes and ground water. If interest is in the effect of different hydraulic conductivity ratios for given water-table combinations, aquifer size and position, and lake depth, that setting is found in equivalent positions in the major quadrants. For example, if one wishes to compare settings where $K_{a q} / K_{t}$ is 100 to another where it is 1,000 , and the setting has a water table $0.35 T(70 \mathrm{ft} ; 2 \mathrm{l})$ higher than lake level on the upslope side and $0.05 T(10 \mathrm{ft} ; 3 \mathrm{~m})$ higher on the downslope side, $K_{h} / K_{v}$ is 1,000 , and the lake is $0.05 T(10 \mathrm{ft} ; 3 \mathrm{~m})$ deep, subquadrant II-2a can be compared with subquadrant IV-2a for whatever aquifer situation is of interest. If interest is in comparison of different water table configurations for given hydraulic conductivity ratios, this can be done within a major quadrant.

The arrangement of table 1 is such that there is a general trend for the difference between lake level and head at the stagnation point to become less and for the potential for water loss from the lake to increase as one moves from quadrant I to quadrant IV. An example of this can be seen by comparing the PBD setting for shallow lakes in each subquadrant 3 . In subquadrant I-3, a ground-water divide exists that extends to the base of the ground-water reservoir (RF 0.5) (RF indicates reverse flow along the base of the system). In subquadrant II-3 the ground-water divide weakens to where the head at the stagnation point is $0.001 T(0.2 \mathrm{ft} ; 0.1 \mathrm{~m})$ higher than lake level. In subquadrant III-3 the ground-water divide is at the threshold of being obliterated ( 0 ) and the lake losing water. And in subquadrant IV-3, where the hydraulic conductivity ratios are highest, the lake loses water through two-eighths of its bed.

For the type of hydrogeologic settings considered in this report, knowing the effect of a certain direction of change of a given parameter on the head at the stagnation point makes simulation of every possible combination of parameters unnecessary. If it can be shown that a ground-water divide exists beneath a lake in a setting that has greatest potential for water loss (for example, PBU in subquadrant IV-4) then an even stronger divide will exist in settings where this potential is less. Conversely, if a lake loses water in a setting that has greatest potential for a divide to exist (for example, PBD in sub-quadrant $\mathrm{I}-2 \mathrm{~b}$ then it should lose even more water in settings where the potential for water loss is greater. In these cases, one simulation is sufficient to determine the relationship for eight others. In some situations, the simulation may have even greater implications because if a shallow lake loses water for a given setting, a deep lake in a similar setting will lose even more water. 
TABLE 2.-Summary of simulations of one-lake system

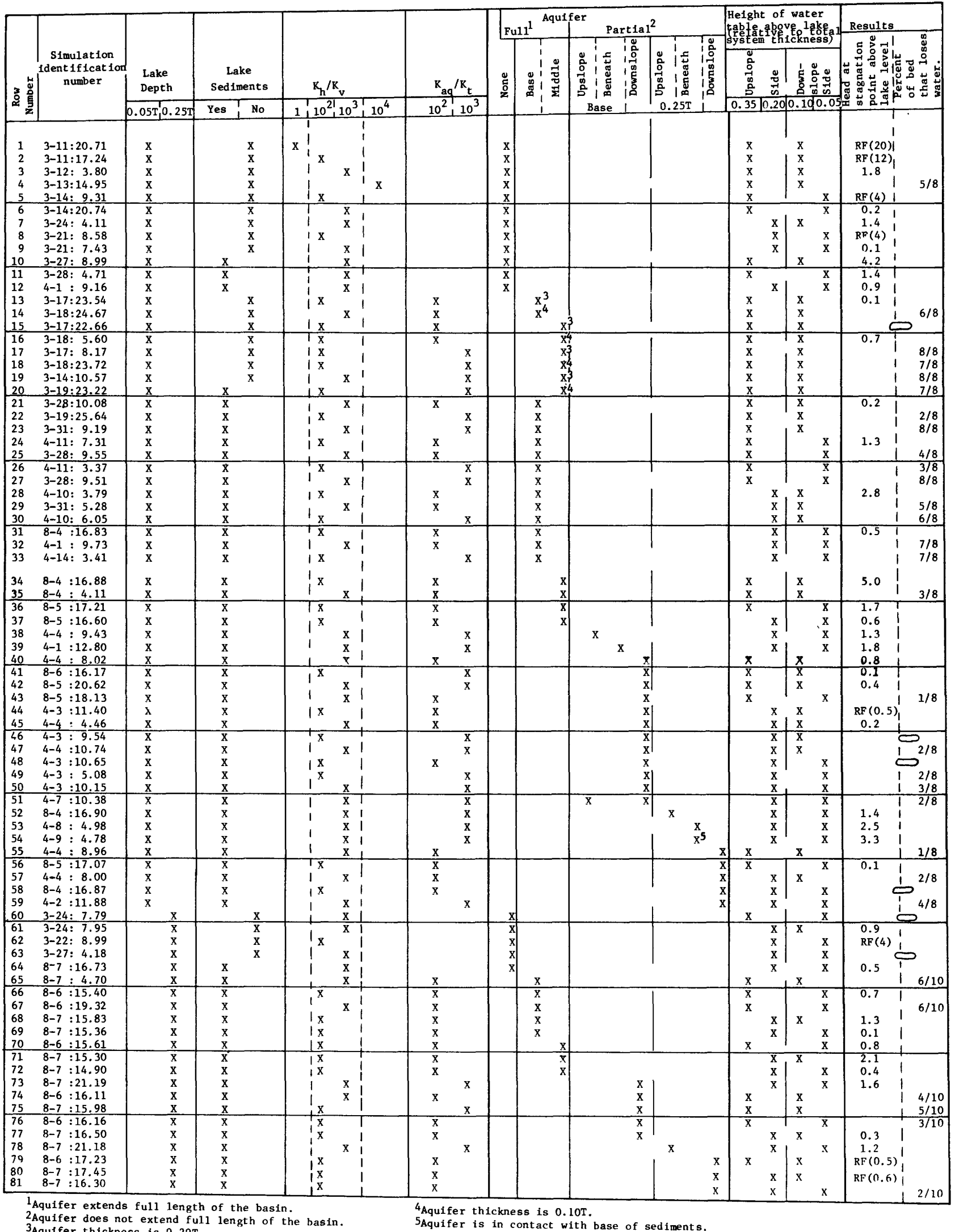

3 Aquifer thickness is $0.20 \mathrm{~T}$.

Aquifer thickness is $0.10 \mathrm{~T}$ 
Some general relationships concerning the one-lake system can be deduced from table 1. For most hydrogeologic settings as simulated in this study, the following changes in parameters tend to weaken the difference in head between the lake and the stagnation point beneath a lake or tend to cause a lake to lose water: (1) Lowering the water table on either side of a lake (lowering it on the downslope side has a greater effect than lowering it on the upslope side), (2) increasing $K_{h} / K_{v}$, (3) increasing the hydraulic conductivity of aquifers relative to the till, which has a slightly greater effect than increasing $K_{h} / K_{v}$, (4) increasing the depth of a lake, and (5) raising aquifers from the base to an intermediate level in the ground-water system. An exception to statement 5 is the situation where an extensive aquifer that has low $K_{h} / K_{v}$ and low $K_{a q} / K_{t}$ (quadrant I, table 1) is raised from the base to an intermediate level. In this case the head at the stagnation point increases slightly.

Aquifers that extend the full length of the ground-water basin have a greater effect on the interaction of lakes and ground water than limited aquifers. If no aquifer is present, a lake generally will not lose water even if $K_{h} / K_{v}$ is 1,000 (table 2). Limited aquifers upslope and beneath a lake have little effect on the ground-water divide beneath a lake. Under the conditions simulated in this study, aquifers in these positions will not cause the divide to weaken regardless of the hydraulic conductivity of the medium. Limited aquifers downslope from a lake, whether at the base or at an intermediate level of the ground-water system, have a significant effect on the interaction of lakes and ground water because under many conditions of high $K_{h} / K_{v}$ and $K_{a q} / K_{t}$ and low water-table configurations, a lake will have a weak ground-water divide or will lose water. In every simulation run for this study, the stagnation point associated with the groundwater divide is always under the downslope littoral or shoreline zone of a lake. This has particular significance when designing an observation-well program for studying the interaction of lakes and ground water because determining the position and head, or absence, of the stagnation point is the key to the relationship.

\section{MULTIPLE-LAKE SYSTEM}

In many geologic environments, lakes occur at different altitudes within major drainage basins. Although it is a common belief that water moves successively from higher lakes to lower lakes through the ground-water system within a major drainage basin-a situation where all the lakes would be the flow-through type, it is shown in the following discussion that this may not be the case. Digital simulations were run of a number of variations in the hydrogeologic setting of three lakes along a regional slope from a major divide to a major drain. The vertical exaggeration of the sections are the same as those in the one-lake system (80:1).
MODERATE REGIONAL SLOPE AND LOCAL RELIEF

The length and thickness dimensions of the multiplelake system are different from those of the one-lake system, thus the proportions of the features are different. As before, the dimensions in parentheses are included as examples of realistic field situations.

A three-lake simulation set will be discussed later in which the models are of a system that has a water table with very low regional slope, a physiographic condition common in many geologic terranes.

One type of lake-ground water setting not simulated in this study is that of a straight-line, sloping water table between adjacent lakes. As will be apparent in the following sections of this report, the height of the water table mound on the downslope side of a lake relative to lake level is an important control on the interaction of lakes and ground water. Lakes in a setting of a straightline water table simply would gain ground-water inflow on one side and lose water out the other.

The thickness of the ground-water reservoir of the threelake system ranges from $T$ (as much as $250 \mathrm{ft} ; 76 \mathrm{~m}$ ) on the upslope end of the section to $0.40 T(100 \mathrm{ft} ; 33 \mathrm{~m})$ on the downslope end. The height of the water table above lake level on the regional upslope sides of the two lower lakes is $0.20 T(50 \mathrm{ft} ; 15 \mathrm{~m})$ and on the downslope side of all three lakes is $0.08 T(20 \mathrm{ft} ; 6 \mathrm{~m})$. The highest lake in the section has the water table $0.12 T(30 \mathrm{ft} ; 9 \mathrm{~m}$ ) above lake level on the upslope side. The difference between the level of the highest lake and the elevation of the water table on the upslope side of that lake was purposely made less than the two lower lakes because it is believed that lakes that occur high topographically are more likely to have lower water tables adjacent to them than the lower lakes. The watertable altitudes were varied in some of the simulations. The dimensions of the shallow lakes are about $0.1 L$ wide and $0.20 T$ deep. The aquifers are about $0.04 T$ thick and those of limited areal extent are $0.15 \mathrm{~L}$ long. As before, the datum for the head values is 100 .

The positions of the three lakes are as follows: The surface of lake $l$ is about $0.65 T$ above the base and $0.32 L$ from the left side of the section, lake 2 is at $0.75 T$ and $0.60 \mathrm{~L}$, and lake 3 is at $0.88 T$ and $0.85 \mathrm{~L}$. The aquifers are positioned at the base and, if at an intermediate level, at $0.30 T$ above the base. The lateral position of the limited aquifers varies as noted in the text.

A simulation of a three-lake system in which each lake is shallow, is underlain by sediment, has a $0.08 T(20 \mathrm{ft} ; 6 \mathrm{~m})$ water-table mound on the downslope side of each, has a ground-water system whose $K_{h} / K_{v}$ is 1,000 , and contains no aquifers, is shown in figure 6 . The position and head of the stagnation point on the ground-water divide beneath each lake is shown as in the discussion of the one-lake simulations. Under the given conditions, each lake gains ground-water discharge from its own local ground-water flow system, and each is completely isolated from the others. 
For the three-lake system, comparison of all possible combinations of different water-table altitudes, lake depths, hydraulic conductivity ratios, and size and position of aquifers, as was done for the one-lake system, would lead to a far more complex summary table. The basic goal of simulating the multiple-lake system is to determine if the lakes have interrelationships with each other that would not be evident in simulations of the onelake system. The results of the multiple-lake simulations in which the water table has moderate regional slope and local relief are summarized in table 3.

The effect on the interaction of lakes and ground water of an extensive aquifer at the base of the system can be seen by comparing row 1 with rows 2 and 3 of table 3 . If an extensive aquifer at the base of the system has a hydraulic conductivity 1,000 times greater than till, and the $K_{h} / K_{v}$ of the ground-water system is 100 , the difference in head between the lake and the stagnation point beneath lake 2 is very small. In this simulation, there is very little change in the head at the stagnation point for lake 1 compared to the simulation listed in row 1 , but there is water loss through the bottom of lake 3. If $K_{h} / K_{v}$ is increased to 1,000 (row 3, table 3 ), holding all other parameters as in row 2 of table 3 , a very strong divide is established beneath lake 1 , and lakes 2 and 3 lose water through most, or all, of their bed (fig. 20).

Evidence that the lakes are independent of each other can be seen by comparing rows 6 and 7 of table 3 . In these simulations, $K_{h} / K_{v}$ and $K_{a q} / K_{t}$ are both 1,000 and two limited aquifers are at the base of the ground-water system at the $0.45 \mathrm{~L}$ and $0.75 \mathrm{~L}$ positions. The only difference between the two is that the water-table mound between lakes 2 and 3 was decreased to only $0.04 T(10 \mathrm{ft} ; 3 \mathrm{~m})$ above the level of lake 3 , and the upslope side of lake 3 was decreased to $0.08 T$ ( $20 \mathrm{ft} ; 6 \mathrm{~m}$ ) higher than lake level for the latter simulation (row 7). The effect of this change in the water-table near lake 3 on lakes 1 and 2 is very little, whereas the head at the stagnation point beneath lake 3 decreases $0.003 T(0.8 \mathrm{ft} ; 0.2 \mathrm{~m})$. If a limited aquifer is added at the $0.15 L$ position, and all other parameters are as in the simulation listed in row 7 (table 3 ), the head at the stagnation point on the ground-water divide beneath lake 1 decreases considerably, and there is little effect on lakes 2 and 3 (compare rows 8 and 7).

The effect on the interaction of lakes and ground water of moving the position of limited aquifers laterally can be seen by comparing rows 14 and 15 of table 3 . In the simulation listed in row 14 , the aquifer at the $0.15 \mathrm{~L}$ position is downslope from the edge of lake 1 (fig. 5). In the simulation listed in row 15 (fig. 21), this aquifer is shifted slightly in the upslope direction (to $0.22 L$ ), so that the upslope part of the aquifer is partially beneath the downslope side of lake 1. All other parameters for these two simulations are held constant. This change lowers the head at the stagnation point near lake 1 by $0.002 T(0.5 \mathrm{ft} ; 0.2 \mathrm{~m})$. Thus, it is evident that the interaction of lakes and ground water is sensitive to the lateral position of limited aquifers downslope from a lake. The maximum effect is felt if the upslope part of an aquifer is beneath the downslope side of a lake, and the aquifer underlies the water-table mound downslope from a lake.

The effect on the interaction of lakes and ground water of moving the limited aquifers vertically from the base of the system to a middle position is similar to the one-lake situation; that is, the head at the stagnation point is lowered. (Compare rows 6 and 12, and rows 11 and 19 of table 3 , and see also figs. 22 and 23.) Note that the middle aquifer in these two simulations is shifted to the right, from the $0.45 L$ to about the $0.53 L$ position, compared to the other simulations discussed to this point. This was done for most of the multiple-lake simulations because of the findings mentioned in the previous paragraph.

The effect of deep lakes compared to shallow lakes is also similar to the simulations of the one-lake system. Comparing rows 9 and 22 of table 3 , in which all parameters are similar except lake depth, shows the relatively greater influence on the ground-water flow systems near deep lakes compared to shallow lakes. The ground-water divide beneath lake $l$ in the simulation of shallow lakes (fig. 24) has a head at the stagnation point $0.004 T$ ( $1 \mathrm{ft} ; 0.3$ $\mathrm{m})$ greater than lake level, whereas in the simulation of deep lakes (fig. 25), the lake loses water through twoeighths of its bed. Beneath lake 2, the head at the stagnation point decreases from $0.014 T(3.4 \mathrm{ft} ; 1.0 \mathrm{~m})$ greater than lake level in the shallow-lake simulation to $0.008 T(2.1 \mathrm{ft}$; $0.6 \mathrm{~m}$ ) in the deep-lake simulation. Beneath lake 3, the difference in head between the lake and the stagnation point of $0.004 T(0.9 \mathrm{ft} ; 0.3 \mathrm{~m})$ for the shallow lake, can be compared to the deep lake which loses water through three-eighths of its bed.

In most of the simulations of three-lake systems discussed thus far, $K_{a q} / K_{t}$ and $K_{h} / K_{v}$ are 1,000. These values were chosen because, as shown in the one-lakesystem simulations, they tend to create conditions for maximum water loss from the lake to the ground-water system. It is of interest, therefore, to compare rows 21 and 22 (table 3 ) and figures 25 and 26 . The simulation summarized in row 21 has $K_{h} / K_{v}=100$ (fig. 26), whereas in the latter this ratio is 1,000 (fig. 25). The stagnation points occur very deep in the system in the former and, in fact, the local flow cells around each of the lakes extend nearly the full thickness of the ground-water system and little ground water flows past the middle lake.

It is evident from the above discussion that, in most cases, lakes in a multiple-lake system act essentially independently. Changing the height of a water-table mound or the position of aquifers by one lake and not by the others has a considerable effect on that one lake that is similar to the equivalent one-lake simulation. The change may have a minor effect on an adjacent lake, changing the head at the stagnation point, for example, by perhaps $0.0004 T$ to $0.0008 T$ (0.1 to $0.2 \mathrm{ft} ; 0.03$ to $0.06 \mathrm{~m}$ ). 
The only situation where a considerable effect is felt on the lakes is in the case of extensive aquifers within the ground-water system, and where $K_{h} / K_{v}$ and $K_{a q} / K_{t}$ are large (row 3 of table 3 ) (fig. 20). In this case, and there are similar cases in the one-lake settings, there is massive downward movement of water in the upper region of the ground-water basin and massive upward movement in the lower region. The great difference in head between the lake and the stagnation point associated with the lowest lake seems to be established because of the large influence of the water-table mound on the downslope side of that lake. If the water-table mound were not there, there would be massive upward movement on the lower side of the diagram and the hinge line (the point at the water table separating regional recharge from regional discharge) would be near the middle of the diagram. Apparently the mound is sufficiently strong to cause downward movement that will not be overcome, but instead, will be responsible for a strong ground-water divide that has a head at the stagnation point of very large magnitude. It is interesting to note in this case that the stagnation point is not beneath the lake. Rather, it is downslope from the lake and is nearly directly beneath the highest part of the watertable mound.

\section{LOW REGIONAL SLOPE AND LOCAL RELIEF}

A series of simulations were run of a multiple-lake system in which regional slope and local relief were kept relatively low (summarized in table 4). The length and thickness dimensions of the multiple-lake system that has low regional slope and local relief are unlike those for the system of moderate slope and relief, thus the proportions of the features again are different. The thickness of the system ranges from $T(160 \mathrm{ft} ; 49 \mathrm{~m})$ on the upslope end to $0.60 T(100 \mathrm{ft} ; 30 \mathrm{~m})$ on the downslope end of the section.

The water table on the upslope side of all the lakes is $0.13 T(20 \mathrm{ft} ; 6 \mathrm{~m})$ higher than the adjacent lake level, and on the downslope side is $0.06 T(10 \mathrm{ft} ; 3 \mathrm{~m})$ higher. The difference in altitude between the lakes is $0.06 T(10 \mathrm{ft} ; 3 \mathrm{~m})$. Only shallow lakes $0.06 T$ ( $10 \mathrm{ft} ; 3 \mathrm{~m}$ ) deep are simulated. The aquifers are $0.06 T(10 \mathrm{ft} ; 3 \mathrm{~m})$ thick, and the limited aquifers are $0.13 L$ long.

A ground-water system that has no aquifers is shown in figure 27. Ground-water divides of equal size and strength (the difference in head between the lake and the stagnation point is $0.02 T(3.0 \mathrm{ft} ; 0.9 \mathrm{~m})$ by each lake) occur beneath each lake. It should be noted that simulations of this sy stem of lower slope and relief differ somewhat from the other three-lake system discussed previously in that the water table relative to lake level by the highest lake is the same as by the two lower lakes.

Simulations that have extensive aquifers at the base of the system, $K_{a q} / K_{t}=100$, and $K_{h} / K_{v}=1,000$ (row 27, table 4 ), show no water loss from any of the lakes for any of the simulations. This is true also if the hydraulic conductivity ratios are reversed; that is, $K_{a q} / K_{t}=1,000$ and $K_{h} / K_{v}=100$ (row 28, table 4). In simulations that have both ratios at 1,000 , a ground-water-flow pattern similar to the other three-lake system occurs-there is water loss through the entire bed of the higher two lakes and a divide established beneath the lowest lake (row 29, table 4).

In simulations that have limited aquifers beneath the water-table mounds between the lakes, and the up-slope edge of the aquifers are partly beneath the lake, a groundwater divide occurs beneath the lake, although the difference in head between the lake and the stagnation point of each is rather small (fig. 28). This result holds even when the limited aquifer is moved to about $0.13 T$ (20 $\mathrm{ft} ; 6 \mathrm{~m}$ ) below the bed of the lower lake.

In the three-lake system that has low regional slope and local relief, it appears that the ground-water divides tend to be slightly stronger in most cases than where a higher regional slope is simulated. The slope of the water table from the lowermost water-table mound to the left edge of the hydrologic sections in the simulation of moderate regional slope, shows a drop of several tens of feet. The water-table slope in this same part of the section, in the simulations of low regional slope, is essentially flat, resulting in very slow ground-water movement. This very flat water table near the valley of the major drain on the system acts as a "check valve" on the entire system and tends to increase the tendency of the lakes to have stronger local ground-water-flow systems than in conditions of a higher-sloping water table.

In none of the simulations does water move from one lake to the next downslope if there is a water-table mound between the two lakes. Even if an upper lake loses water to the ground-water system, the movement generally is deep to the system and the water moves beneath the local flow systems associated with lower lakes. Thus, even in settings where lakes occur at various altitudes down a sloping valley side, each of the lakes, for most settings, acts as an independent entity and has little relationship to lakes either upslope or downslope from it. This conclusion gives increased importance to the summary table (table 1) of the one-lake system.

The effect of reservoir thickness on ground-water-flow systems is extensively discussed by Tóth (1963), and to a lesser extent by Freeze (1969b). The general effect of a thin ground-water reservoir is that regional flow does not occur for many settings, especially if regional slope is low. To check the effect of a thin ground-water system on the interaction of lakes and ground water, a setting was simulated that was 100 feet $(30 \mathrm{~m})$ thick on the upper end of the section and 50 feet $(15 \mathrm{~m})$ thick on the lower end. The difference between the section and figure 29 is that the local flow systems associated with each lake extend to the base of the ground-water reservoir, and regional flow does not occur (row 33, table 4). 


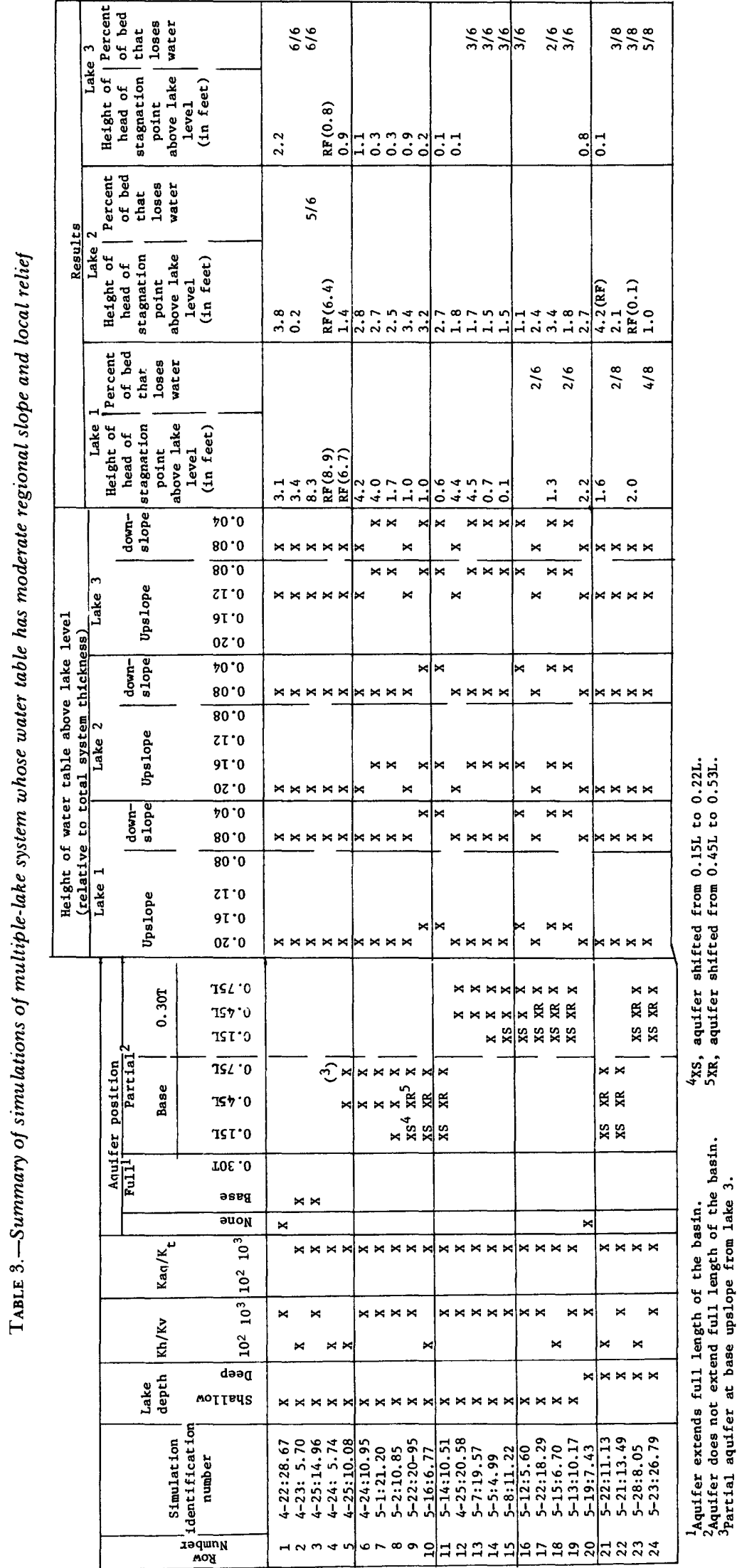

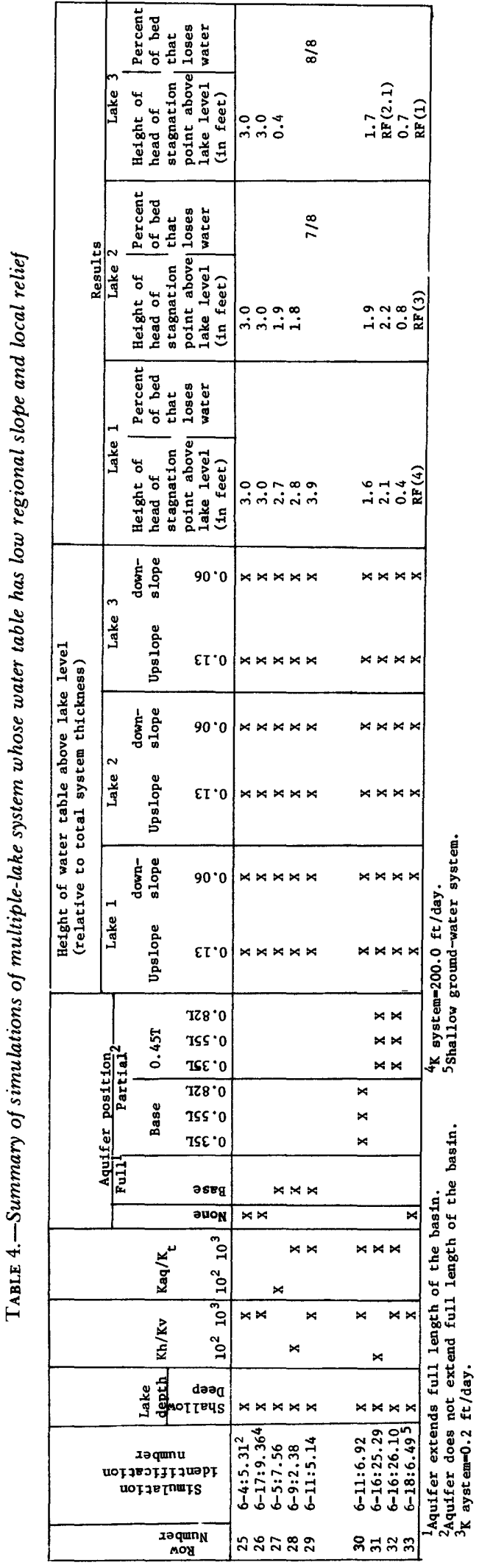



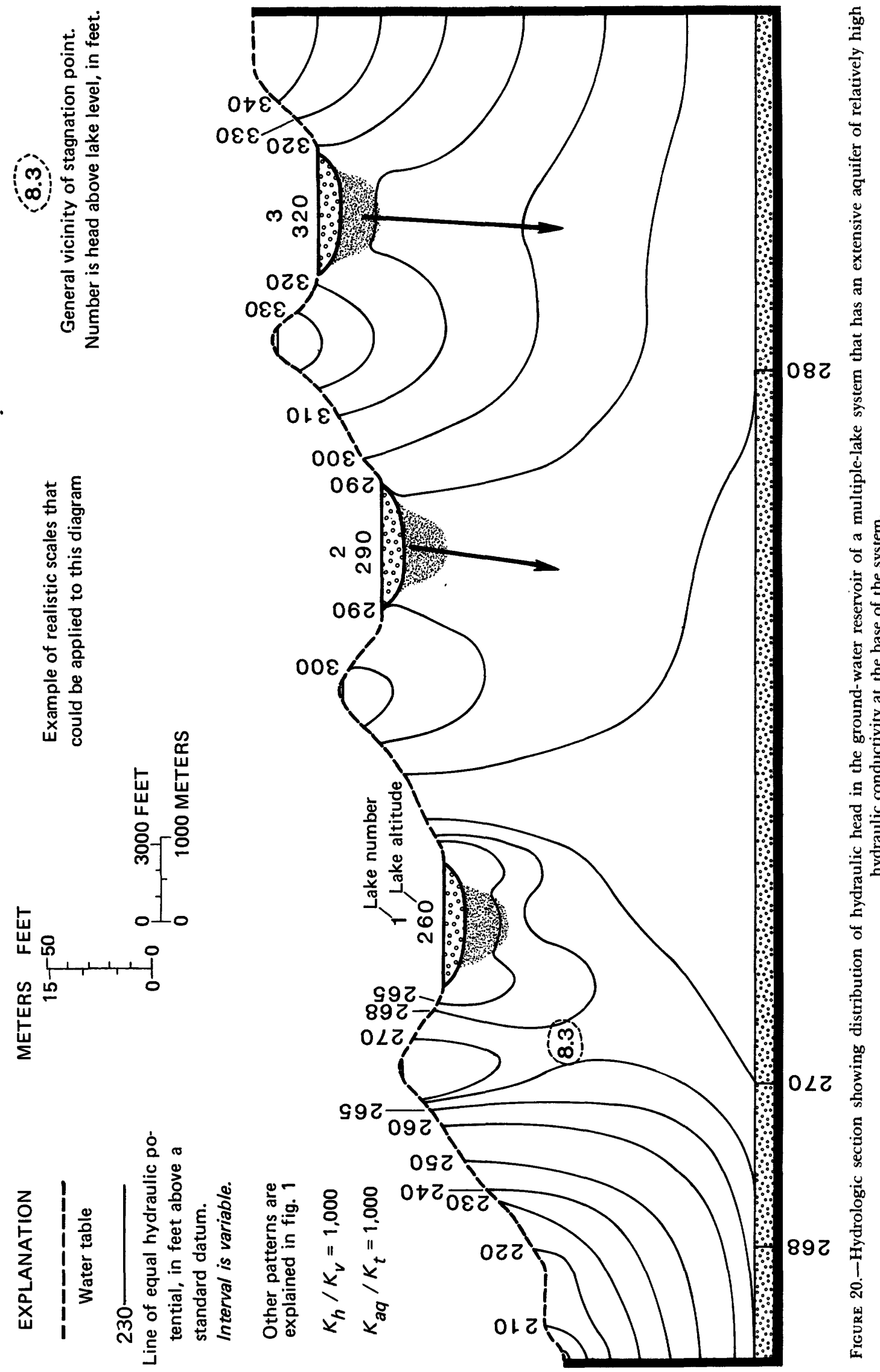

$0<2$ 

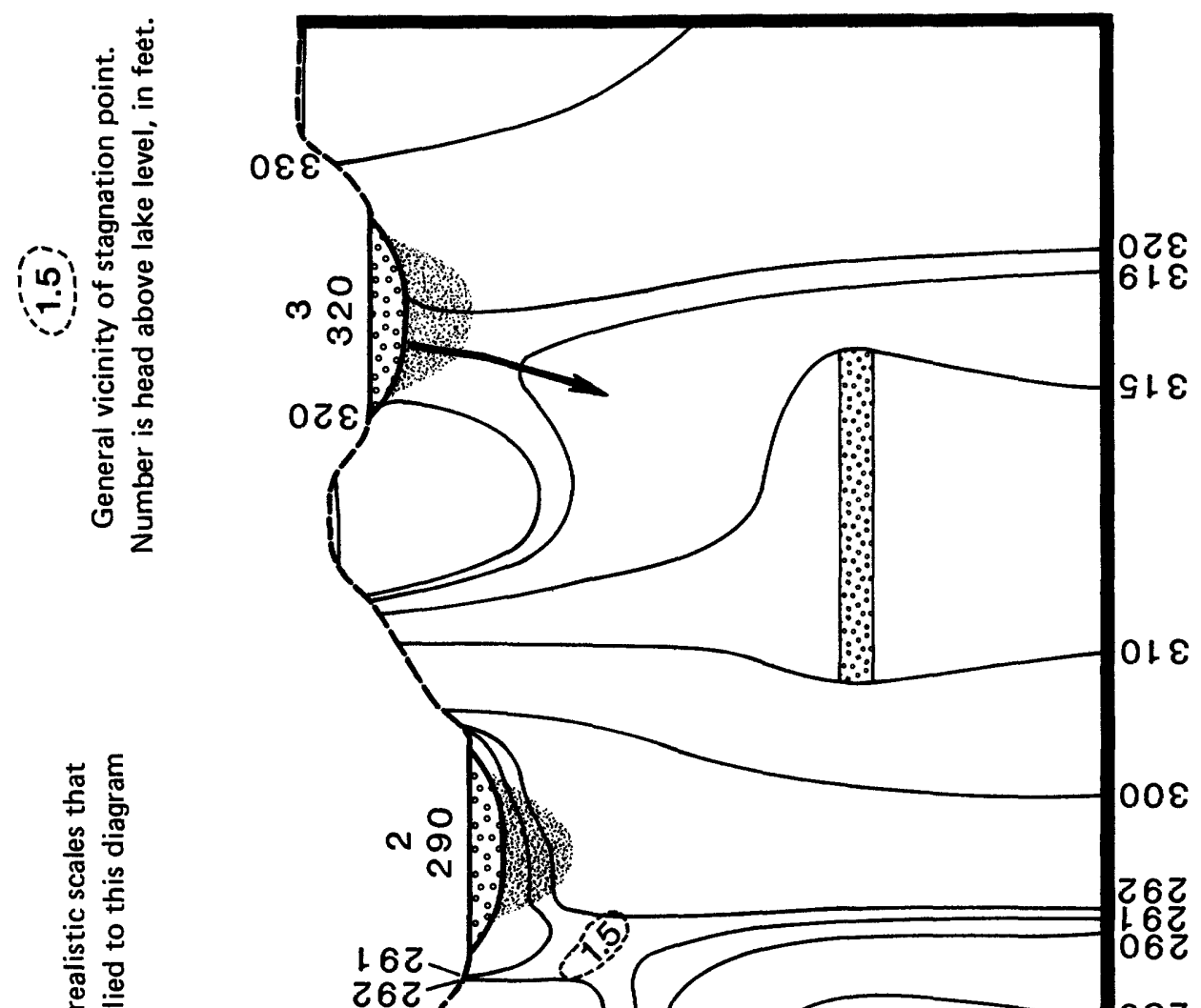

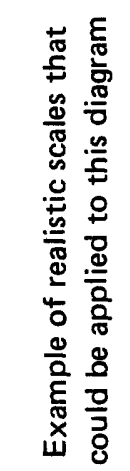

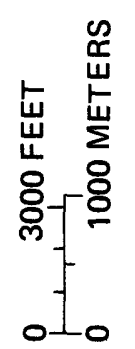

崫员,

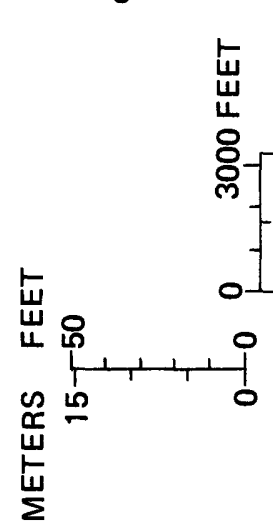
$00 \varepsilon$

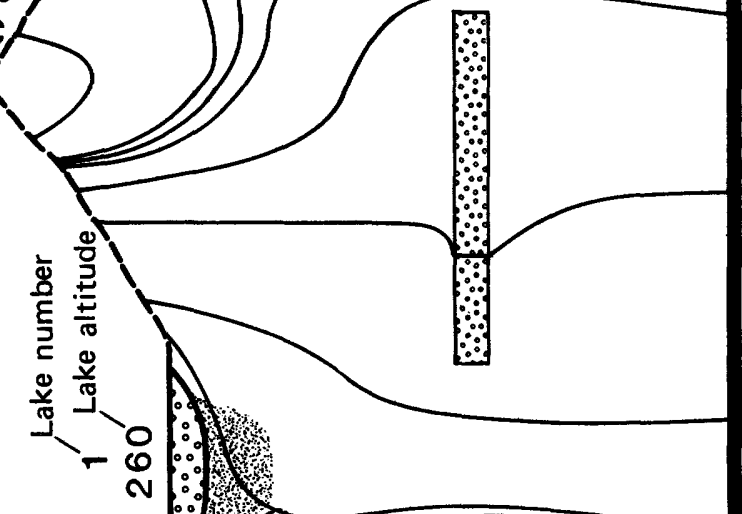

082

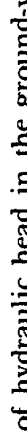

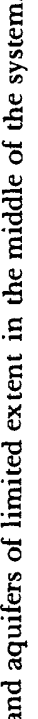



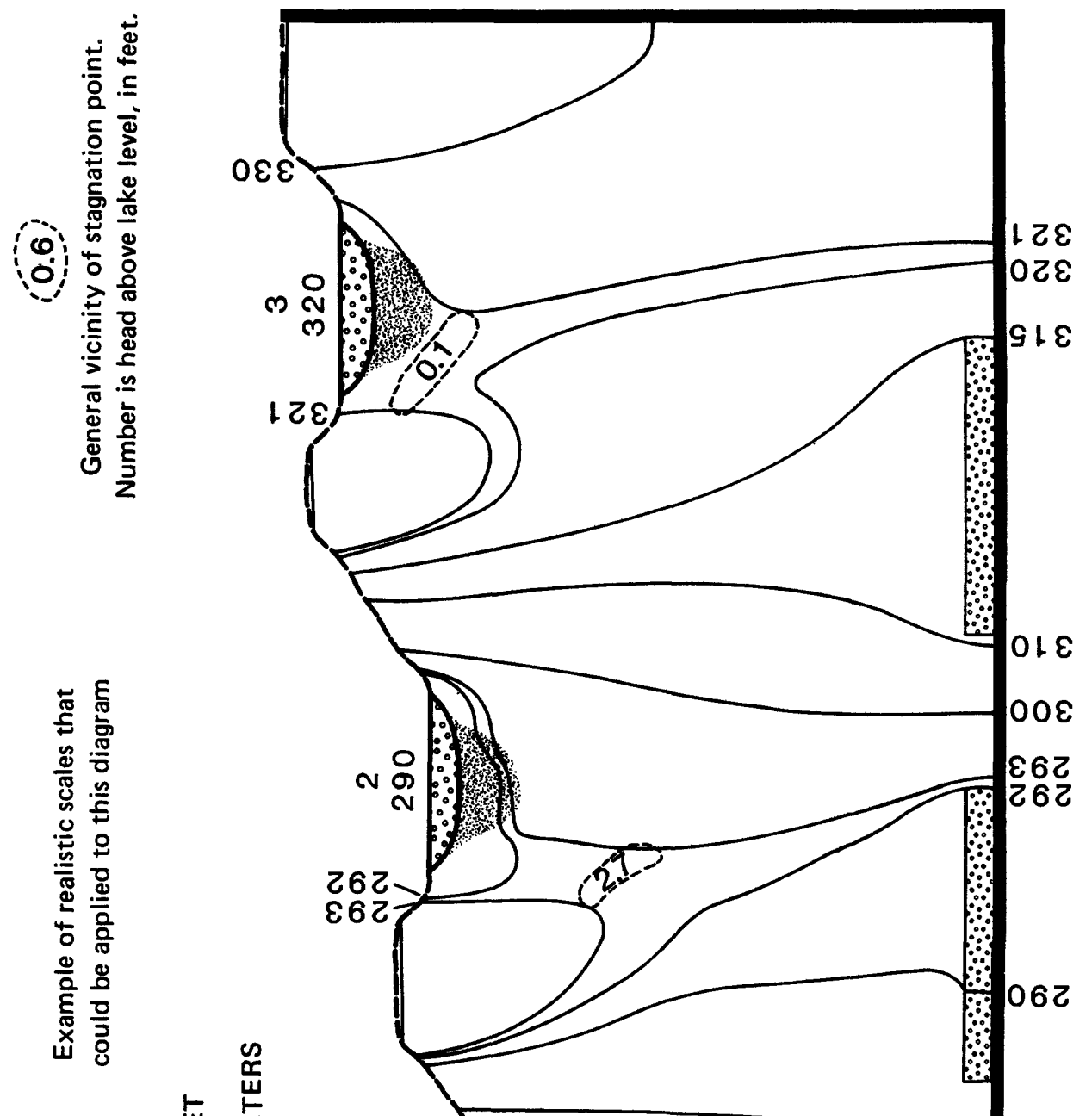

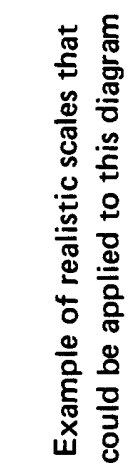

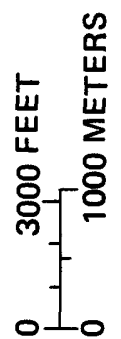

岀。
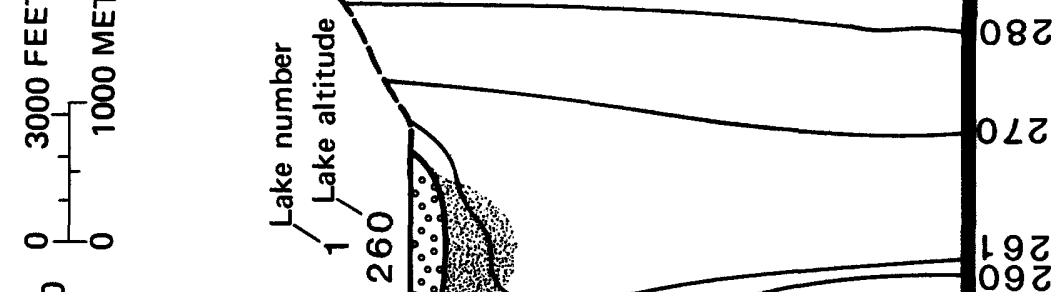

.
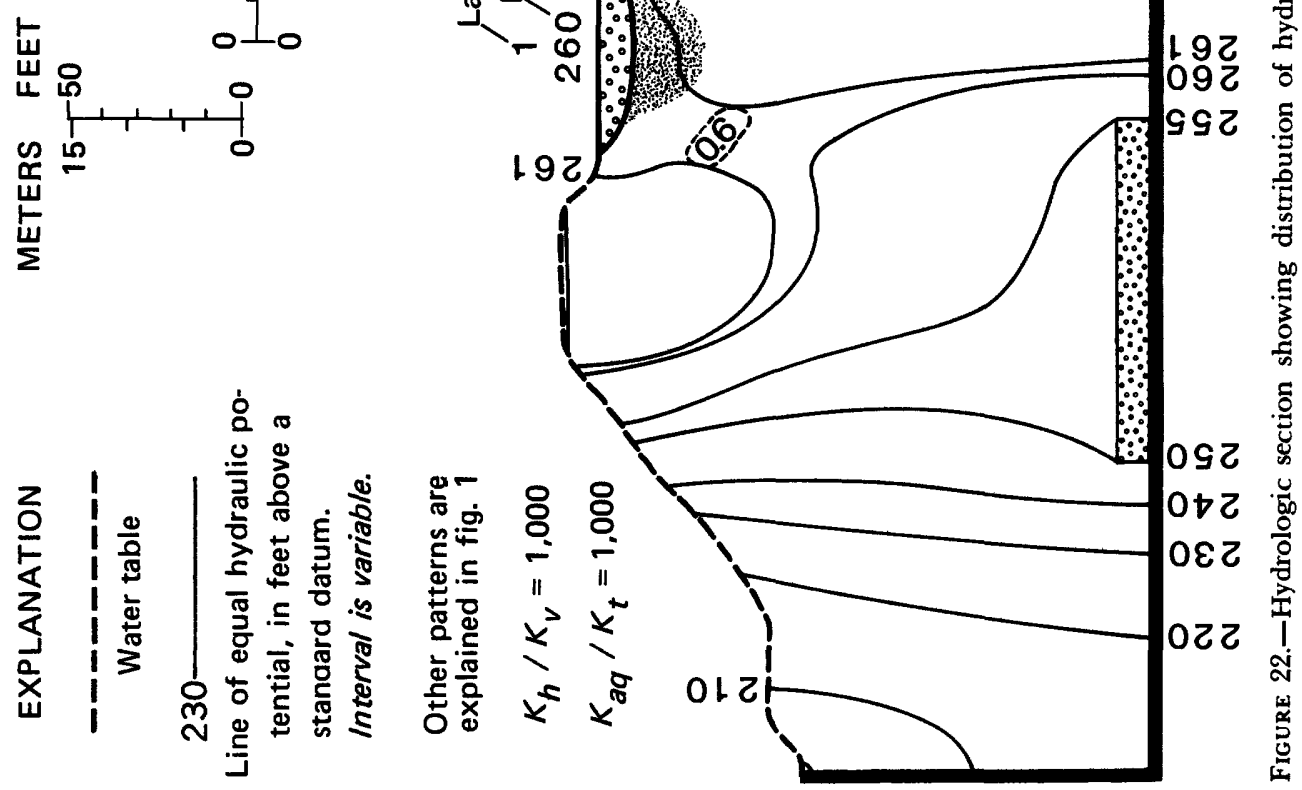

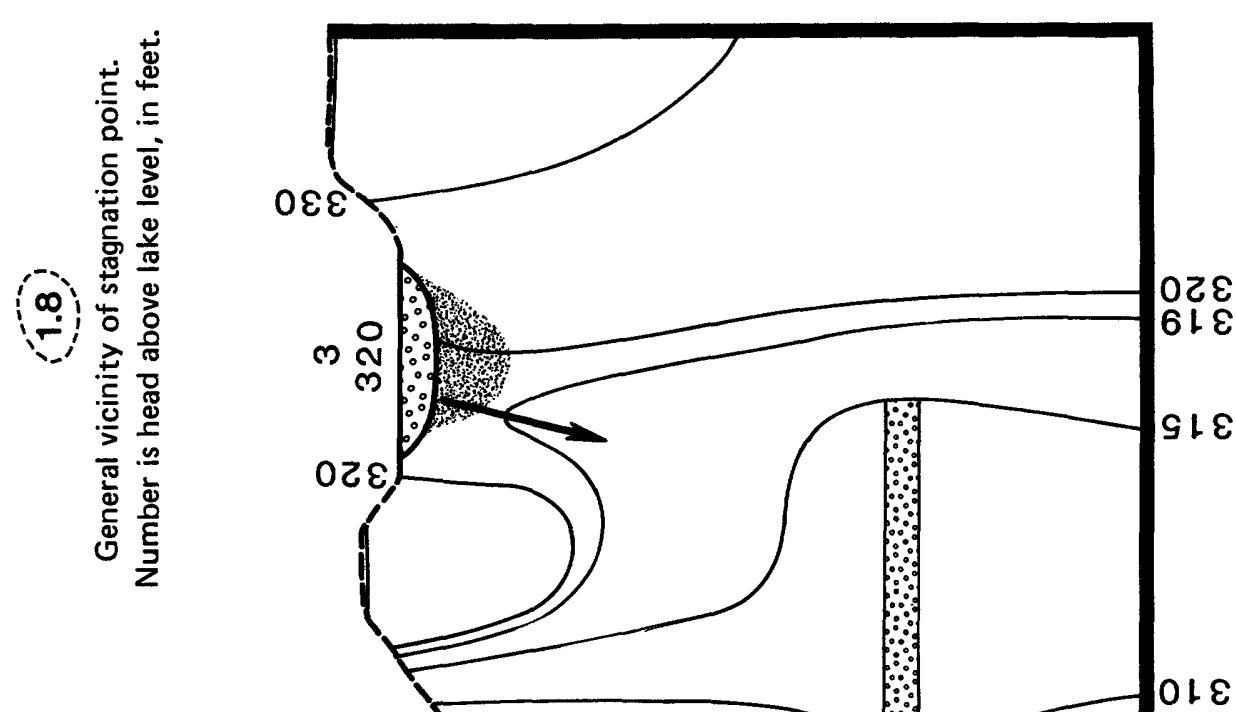

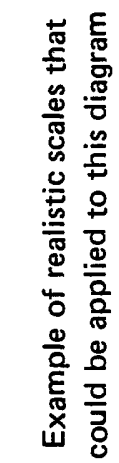

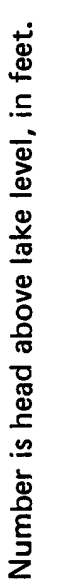
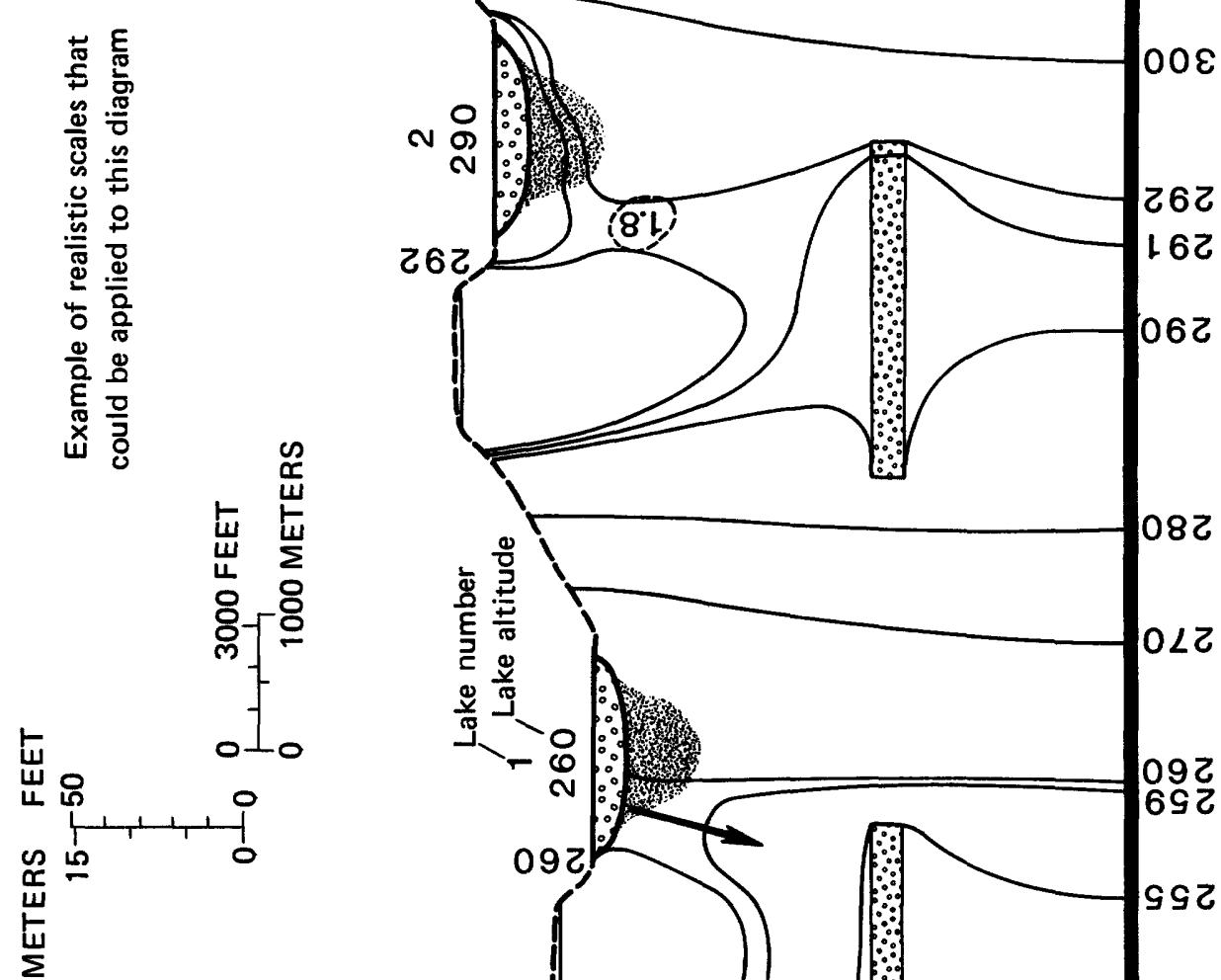

262

๘

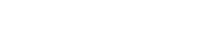



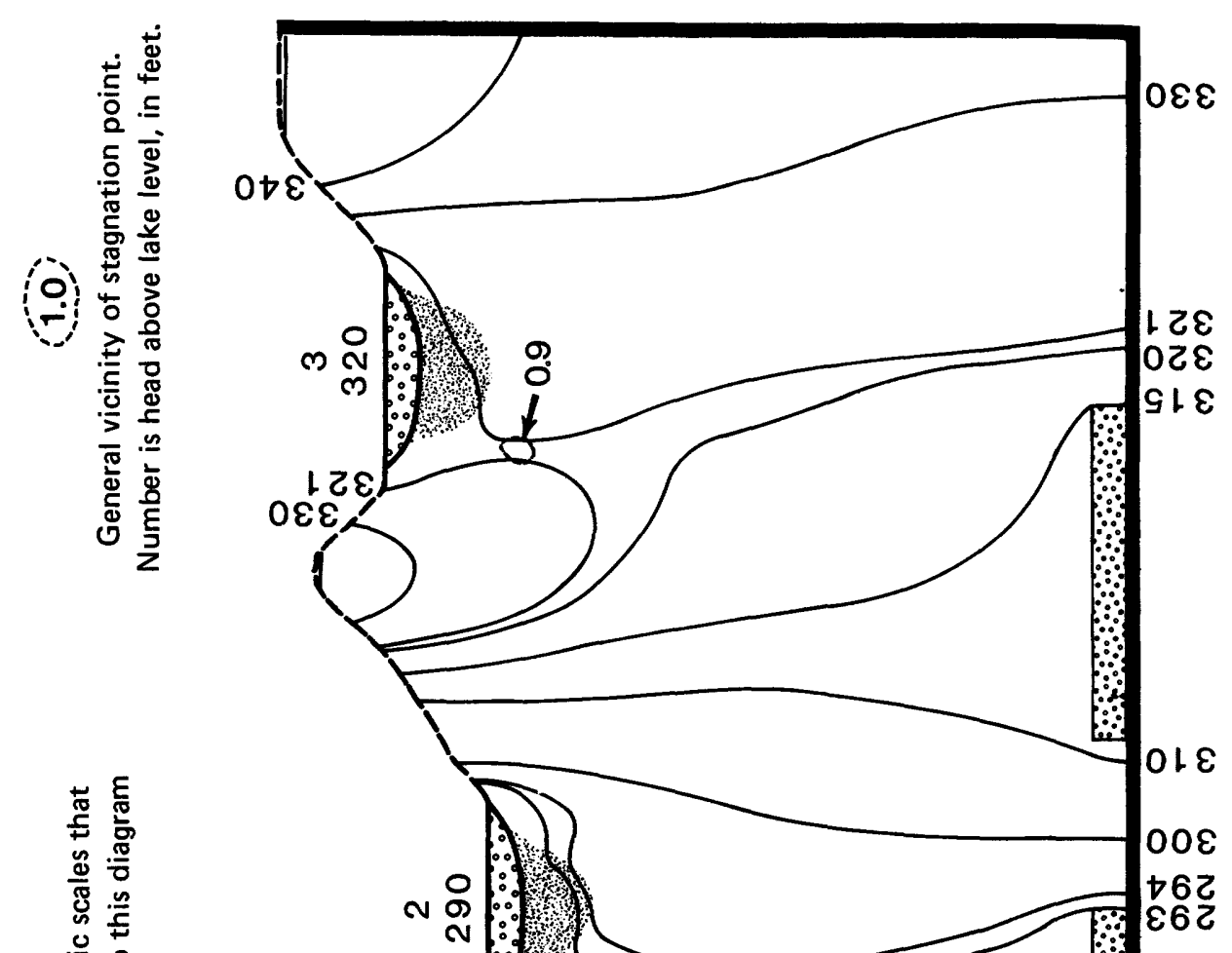

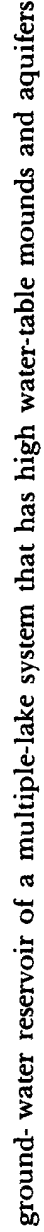

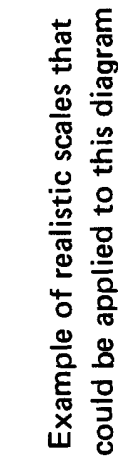

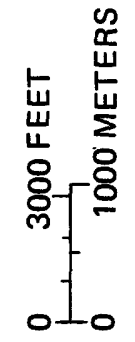

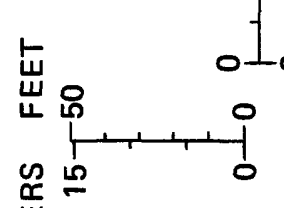

岕
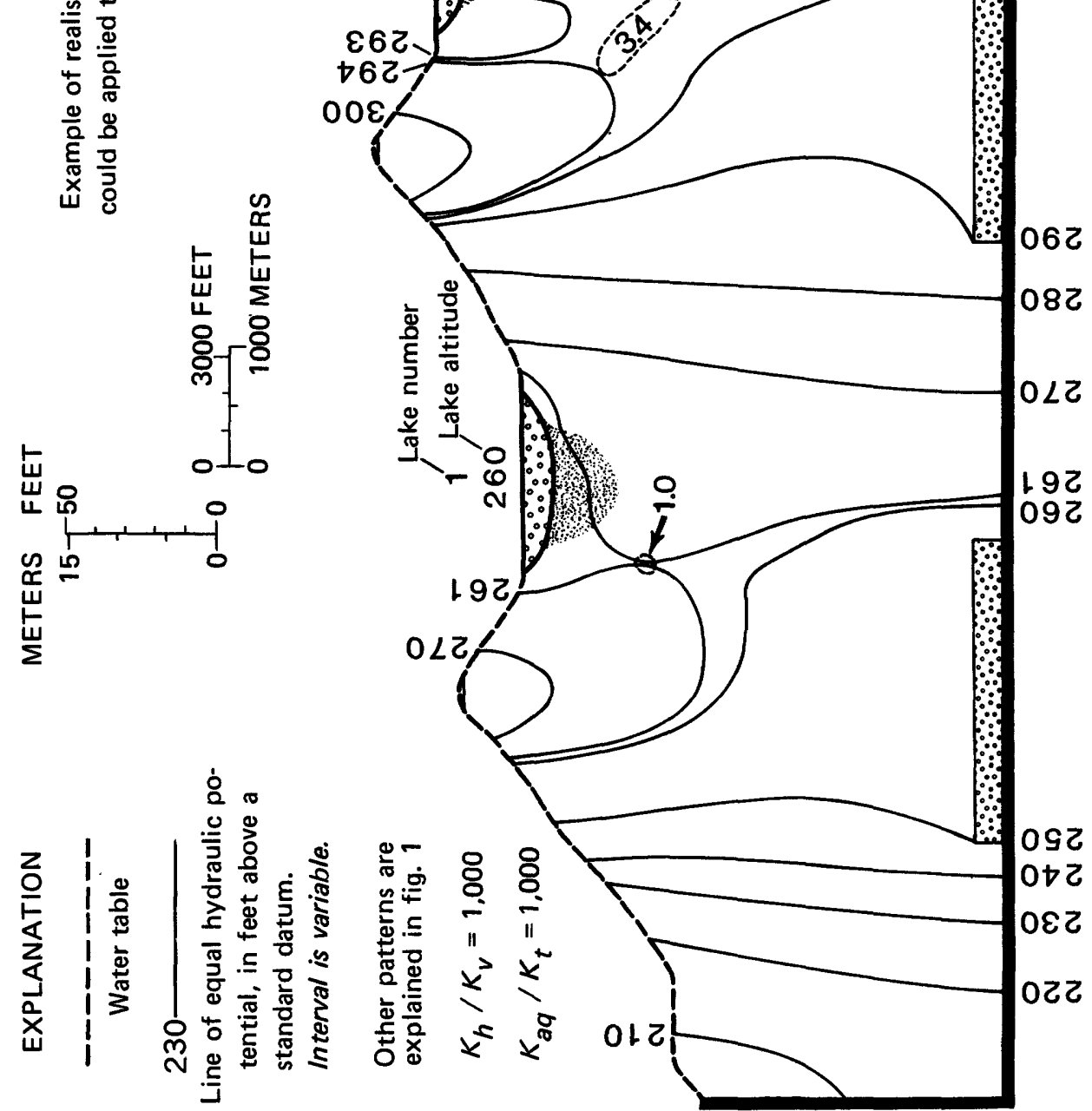

062 吾

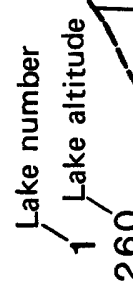

082

䒰
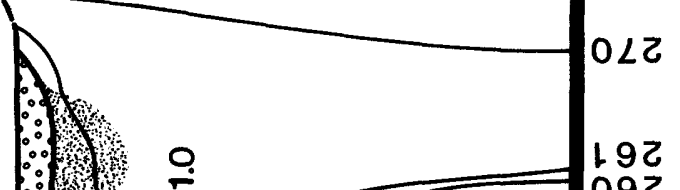

192
092

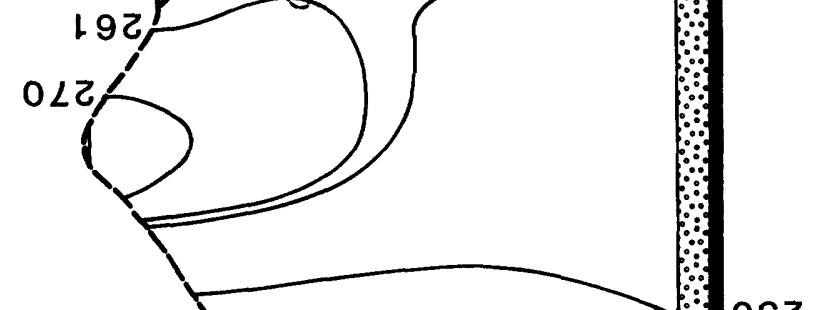

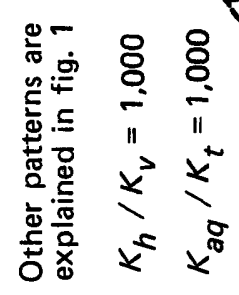

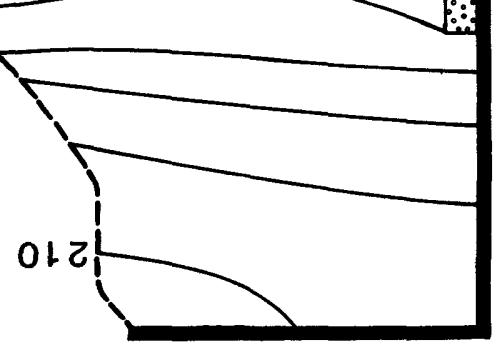

OSट

०६ट

OटZ

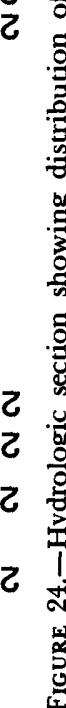


INTERACTION OF LAKES AND GROUND WATER
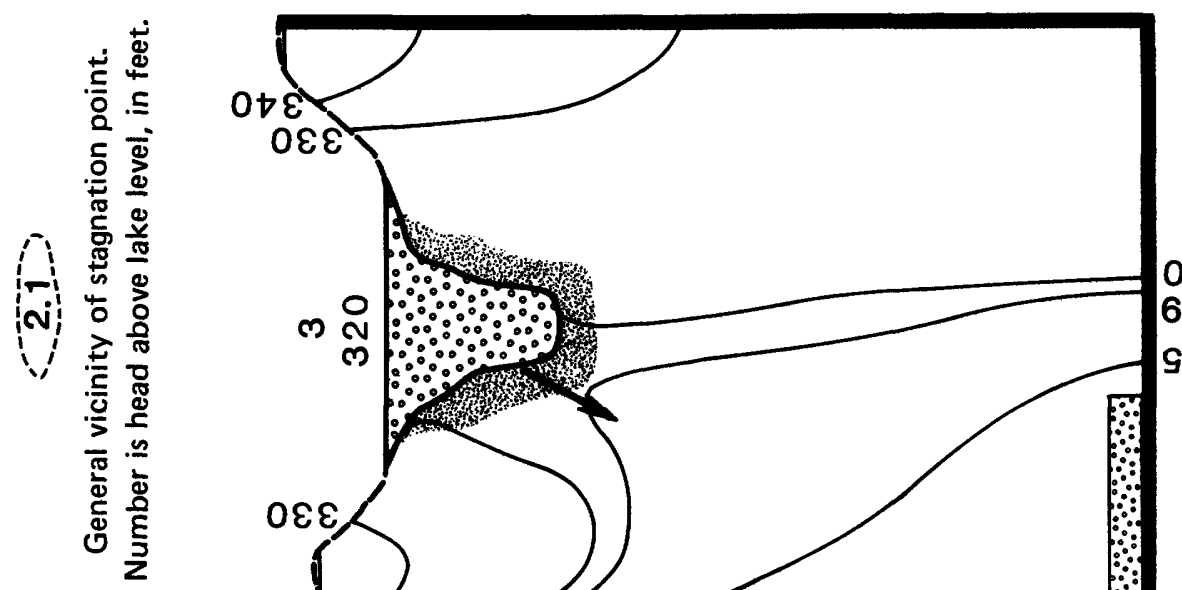

Оटह

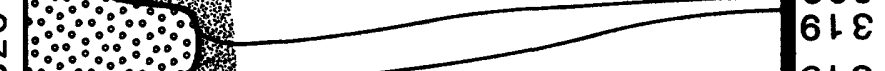

st $\varepsilon$

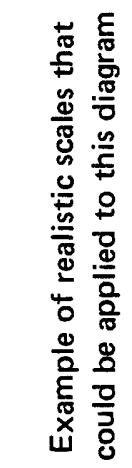
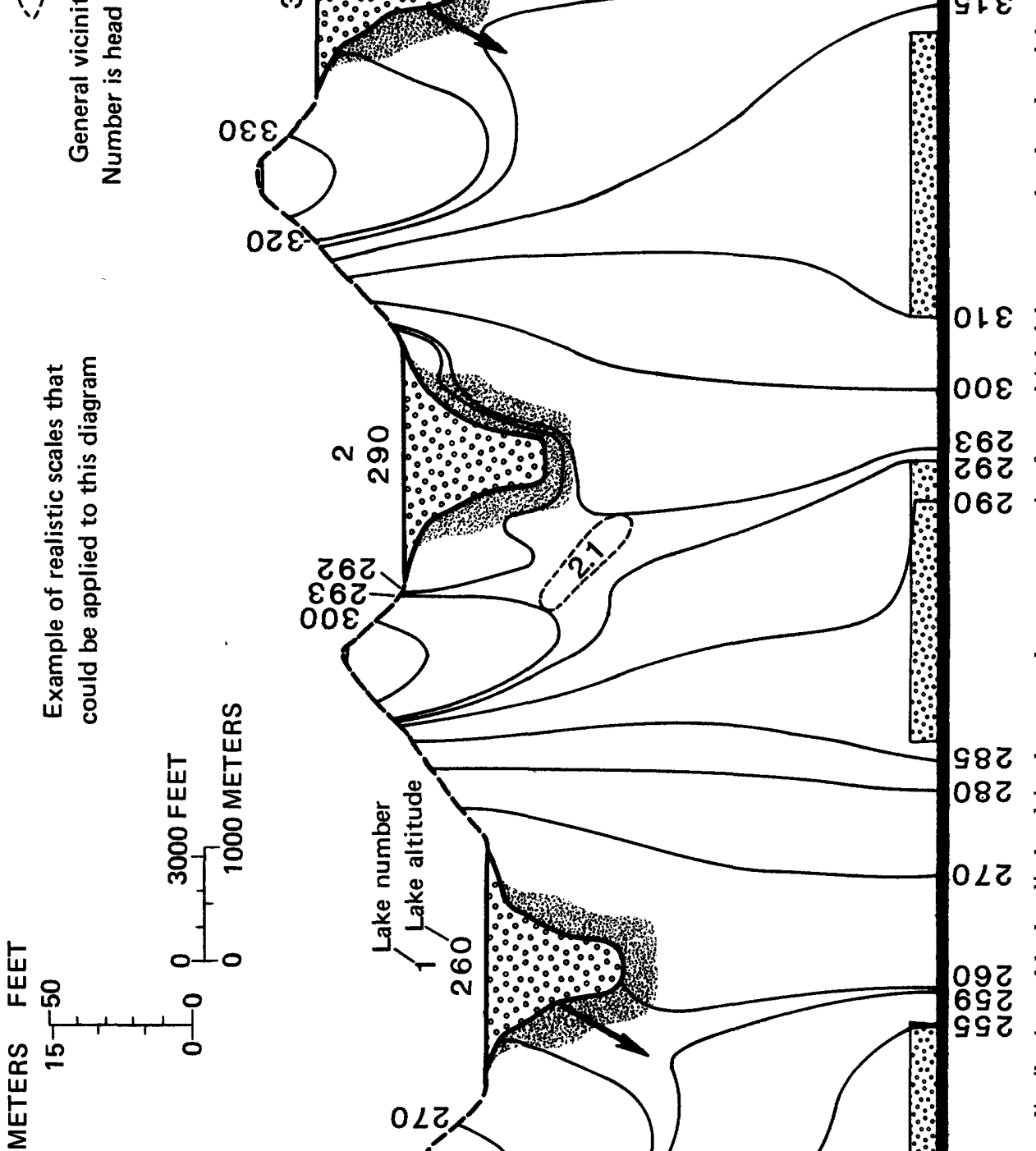

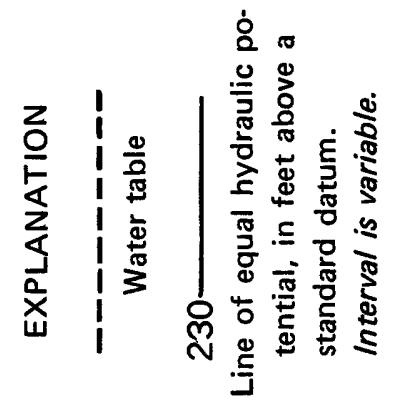
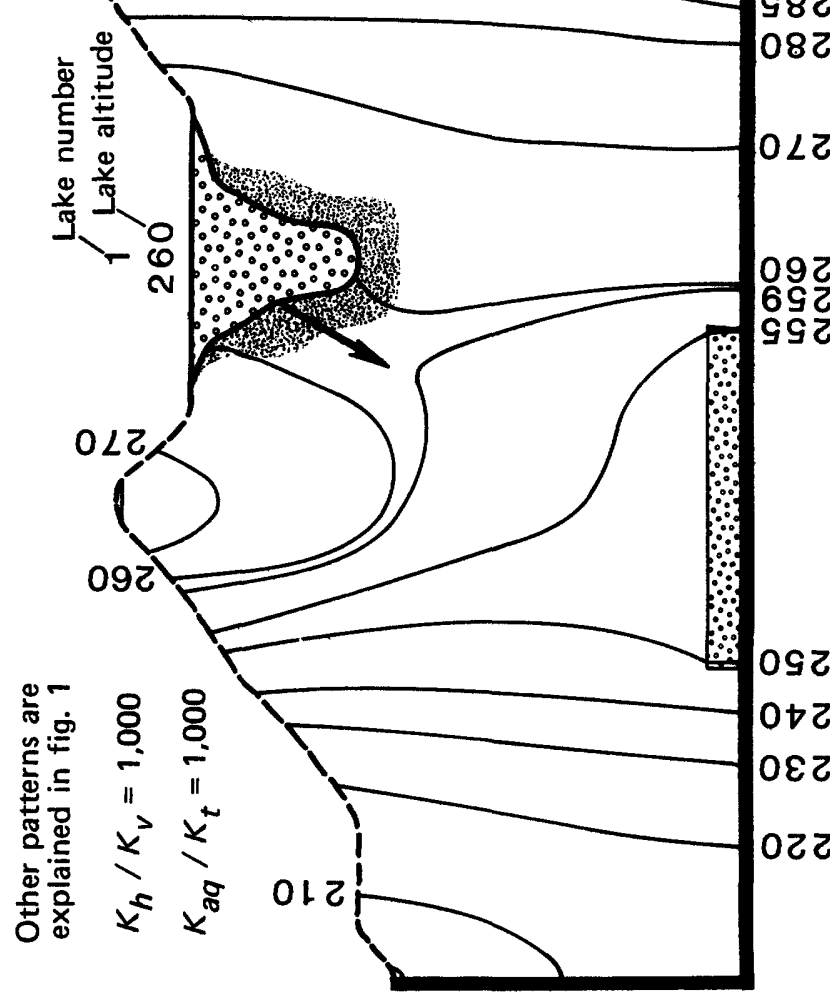

082

¿ִ.

$0<2$

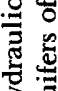

092

692 


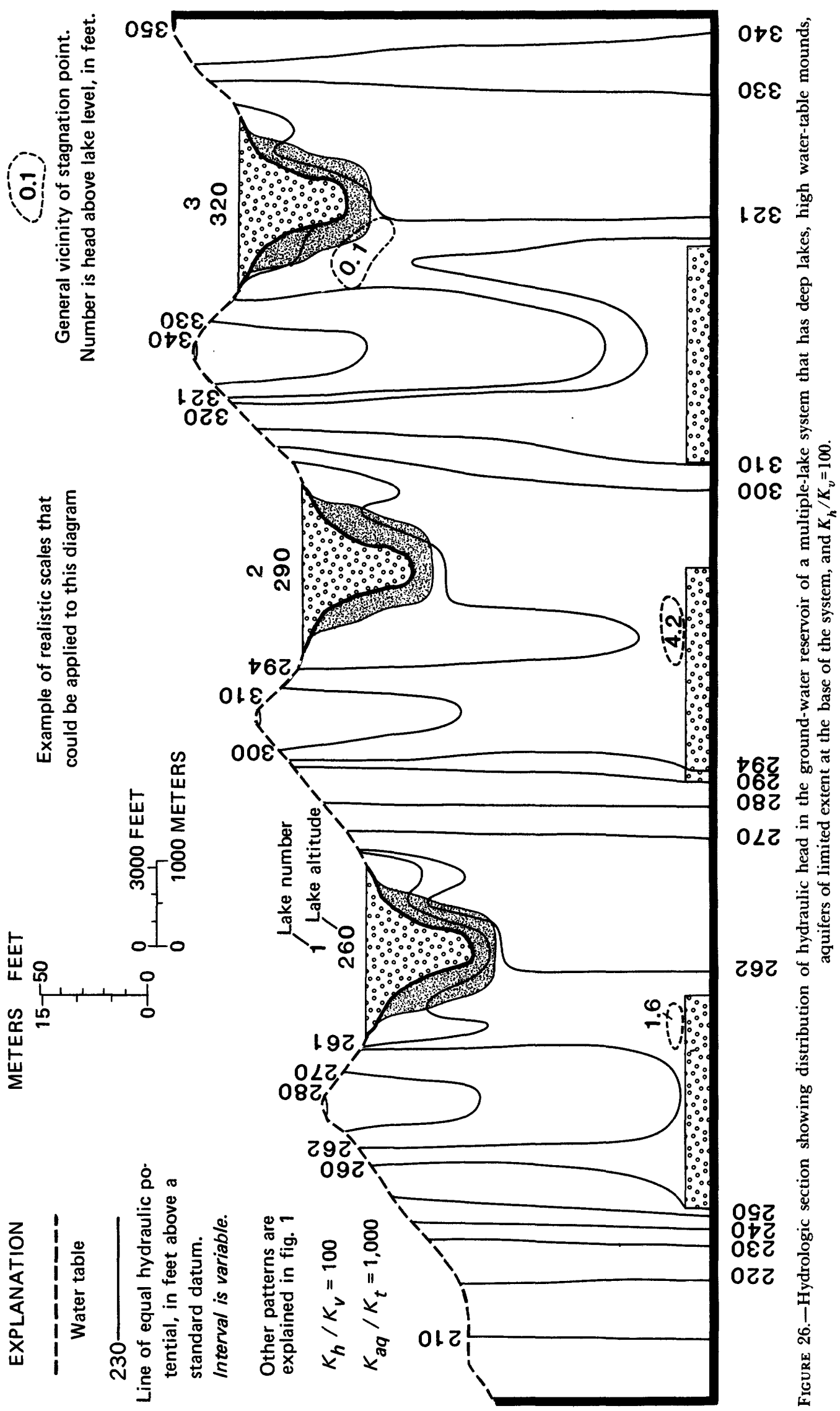



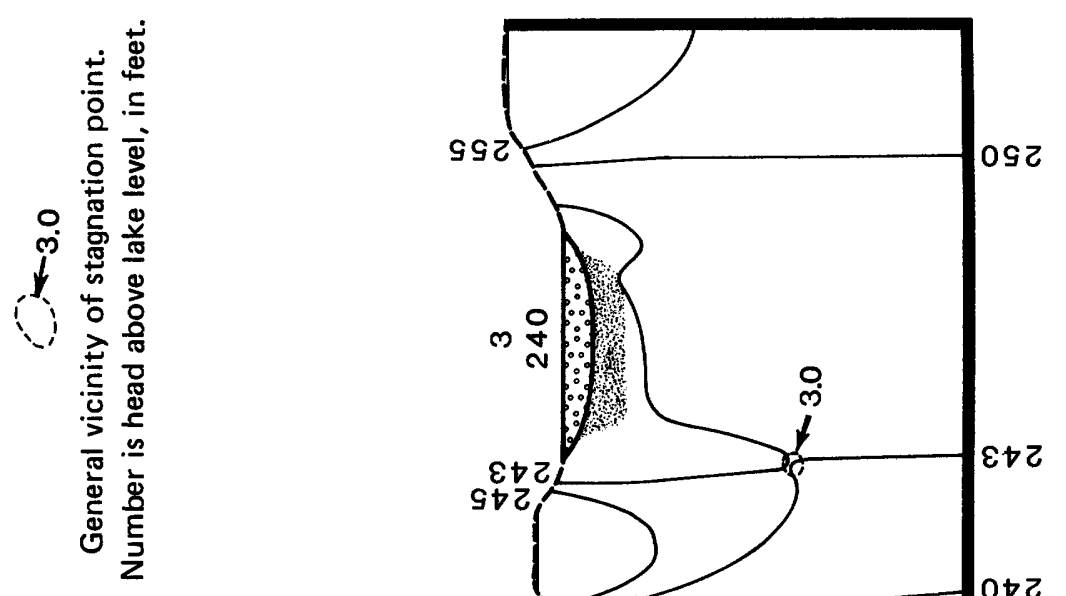

(⿸丆口

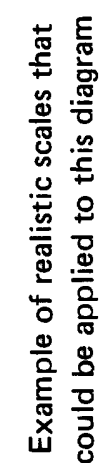
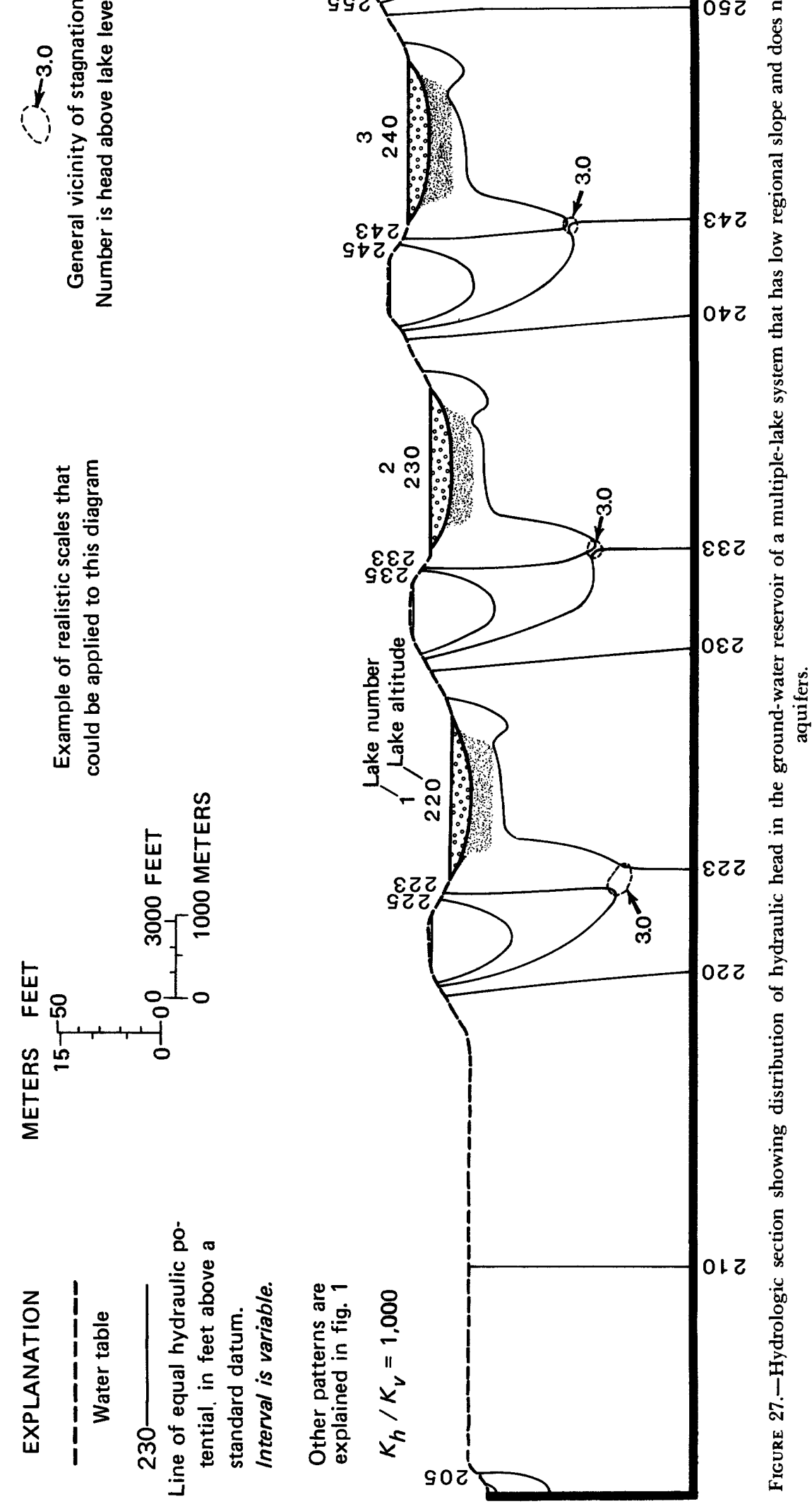

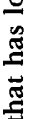


MULTIPLE-LAKE SYSTEM
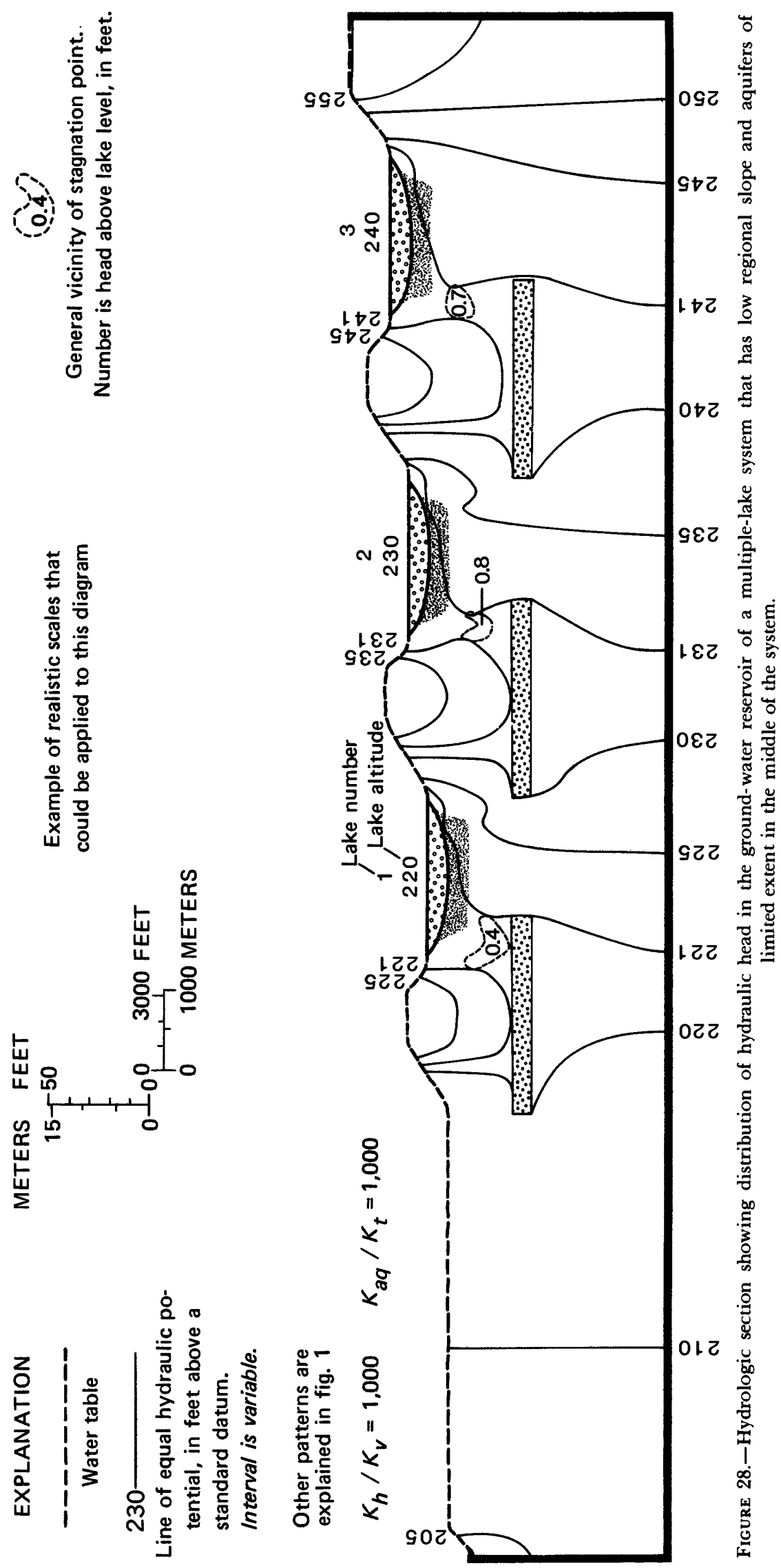


\section{QUANTITATIVE ASPECTS OF GROUND-WATER INTERCHANGE WITH LAKES}

Most of the discussion to this point is concerned with the qualitative aspects of the relationship of ground water to lakes. Attention is focused on factors that control the presence and strength, or the absence of a ground-water divide beneath a lake. The importance of the position and head relative to lake level of the stagnation point of a ground-water divide, if present, is stressed. Not only is the basic presence or absence of a divide of interest to those concerned with lake hydrology, but the quantities of water involved are also of great interest.

The basic concept of a flow net is presented in the discussion of ground-water-flow diagrams. It is pointed out in that section that figures 4 and 5 are not quantitative flow nets in the precise meaning of the term, because the ground-water reservoirs they illustrate are considerably anisotropic and vertical exaggeration is great.

A quantitative flow net can be used to calculate groundwater discharge through an isotropic medium using the following form of Darcy's Law (Freeze, 1969b):

$$
Q=K \frac{\Delta \phi}{\Delta s} w \Delta m,
$$

where $Q=$ discharge through a segment of the flow net,

$K$ =hydraulic conductivity,

$\Delta \phi=$ drop in hydraulic potential between equipotential surfaces,

$\Delta s$ length of flow path in the segment of the flow net,

$\Delta m=$ width of the segment of the flow net perpendicular to the flow direction, and

$\Delta w=$ thickness of the flow system perpendicular to the plane of the diagram.

Taking a unit thickness of the system $(w=1)$, and considering that for the squares of the net $\Delta s=\Delta m$, equation 2 reduces to

$$
Q=K \Delta \phi \text {. }
$$

Useful properties of a flow net are that discharge in each flow channel (zone located between two adjacent flow lines) remains constant throughout its length, and equal quantities of water move through each flow channel. In spite of the fact that figures 4 and 5 cannot be used to accurately calculate discharge, they are useful in estimating relative quantities because the proportions of flow between the various flow systems (local, intermediate, and regional) remain constant.

Referring to figure 4 , it is shown by relative spacing of stream lines that much more water moves through the local flow systems than the intermediate or regional systems. The difference in quantities of flow between the various flow systems is not as great in the situation represented by figure 5 , partly because of the relatively weak local flow near, and the leakage from, lake 3.
The relationship of ground water to lake 3 of figure 5 is of interest when considering quantities of flow into and out of the lake. Despite the fact that the lake loses water through at least half of its bed, the flow net indicates more ground-water gain into the lake than loss out of it. Not only is the loss relatively low when considering only the hydraulic potential distribution, but most of the outflow must be through the bottom sediments rather than through the littoral zone, which is true of nearly all situations where lakes lose water to the ground-water system. From equation 3 , it is clear that $Q$ must be rather low if both $K$ and $\Delta \phi$ are low. This pattern of inflow in the littoral zone of a lake, even on the downslope side, and loss, if present, through the lake sediments is a common phenomenon in nearly all the simulations in which loss occurs.

McBride (1969) found that the inflow to Lake Sallie, Minnesota, is greatest in the shallows near the shoreline and decreases logarithmically toward the deeper part of the lake. He later showed, through a modeling approach (McBride and Pfannkuch, 1975), that this is a general phenomenon. It can also be corroborated by a detailed flow net analysis.

The results of this study and those of McBride are important to the calculation of water budgets for lakes. Because even if a lake loses water through much of its bed, the quantity of ground-water gain in the littoral zone may be considerably greater than loss through the sediments of the lake.

The other important factor in calculating the quantities of ground-water interchange with a lake is the hydraulic conductivity $(K)$ of the ground-water system. Specific values of hydraulic conductivity have been mentioned little in the discussion up to this point, because in the models all $K$ values are relative. If hydraulic conductivity is changed from $0.2 \mathrm{ft} /$ day $(0.06 \mathrm{~m} /$ day $)$ to $200.0 \mathrm{ft} /$ day $(61$ $\mathrm{m} /$ day), but all the other $K$ values in each simulation are changed accordingly, the resulting head configurations are identical. (Compare rows 25 and 26 of table 4.)

If interest is in quantities of ground-water discharge, for use in determining water budgets for example, specific values of $K$ are extremely important. (See equation 3.) Obviously, far more ground water will interact with a lake situated in highly conductive rock material such as sand and gravel than a lake situated in silty till, provided the hydraulic gradients $(\Delta \phi)$ are similar.

\section{AREAL AND TEMPORAL VARIATIONS}

The hydrologic sections discussed in this report represent a two-dimensional vertical view of the groundwater system. By carefully selecting the line of section on a map, the general qualitative interrelationship of lakes and ground water can be adequately determined. To assure areal coverage of the lake's entire ground-water basin, however, a more accurate analysis of the entire drainage 
basin of a lake would have to consider radial flow. Perhaps the best approach would be to use three-dimensional modeling techniques which have recently received much research attention and are becoming available for general use. Until three-dimensional models of ground water flow near lakes are operational, an alternate approach to providing areal coverage is to run two-dimensional models of selected lines of section. (The lines of section must be chosen so they radiate from a lake and are representative of a pie-shaped part of the ground-water system near a lake.)

Because the ground-water system is dynamic, a steadystate hydrologic section can be representative of a system in which changes occur very slowly over a period of time. If lake and water-table altitudes change rapidly, the most accurate analysis would be to solve the equations of transient ground-water flow. Examples are lakes in a setting of widely fluctuating water-table and lake levels, especially if the changes are out of phase with one another, or are much greater in one than the other. Not only would flow nets be needed to calculate the changed rates of ground-water discharge but the basic relationship of a losing versus a gaining lake might be changed. An example of this is given by Meyboom (1967), who found that some lakes in the prairie provinces of Canada are underlain by ground-water divides for part of the year (spring and summer), but lose water to the ground-water system for the remainder of the year (fall and winter). Depending on the accuracy needed for calculation of ground-water discharge, sections would have to be drawn to reflect the changing conditions.

There are probably many lakes in hydrogeologic settings where the trends in lake levels and water-table levels are essentially parallel for most of the year (Winter and Pfannkuch, 1976; McBride, 1969). In such situations, hydrologic sections would be needed for one time or only a few times during the year. Freeze (1969b) argues, in considering large basins, that the effect of small-scale cycles of wetting and drying during the year can be approximated by a steady-state average.

The most likely situations where hydrologic sections would be needed for more than one or two times during a year would be if: (1) A large rise in lake level would not be accompanied by a similar rise in the water table-for example, a flood wave passing through a lake that has streamflow in and out or a large drop in lake level caused by release of water through a dam, or (2) a large drop in the water table were caused by discharge of ground water by phreatophytes, or by dissipation of water-table mounds because of lack of rainfall. Both latter conditions had a bearing on the results of Meyboom's study.

\section{IMPLICATIONS FOR FIELD STUDIES OF THE} INTERACTION OF LAKES AND GROUND WATER

It was pointed out in the introductory paragraphs of this report that a number of different approaches to studying the relationship of ground water to lakes have been tried. Some workers have thought that a single piezometer (observation well) beside a lake would adequately define the relationship, while others have placed large numbers of piezometers near a lake. Knowledge of the possible variations of ground-water flow systems near lakes, as demonstrated in the simulations of this study, suggest placement of piezometers that would optimize information on the interaction of lakes and ground water using a minimum number of piezometers.

Rather than place piezometers within the drainage basin of a lake, most effort should be on finding the maximum altitude of the water-table along the areal ground-water divide around a lake where such a divide exists. For flow-net analysis it is necessary to find this water-table-mound maximum and to place a piezometer on it for each segment of the lake's drainage basin where different ground-water-flow patterns are suspected. As seen from the simulations, one of the most important locations is the height of the water table above lake level on the downslope side of a lake.

Finding the maximum height of a water-table mound can be difficult. It has been demonstrated a number of times in the field that water-table mounds do not underlie directly topographic highs. Topography is not shown on the hydrologic sections-one can visualize topographic highs anywhere along the sections. In addition, the accessibility of roads and the need to obtain the land owner's permission is an important constraint in locating drilling sites and observation wells. It is easily demonstrated in any of the simulations of a three-lake system (fig. 4 , for example) that a piezometer placed closer to lake 2 than lake 3 along the water-table profile between lakes 2 and 3 would record water-table altitudes lower than the level of lake 3. One would conclude in this case that, since the water table at that point is at an intermediate altitude between the two lakes, water flows from lake 3 to lake 2 , an erroneous conclusion reached in many studies of lakeground water interaction in which few wells are placed and the principles of ground-water flow near lakes are not understood.

In addition to locating key points along the water-table divide around a lake, it is important to know the location and head relative to lake level of the stagnation point on the ground-water divide beneath the lake, if such a point exists. This is best accomplished by placing a nest of closely spaced piezometers, each completed at a different depth, in the most appropriate location. As suggested by the simulations of this study, the most appropriate location to look for the stagnation point is beneath the shoreline on the downslope side of the lake.

Data on the other factors that control ground-water flow (hydraulic conductivity of the various geologic units, hydrogeologic boundaries, location of aquifers) are not easily obtained, but there are accepted methods for acquiring them. 
Field determination of the critical $K_{h} / K_{v}$ ratio, on the other hand, is a serious problem. Although it has not been field tested, the method of determining $K_{h} / K_{v}$ from measured head values proposed by Gillham and Farvolden (1974) may prove useful.

\section{SUMMARY}

The relationship of ground water to lakes is the least well known aspect of lake hydrology. This report discusses steady-state digital-model simulations of ground-water flow near lakes as a first step toward a general theoretical understanding of the interaction of lakes and ground water. Numerical-model simulations were run to define the principles of the interaction of lakes and ground water, and to evaluate parameters that control ground-water flow near lakes.

The numerical models, using the alternating-directionimplicit (ADI) and strongly implicit procedure (SIP) methods to solve the steady-state ground-water-flow equation for vertical sections, were used to simulate onelake and multiple-lake systems.

The report demonstrates by analysis of ground-water flow in vertical sections that the existence, position, and head value at the stagnation point of the ground-waterflow field, relative to the head represented by lake level, is the key to understanding the interaction of lakes and ground water. The stagnation point is the point of least head along the divide between ground-water-flow cells beneath a lake. Therefore, if a stagnation point exists, the divide is continuous, the lake cannot leak, and it is the discharge point of the ground-water flow system. If there is no stagnation point, the ground-water divide related to the lake is not continuous, and the lake can leak through part or all of its bed.

Factors that strongly influence the interaction of lakes and ground water are height of the water table on the downslope side of the lake relative to lake level, position and relative hydraulic conductivity of aquifers within the ground-water reservoir, ratio of horizontal to vertical hydraulic conductivity of the ground-water system, regional slope, and lake depth. Of lesser significance to lakeground water interaction are height of the water table on the upslope side of a lake relative to lake level, groundwater reservoir thickness, and presence of lake sediments.

The models are believed to be the first to show the detailed patterns of ground-water flow beside and beneath lakes in a wide variety of hydrogeologic settings. They are unique because they show ground-water-flow patterns beneath and between a series of lakes, each at a different altitude, along a valley side. A significant finding is that, for most settings, water does not move from higher lakes through the ground to lower lakes if a water-table mound exists between the lakes. This can happen only if one presumes a straight-line water-table profile connects the lakes.
In field studies of the interaction of lakes and ground water it is especially important to define the geologic framework including the hydraulic conductivities of the geologic units-the boundaries of the system, the ratio of horizontal to vertical hydraulic conductivity, the height of the ground-water watershed relative to lake level, and the strength (head at the stagnation point relative to that represented by lake level) and position of the stagnation point.

\section{REFERENCES CITED}

Allred, E. R., Manson, P. W., Schwartz, G. M., Golany, P., and Reinke, J. W., 1971, Continuation of studies on the hydrology of ponds and small lakes: Agr. Expt. Sta. Univ. of Minnesota Tech. Bull. 274, $62 \mathrm{p}$.

Bennett, G. D., and Giusti, E. V., 1971, Coastal ground-water flow near Ponce, Puerto Rico: U.S. Geol. Survey Prof. Paper 750-D, p. 206-211.

Born, S. M., Smith, S. A., and Stephenson, D. A., 1974, The hydrogeologic regime of glacial-terrain lakes, with management and planning applications: Univ. of Wisconsin, Inland Lake Renewal and Management Demonstration Project, 73 p.

Cooley, R. L., 1974, Finite element solutions for the equations of ground-water flow: Univ. of Nevada, Desert Research Institute, Hydrology and Water Resources Publication No. 18, 134 p.

DeWiest, R. J. M., 1965, Geohydrology: New York, John Wiley \& Sons, 366 p.

Domenico, P. A., 1972, Concepts and models in ground water hydrology: New York, McGraw-Hill, 405 p.

Downey, J. S., and Paulson, Q. F., 1974, Predictive modeling of effects of the planned Kindred Lake on ground-water levels and discharge, southeastern North Dakota: U.S. Geol. Survey Water-Resources Inv. 30-74, $22 \mathrm{p}$.

Eisenlohr, W. S., and others, 1972, Hydrologic investigations of prairie potholes in North Dakota, 1959-68: U.S. Geol. Survey Prof. Paper 585-A, 102 p.

Everdingen, R. O. Van, 1963, Groundwater flow-diagrams in sections with exaggerated vertical scale: Geol. Survey of Canada, Paper 63-27, $21 \mathrm{p}$.

Everdingen, R. O. Van, 1972, Observed changes in groundwater regime caused by the creation of Lake Diefenbaker, Saskatchewan: Canadian Dept. of the Environment, Inland Waters Branch Tech. Bull. no. 59, 65 p.

Freeze, R. A., 1969a, Regional groundwater flow-Old Wives Lake Drainage Basin, Saskatchewan: Canadian Dept. of Energy, Mines, and Resources, Inland Waters Branch, Sci. Ser. no. 5, 245 p.

Freeze, R. A., 1969b, Theoretical analysis of regional ground-water flow: Canadian Dept. of Energy, Mines, and Resources, Inland Waters Branch, Sci. Ser. no. 3, 147 p.

Freeze, R. A., 1972, Regionalization of hydrogeologic parameters for use in mathematical models of groundwater flow: 24th Int. Geol. Congr. Proceedings, Sec. 11, p. 177-190.

Gillham, R. W., and Farvolden, R. N., 1974, Sensitivity analysis of input parameters in numerical modeling of steady state regional ground-water flow: Water Resources Research, v. 10, no. 3, p. 529-538.

Hackbarth, D. A., 1968, Hydrogeology of the Little St. Germain Lake Basin, Vilas County, Wisconsin: Univ. of Wisconsin, Madison, unpublished M.S. thesis.

Haefeli, C. J., 1972, Ground water inflow into Lake Ontario from the Canadian side: Canada Dept. Environment, Inland Waters Branch Scientific Series no, 9, 101 p.

Harr, M. E., 1962, Groundwater and seepage: New York, McGrawHill, 315 p. 
Hennings, R. G., 1974, A Hydrologic investigation of the Pickerel Lake Basin, Portage County, Wisconsin: Univ. of Wisconsin, Madison, M.S. thesis.

Manson, P. W., Schwartz, G. M., and Allred, E. R., 1968, Some aspects of the hydrology of ponds and small lakes: Univ. of Minnesota Agric. Exp. Sta. Techn. Bull. 257, 88 p.

McBride, M.S., 1969, Hydrology of Lake Sallie, northwestern Minnesota, with special attention to ground water-surface water interactions: Univ. of Minnesota, M.S. thesis, 61 p.

McBride, M. S., and Pfannkuch, H. O., 1975, The distribution of seepage within lakes: U.S. Geol. Survey Jour. Research, v. 3, no. 5, p. 595-512.

Meyboom, P., 1966, Unsteady groundwater flow near a willow ring in hummocky moraine: Jour. Hydrology, v. 4, p. 38-62.

Meyboom, P., 1967, Mass-transfer studies to determine the groundwater regime of permanent lakes in hummocky moraine of western Canada: Jour. Hydrology, v. 5, p. 117-142.

Payne, Bryan R., 1970, Water balance of Lake Chala and its relation to groundwater from tritium and stable isotope data: Jour. $\mathrm{Hy}$ drology, v. 11, p. 47-58.

Pinder, G. F., 1970, An interative digital model for aquifer evaluation: U.S. Geol. Survey open-file report, $44 \mathrm{p}$.

Pinder, G. F., and Bredehoeft, J. D., 1968, Application of the digital computer for aquifer evaluation: Water Resources Research, v. 4, no. 5, p. 1069- 1093.

Possin, Boyd, 1973, Hydrogeology of Mirror and Shadow Lakes in Waupaca, Wisconsin: Univ. of Wisconsin, M.S. thesis, $66 \mathrm{p}$.

Prickett, T. A., and Lonnquist, C. G., 1971, Selected digital computer techniques for groundwater resource evaluation: Illinois State Water Survey Bull. 55, 62 p.

Remson, I., Hornberger, G. M., and Molz, F. J., 1971, Numerical methods in subsurface hydrology: New York, Wiley-Interscience, $389 \mathrm{p}$.

Schumann, D., 1973, Annual variation of seepage of lakes in the moraine area of the German Democratic Republic: Hydrology of Lakes Symposium, Proceedings of the Helsinki Symposium, July, 1973, Int. Assoc. Hydrol. Sci. Pub. no. 109, p. 101-108.
Sloan, C. E., 1972, Ground-water hydrology of prairie potholes in North Dakota: U.S. Geol. Survey Prof. Paper 585-C, 28 p.

Stone, H. K., 1968, Iterative solution of implicit approximations of multidimensional partial differential equations: SIAM Jour. Numer. Anal., v. 5, no. 3, p. 530-558.

Tóth, J., 1963, A theoretical analysis of groundwater flow in small drainage basins: in Proceedings of Hydrology Symposium no. 3, Groundwater: Ottawa, Queen's Printer, p. 75-96.

Trescott, P. C., 1973, Iterative digital model for aquifer evaluation: U.S. Geol. Survey open-file report, $63 \mathrm{p}$.

Trescott, P. C., and Pinder, G. F., 1975, Finite difference model for aquifer simulation in two dimensions and results of numerical experiments: U.S. Geol. Survey administrative report.

Vecchioli, J., Bennett, G. D., Pearson, F. J., Jr., and Cerrillo, L. A., 1974, Geohydrology of the artificial-recharge site at Bay Park, Long Island, New York: U.S. Geol. Survey Prof. Paper 751-C, $29 \mathrm{p}$.

Weeks, E. P., 1969, Determining the ratio of horizontal to vertical permeability by aquifer-test analysis: Water Resources Research, v. 5, no. 1 , p. 196-214.

Williams, R. E., 1968, Flow of ground water adjacent to small, closed basins in glacial till: Water Resources Research, v. 4, p. 777-783.

Winter, T. C., 1976a, The hydrologic setting of lakes in Minnesota and adjacent states, with emphasis on the interaction of lakes and ground water: Univ. of Minnesota, $\mathrm{Ph}$. D. thesis, $237 \mathrm{p}$.

Winter, T. C., 1976b, The hydrologic setting of lakes in Minnesota and adjacent states-with emphasis on the interaction of lakes and ground water: U.S. Geol. Survey open-file report 76-81.

Winter, T. C., and Pfannkuch, H. O., 1976, Hydrogeology of a driftfilled bedrock valley near Lino Lakes, Anoka County, Minnesota: U.S. Geol. Survey Jour. Research, v. 4, no. 3, p. 267-276.

Zektzer, I. S., 1973, studying the role of groundwater flow in water and salt balances of lakes: Hydrology of Lakes, Helsinki Symposium, IAHS Publ. 109, p. 197-201.

Zektzer, I. S., and Kudelin, B. I., 1966, The methods of determining ground water flow to lakes with special reference to Lake Ladoga: Hydrology of Lakes and Reservoirs, Symposium of Garda: IASH pub. 71, v. 1, p. 31-38. 